\title{
The effect of non-contributory pensions on labour supply and private income transfers: evidence from Singapore
}

Yanying Chen ${ }^{*}$ and Yi Jin Tan

\author{
* Correspondence: yy.chen.2013@ \\ phdecons.smu.edu.sg \\ School of Economics, Singapore \\ Management University, 90 \\ Stamford Road, Singapore 178903, \\ Singapore
}

\begin{abstract}
Non-contributory pensions are becoming increasingly prevalent worldwide. As their effects are likely to be context-dependent, evaluating their effects in a wide range of settings is important for establishing the external validity of the non-contributory pension literature. We use a new monthly panel dataset and a difference-in-differences strategy to study the effect of a new non-contributory pension in Singapore (the Silver Support Scheme or SSS) on labour supply, work expectations, private cash transfers, and expenditure, 1 year after its implementation. We find no evidence that receiving SSS payouts led to a fall in labour supply, work expectations, or the receipt of private cash transfers in the first year after SSS implementation-our estimated effects for these outcomes are statistically insignificant and are either negative but close to zero or positive. Our point estimates of the effects of receiving SSS payouts on expenditure are positive but too imprecise to allow us to make any definitive conclusions. Lastly, we do not find evidence of anticipatory effects among younger individuals who are not ageeligible for payouts yet. These results, when coupled with our finding in a companion paper that the SSS improved recipients' subjective well-being, suggest that the SSS was successful in improving recipients' welfare without substantial crowding out of private transfers or changes in labour market behaviour of current and future SSS beneficiaries.

Keywords: Non-contributory pensions, Labour supply, Private income transfers, Crowding out

JEL Classification: $\mathrm{H} 3, \mathrm{H} 4, \mathrm{I} 3, \mathrm{~J} 2$
\end{abstract}

\section{Introduction}

Non-contributory pensions are becoming increasingly prevalent worldwide (International Labour Office 2014). These pensions play a crucial role in improving the retirement security of individuals who do not receive sufficient benefits from contributory pension schemes (e.g. lower-income workers, informal sector workers, or housewives), but can have potentially large effects on labour markets and household dynamics. The importance and increasing prevalence of non-contributory pensions has led to a growing body of research that evaluates their impact on key outcomes such as labour decisions, intra-family cash transfers, and expenditure (see, e.g. AmuedoDorantes and Juarez 2015; Bando et al. 2016; Case and Deaton 1998; Fan 2010; Galiani et al. 2016). However, the effect of non-contributory pensions can vary across countries

(C) The Author(s). 2018 Open Access This article is distributed under the terms of the Creative Commons Attribution 4.0 International License (http://creativecommons.org/licenses/by/4.0/), which permits unrestricted use, distribution, and reproduction in any medium, provided you give appropriate credit to the original author(s) and the source, provide a link to the Creative Commons license, and indicate if changes were made. 
due to differences in institutions, social norms, and benefit levels. It thus remains important to evaluate each new or reformed non-contributory pension, to improve the external validity of the literature as a whole. ${ }^{1}$

In this paper, we evaluate the effects of Singapore's first national non-contributory pension (the Silver Support Scheme or SSS) on labour decisions, cash transfers among family and friends, and expenditure, 1 year after its implementation. The SSS is a means-tested scheme that targets the neediest $20-30 \%$ of Singaporean citizens aged 65 and above. It was announced in end-March 2016 with details on the exact qualifying criteria and payout levels. The first payout was disbursed in end-July 2016. Payouts are disbursed on a quarterly basis, and on average, recipients of SSS payouts in our sample receive around $S \$ 500$ per quarter, which corresponds to about $14 \%$ of the pre-SSSannouncement mean monthly income from work among SSS recipients who worked during that period. Eligibility for the SSS is automatically determined based on government administrative data and updated yearly. Disbursement of payouts is equally automatic and fuss-free, as it is processed through well-established distribution channels.

We use a difference-in-differences (DiD) strategy to identify the causal effects of the SSS. The sample for our main analysis is made up of individuals aged 65 and above in 2016. ${ }^{2}$ The treated group consists of those who reported receiving an SSS payout at least once in 2016, while the control group consists of those who did not. Our treatment definition allows us to interpret the policy shock as exogenous, since eligibility of payouts for 2016 was based on 2015 administrative data. Individuals were thus unable to select into treatment after the SSS was announced in March 2016. To tackle the possibility that our treatment and control groups may be sufficiently different to invalidate the $\mathrm{DiD}$ parallel trends assumption, we trim our sample, using individuals' treatment propensity, to construct more similar treatment and control groups. We also verify that our results are robust to a battery of checks that include the use of different control groups, different re-weighting techniques, and the addition of group-specific time fixed effects (details in Section 5).

Our data comes from the Singapore Life Panel (SLP), a new longitudinal monthly survey, which aims to follow a population-representative sample of Singapore citizens and permanent residents aged 50-70 and their spouses. (See Vaithianathan et al. (2017) for more details on the SLP.) It captures a rich set of data including demographic characteristics, labour decisions, private cash transfers, and expenditure. Its monthly responses allow us to precisely account for announcement effects, to avoid underestimating the SSS's effects (see, e.g. Blundell et al. 2011 for evidence on the importance of accounting for announcement effects).

We find no evidence that receiving SSS payouts led to a reduction in labour supply at the extensive or intensive margins-the estimated effects are statistically insignificant and either negative but close to zero or positive. However, we do find suggestive but weak evidence that the adjustment in labour supply may not be complete. In a study of the dynamic effects of SSS, the estimated effects become increasingly negative as time goes by, even though they remain insignificant. ${ }^{3}$ In addition, we find no evidence of persistent changes in expectations about working full-time after age 70 among SSS recipients. Their expectations of having to work full-time after 70 fell sharply after disbursement but rebounded soon after. We also find no evidence that SSS recipients received less from, or gave more private cash transfers to, their family and friends. Our 
estimates, which reflect effects on both the extensive and intensive margins, are statistically insignificant. In particular, the effects on the probabilities of receiving or giving cash transfers are close to zero, suggesting that SSS was unlikely to have crowded out cash transfers from family and friends, or led to a rise in transfers to others. ${ }^{4}$ Lastly, in a supplementary analysis (discussed in more detail only in Section 7) based on younger individuals who are not age-eligible for payouts yet, we find no evidence that expecting to receive the SSS led to changes in private cash transfers, labour-related decisions, or expenditure.

Our results, when coupled with the findings in a companion paper that the SSS improved recipients' subjective well-being (Chen and Tan 2017), ${ }^{5}$ suggest that the SSS was successful in improving recipients' welfare without substantial crowding out of private transfers, reductions in labour supply, or changes in the behaviour of younger individuals who expect to receive SSS payouts in future.

Apart from evaluating an important new pension reform in Singapore, our paper contributes to the literature on the effects of non-contributory pensions on the labour market. In our paper, the estimated effect of the SSS on participation in paid work is lower (close to zero, and statistically insignificant) than the fall of 4 to 6 percentage points that many other studies on non-contributory pensions find (Aguila et al. 2011; Bando et al. 2016; Cheng et al. 2018; Fetter and Lockwood 2016; Galiani et al. 2016; Hernani-Limarino and Mena 2015; Juárez and Pfutze 2015). ${ }^{6}$ Interestingly, Galiani et al. (2016) and Bando et al. (2016) find no effects on overall labour supply about 1 year after a non-contributory pension was rolled out in Mexico and Peru respectively, as there was a shift from paid work to unpaid work. Galiani et al. (2016) explain that the shift could be due to beneficiaries preferring "less stressful and less demanding informal unpaid work within the household". Following this line of argument, it is possible that we do not see a drop in paid work participation because paid work in Singapore could be less stressful and demanding than that in the developing countries, and little informal unpaid work within the household (such as farming and handicrafts) is available in Singapore. The lack of an effect on the intensive margin may also be partially explained by labour market constraints on minimum working hours (see, e.g. Euwals 2001; Martinez-Granado 2005 for evidence on constraints on working hours; Stewart and Swaffield 1997). In addition, the relatively small quantum of SSS payouts (in relation to both recipients' wage and payouts from many other non-contributory pensions), ${ }^{7}$ as well as the possibility that work behaviour may take time to change, may also explain our result. Regardless of the exact reasons for the smaller estimated effects in our sample, our results suggest that the effects of non-contributory pensions on labour supply, as well as the speed of labour market adjustment, are likely to vary by payout level and/ or institutional context.

Our results also add to the literature on whether private cash transfers are crowded out by public transfers. Findings from this literature are more disparate; effects can range from complete crowding out to little response, though many studies suggest that increasing public transfers by a dollar leads to a 20-30 cent fall in private transfers (Cox and Fafchamps 2007). In the specific context of non-contributory old age pensions, Koh and Yang (2017) find that a new old age pension in South Korea completely crowded out money transfers from adult children to parents. Jensen (2004) and Fan (2010) find that expansion or the introduction of new non-contributory pensions led to 
falls in private cash transfers equivalent to $25-30 \%$ (for South Africa) and 30-39\% (for Taiwan) of the payout quantum respectively. Bando et al. (2016) and Amuedo-Dorantes and Juarez (2015) estimate that the probability of receiving a private transfer dropped by $7-8$ percentage points respectively in Peru and Mexico respectively about 1 year after the implementation of a non-contributory pension for the elderly. On the other hand, Hernani-Limarino and Mena (2015), Behrman et al. (2011), and Cheng et al. (2018) find little evidence that the introduction or expansion of non-contributory old age pensions in Bolivia, Chile, and China had an effect on receipt of private transfers. Against this backdrop, our finding that SSS recipients do not appear to receive less private transfers may not be surprising. Our result could be driven by a few reasons. The exchange motive could be stronger than the altruistic motive for private transfers (see, e.g. Cox 1987; Cox and Jakubson 1995), as it is common for grandparents in Singapore to provide care for their grandchildren. The SSS payout quantum could also be small enough for "donors" of private transfers to brush off, ${ }^{8}$ and lastly, donors' behaviour may also take time to adjust. In all, our results for labour decisions and private transfers suggest that the effects of non-contributory pensions are likely to vary by institutional context and payout levels.

The rest of this paper proceeds as follows. Section 2 provides background information on SSS. Section 3 describes our data and construction of the key treatment variable. Section 4 elaborates on our identification strategy and main empirical specifications, while Section 5 describes our alternative specifications for robustness checks. Section 6 presents our results. Section 7 discusses our supplementary analysis on the anticipatory effects of the SSS on younger individuals who are not age-eligible for payouts yet. Note that Sections 2, 3, 4, 5, and 6 focus only on the main analysis, which looks at the effect of receiving SSS payouts among those who can already start to receive payouts, i.e. those aged 65 and above in 2016. Lastly, Section 8 concludes.

\section{Background on the silver support scheme ${ }^{9}$}

The Silver Support Scheme (SSS) is the first non-contributory pension implemented in Singapore and is targeted at the neediest $20-30 \%$ of Singaporean citizens aged 65 and above. The introduction of SSS is a significant turning point in Singapore's pension system, which has been dominated by a defined contribution scheme, the Central Provident Fund (CPF). ${ }^{10}$

SSS details, such as the exact eligibility criteria and payout amounts, were announced at the end of March 2016. ${ }^{11}$ Eligible individuals receive quarterly payouts of $\$ \$ 300-$ S\$750 to supplement their existing retirement income; the exact quantum depends on the type of public housing (Housing and Development Board, HDB) flat they live in. ${ }^{12}$ Singaporeans who live in smaller flats will receive more as the government uses flattype as a proxy for socioeconomic status. On average, recipients of SSS payouts in our sample receive around $\$ \$ 500$ per quarter, which corresponds to about $14 \%$ of the preSSS-announcement mean monthly income from work among SSS recipients who worked during that period in our sample. The first payout was made in end-July 2016, followed by end-September 2016. Payouts meant for 2017 were/would be made in endDecember 2016, end-March 2017, end-June 2017, and end-September 2017, ahead of each calendar quarter. In this study, we focus on the SSS's effects in its first year of implementation. 
Individuals' eligibility for SSS is automatically determined based on administrative data and is updated yearly. Eligible individuals must (i) be Singapore citizens; (ii) live in a one- to five-room HDB flat; (iii) not personally own or have a spouse who owns five-room or larger HDB flats, private property, or multiple properties; (iv) have contributed no more than $\$ \$ 70,000$ to their defined contribution accounts by age 55; and (v) have a monthly household per-capita income of $\mathrm{S} \$ 1100$ or below. ${ }^{13}$ Self-employed persons should also have an average annual net trade income of not more than $\$ \$ 22,800$ when they were between the ages of 45 and 54 . Since the eligibility for the 2016 payouts is based on government data available in 2015, the receipt of SSS payouts in end-July and end-September 2016 is predetermined and hence exogenous. However, individuals may be able to self-select into being eligible for SSS payouts in 2017 by moving into a smaller flat, or by reducing their income. We discuss how we deal with this issue in Sections 3.2, 4 and $5 .{ }^{14}$

The disbursement of SSS payouts is fuss-free for recipients, as the Singapore government has been giving out ad hoc or regular cash transfers to Singaporeans since (at least) 2008, and thus has efficient systems in place that can be used to disburse new types of cash transfers. The government credits the payouts to bank accounts that most Singaporeans have already registered with the government. Those who do not have a registered bank account will receive a cheque that is mailed to their registered residential address. If the cheque is not encashed or banked in within 6 months, the government will credit the payouts into the individuals' defined contribution accounts, which are withdrawable within a year. The set-up for determining eligibility and disbursing payouts suggests that Singaporeans who are eligible for the SSS payouts will almost certainly receive their payouts.

\section{Data and variables}

\subsection{Data source}

Our data comes from the Singapore Life Panel (SLP), a new longitudinal monthly survey, which aims to follow a population-representative sample of about 15,000 Singapore citizens and permanent residents aged 50-70 and their spouses. The survey is conducted by the Centre for Research on the Economics of Ageing (CREA), and it captures a rich set of data including demographic characteristics, labour decisions, private cash transfers, and expenditure. More details on the SLP can be found in Vaithianathan et al. (2017).

We use data from waves 0-23 of the SLP, covering the period May 2015 to Jun 2017. This data allows us to implement a difference-in-differences (DiD) identification strategy, since SSS details were announced in end-Mar 2016 and payouts were disbursed from end-Jul 2016 onwards.

Before we move on, we highlight two advantages of using this dataset, compared to surveys which collect data at lower (i.e. yearly or longer) frequencies. First, the high frequency at which the SSS is collected enables us to precisely time and separately estimate the announcement and disbursement effects of the SSS. Capturing the announcement effect allows us to avoid under-estimating the SSS's effects (Blundell et al. 2011). Second, the SLP also allows us to directly test the validity of 
the DiD identifying assumption of parallel trends, which other studies that use data from surveys with only two or three time points cannot do.

\subsection{Sample and variables}

Our main analysis focuses on the impact of receiving Silver Support Scheme (SSS) payouts. Thus, we restrict our sample to those who would be age-eligible to receive SSS payouts from 2016 onwards (i.e. those aged 65 and above in 2016). In addition, our sample includes only Singapore citizens who live in public housing flats ${ }^{15}$ (two of the eligibility criteria for SSS receipt). This reduces the extent of heterogeneity within our sample.

Our main treatment variable, Received SS, is an indicator for whether an individual received SSS payouts. This is based on a survey question that is timed to appear in the month after each SSS disbursement, asking respondents if they received SSS in the previous month. This dummy variable takes value 1 if individuals reported that they received at least one payout for the year of 2016. This specification of the treatment status, which hinges only on the receipt of SSS for the year of 2016, for which eligibility is pre-determined before the announcement of SSS details, assures us that treatment status is pre-determined and exogenous. Such a treatment definition may attenuate our treatment effects; we address this by performing a robustness check where we restrict the control group to those who definitely did not receive SSS payouts in either 2016 or 2017 (see Section 5).

In addition, we define indicators for the following periods, to allow us to separately estimate announcement and disbursement effects: (i) the pre-SSS announcement period covering outcome responses corresponding to months before April 2016; (ii) the post-announcement period covering April 2016 to July 2016; and (iii) the post-disbursement period from August 2016 to June 2017. The periods are defined in this way because SLP surveys are conducted before the last week of the month, while the announcement and disbursements were made at the end of the month.

The outcome variables we focus on are variables related to labour decisions, private cash transfers, and expenditure. For labour decisions, we look at whether the respondent received income from work and the amount received. We also have data on individuals' subjective probability of working full-time after age 70, which is reported on a scale of $0-100$. For private cash transfers, we examine if the respondent received or gave money to family/friends, as well as the amount involved. These transfers-related outcomes are reported by the respondent at the couple level, i.e. based on whether and what the respondent and his/her spouse received/gave. (If the respondent is single, the reported value will be based only on the respondent.) Lastly, we investigate the effect of SSS on total expenditure (which excludes cash gifts, as these are already included as part of private transfers) and sub-categories of expenditure which are reported by the respondent at the couple level. All outcome variables are collected monthly, other than the question on one's subjective probability of working full-time after age 70, which is posed quarterly. ${ }^{16}$

The Singapore Life Panel also contains a rich set of demographic variables which we use to compare individuals who received SSS against those who did not, and 
refine our identification strategy by restricting our sample to individuals who are demographically more similar (more details on our identification strategy in Section 4).

\subsection{Summary statistics}

In Table 1, we show summary statistics that compare baseline demographics between those who received SSS and those who did not. Focusing on the left panel, we see that the proportion of respondents who received the Silver Support Scheme (SSS) payouts (as determined by our key treatment variable described in Section 3.2) is approximately 26\%. This is within the range anticipated by the policymakers. Across the range of demographic variables, the differences in means between those who received SSS and

Table 1 Summary statistics for baseline demographics - comparison between those who received and did not receive SSS payout, among individuals aged 65 and above in 2016

\begin{tabular}{|c|c|c|c|c|c|c|c|c|}
\hline & \multicolumn{4}{|c|}{ Untrimmed sample } & \multicolumn{4}{|c|}{ Trimmed sample (propensity score 0.2-0.8) } \\
\hline & \multicolumn{2}{|l|}{ Mean } & \multirow[t]{2}{*}{ Norm diff $^{2}$} & \multirow[t]{2}{*}{ Diff in means ${ }^{3}$} & \multicolumn{2}{|l|}{ Mean } & \multirow[t]{2}{*}{ Norm diff $^{2}$} & \multirow[t]{2}{*}{ Diff in means ${ }^{3}$} \\
\hline & $\begin{array}{l}\text { SS } \\
\left(N^{1}=429\right)\end{array}$ & $\begin{array}{l}\text { No SS } \\
\left(N^{1}=1246\right)\end{array}$ & & & $\begin{array}{l}\mathrm{SS} \\
\left(N^{1}=326\right)\end{array}$ & $\begin{array}{l}\text { No SS } \\
\left(N^{1}=564\right)\end{array}$ & & \\
\hline Age at 2016 & 68.86 & 68.03 & 0.28 & $0.83^{* * *}$ & 68.99 & 68.67 & 0.10 & 0.32 \\
\hline Married & 0.69 & 0.77 & -0.18 & $-0.08^{* * *}$ & 0.67 & 0.72 & -0.12 & $-0.05^{*}$ \\
\hline Male & 0.40 & 0.54 & -0.30 & $-0.15^{* * *}$ & 0.34 & 0.39 & -0.11 & -0.05 \\
\hline Chinese & 0.87 & 0.87 & 0.01 & 0.00 & 0.88 & 0.90 & -0.05 & -0.02 \\
\hline Malay & 0.07 & 0.07 & 0.00 & 0.00 & 0.06 & 0.06 & 0.02 & 0.01 \\
\hline Indian & 0.05 & 0.05 & 0.01 & 0.00 & 0.05 & 0.04 & 0.03 & 0.01 \\
\hline $\begin{array}{l}\text { No formal } \\
\text { schooling }\end{array}$ & 0.17 & 0.12 & 0.13 & $0.05^{* *}$ & 0.17 & 0.15 & 0.06 & 0.02 \\
\hline $\begin{array}{l}\text { Primary } \\
\text { schooling }\end{array}$ & 0.35 & 0.26 & 0.20 & $0.09 * * *$ & 0.40 & 0.37 & 0.06 & 0.03 \\
\hline $\begin{array}{l}\text { Secondary } \\
\text { schooling }\end{array}$ & 0.36 & 0.41 & -0.11 & $-0.05^{*}$ & 0.36 & 0.36 & 0.00 & 0.00 \\
\hline $\begin{array}{l}\text { Lives in 1- } \\
\text { room flat }\end{array}$ & 0.05 & 0.01 & 0.22 & $0.04^{* * *}$ & 0.05 & 0.02 & 0.14 & $0.03^{*}$ \\
\hline $\begin{array}{l}\text { Lives in 2- } \\
\text { room flat }\end{array}$ & 0.05 & 0.02 & 0.15 & $0.03^{* *}$ & 0.05 & 0.03 & 0.06 & 0.01 \\
\hline $\begin{array}{l}\text { Lives in 3- } \\
\text { room flat }\end{array}$ & 0.33 & 0.21 & 0.27 & $0.12^{* * * *}$ & 0.39 & 0.33 & 0.11 & 0.05 \\
\hline $\begin{array}{l}\text { Lives in 4- } \\
\text { room flat }\end{array}$ & 0.36 & 0.37 & -0.03 & -0.01 & 0.36 & 0.40 & -0.09 & -0.04 \\
\hline $\begin{array}{l}\text { Lives in 5- } \\
\text { room flat }\end{array}$ & 0.16 & 0.29 & -0.32 & $-0.13^{* * *}$ & 0.12 & 0.15 & -0.11 & -0.04 \\
\hline Owns home & 0.83 & 0.88 & -0.15 & $-0.05^{* *}$ & 0.82 & 0.84 & -0.04 & -0.01 \\
\hline $\begin{array}{l}\text { No. of hh } \\
\text { members }\end{array}$ & 2.95 & 3.28 & -0.22 & $-0.33^{* * *}$ & 2.83 & 3.02 & -0.13 & $-0.19^{*}$ \\
\hline $\begin{array}{l}\text { No. of total } \\
\text { children }\end{array}$ & 2.18 & 2.15 & 0.02 & 0.03 & 2.14 & 2.21 & -0.05 & -0.07 \\
\hline $\begin{array}{l}\text { Retirement } \\
\text { preparedness }\end{array}$ & 2.17 & 2.33 & -0.18 & $-0.16^{* * *}$ & 2.12 & 2.15 & -0.04 & -0.03 \\
\hline
\end{tabular}

Notes:

${ }^{1} N$ refers to number of respondents

${ }^{2}$ Normalised differences are computed as in Imbens (2015) (as the difference in means standardised by the square root of the mean variance of both groups)

$3 * * *, * * *$ represent statistical significance at the 10,5 , and $1 \%$ levels respectively, based on a t-test

${ }^{4} \mathrm{Th}$ 's is a self-assessment on preparedness for retirement, captured on a scale of 1 to 5 , with a higher value representing greater preparedness. This was captured during the baseline survey, which was conducted before the announcement of details on the Silver Support Scheme 
those who did not are mostly statistically significant and in the expected direction. For example, recipients are less likely to live in five-room flats, and they feel less financially prepared for retirement.

While differences in characteristics between treatment and control groups do not necessarily invalidate our chosen identification strategy (i.e. difference-in-differences (DiD)), there could be concerns that these differences are sufficient to lead to nonparallel trends in our outcome variables in the absence of treatment, which would then violate the DiD identifying assumption. As alluded to at the end of Section 3.2, we will address this concern by restricting our sample using the method we will describe in Section 4.

\section{Identification strategy and empirical model}

\subsection{Identification strategy}

We implement a difference-in-differences (DiD) strategy to estimate the causal average treatment-on-treated effect of receiving Silver Support Scheme (SSS) payouts on labour decisions, private cash transfers, and expenditure. Our sample consists of Singapore citizen respondents aged 65 and above in 2016 who live in public housing flats. The treated group comprises those who received SSS payouts, and the control group those who did not. As discussed in Section 3.2, our treatment variable takes value 1 if individuals reported that they received at least one payout in 2016. This means that treatment status is exogenous, as eligibility for SSS payouts in 2016 was pre-determined before the announcement of SSS details. Such a treatment definition may attenuate our treatment effects, as some members of the control group may be treated; we address this by performing a robustness check where we restrict the control group to those who definitely did not receive SSS payouts (see Section 5).

To tackle the possibility that our treatment and control groups may be sufficiently different to violate the DiD identifying assumption of parallel trends in the absence of treatment, we restrict our sample to individuals who are more similar demographically. We do so by first estimating the propensity score of being a SSS recipient using the data-driven algorithm described in Imbens (2015) on a rich set of baseline demographic characteristics. The propensity score is eventually estimated based on the following selection of covariates and some of their interactions: age as at 2016, marital status, gender, ethnicity, education, public housing flat-type, whether respondent's father is still living, number of household members, number of living children, income of self and spouse, self-assessment of financial preparedness for retirement, and satisfaction with one's economic situation. We then exclude individuals with either very low or high propensity scores, and retain a sample which includes only those with propensity scores from 0.2 to 0.8 .

Trimming the sample in this way improves the comparability of the treatment and control groups (see right panel of Table 1). Most differences in mean values of demographic characteristics are no longer statistically significant, and the magnitude of the normalised differences are small (the largest is 0.14). (The normalised differences are computed as the difference in means standardised by the square root of the mean variance of both groups (Imbens 2015)). The distributions of 
variables related to the SSS eligibility criteria for both the control and treatment groups also became more similar (Fig. 1). The improved similarity of both groups increases the probability that the $\mathrm{DiD}$ identifying assumption will be met.

Having said this, we acknowledge that the improved similarity of both groups in terms of observables does not necessarily imply improved similarity in unobservables. However, remaining differences in unobservables are unlikely to lead to differences in trend between the treated and control groups as our treatment definition excludes the possibility of self-selection into receiving SSS payouts.

In addition, we check the validity of the DiD identifying assumption for our study more directly. We do so by performing visual checks (by plotting the unconditional means of our outcome variables) and statistical checks (by including placebo leads in our empirical specification-see Section 4.2). Our checks suggest that our identifying

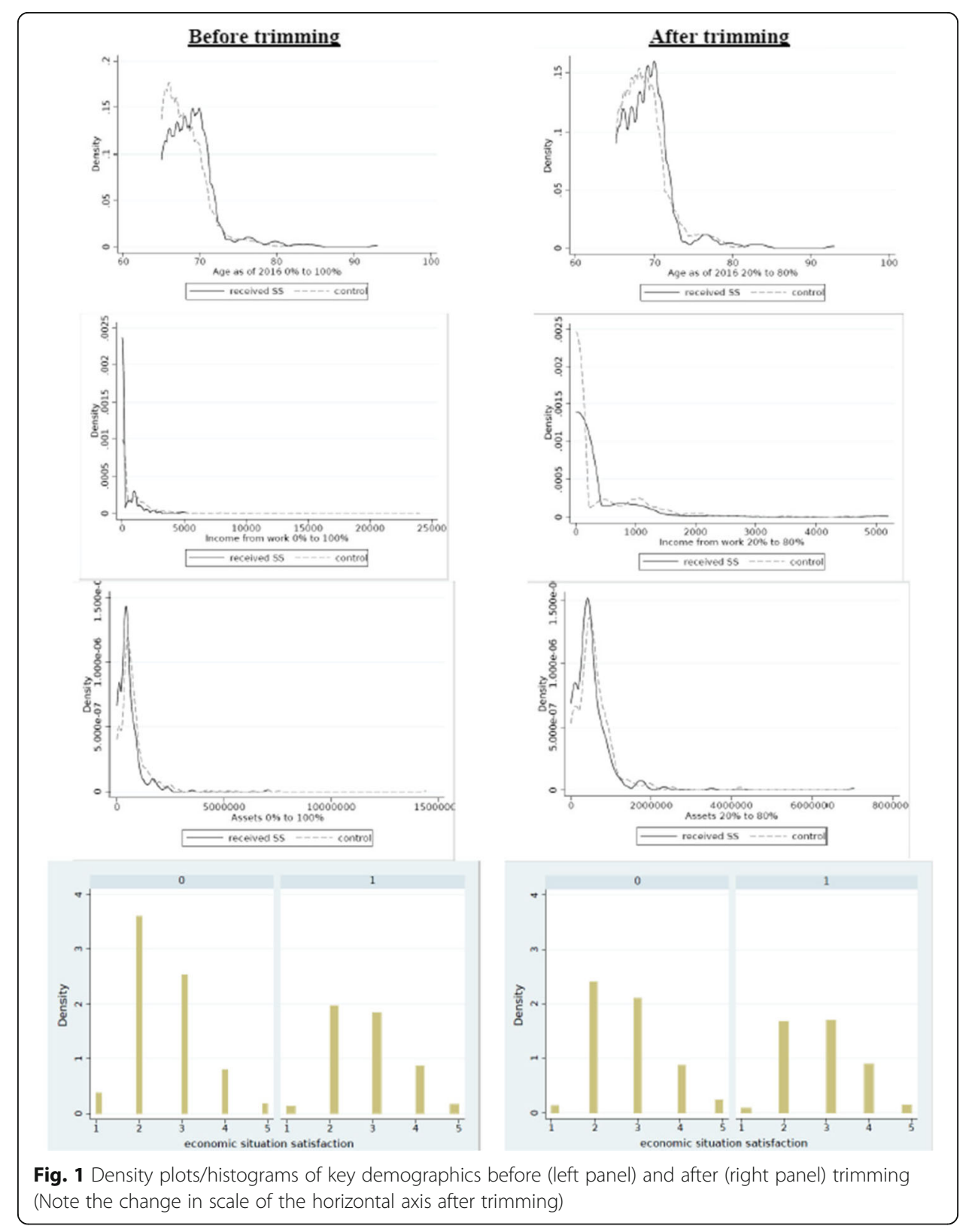


assumptions are generally valid. We discuss the results of these checks in more detail in Section 6.

\subsection{Main specifications}

Our key regression specification is used to estimate the overall effects of Silver Support Scheme (SSS):

$$
\begin{aligned}
Y_{i t}= & \sum_{k=-3}^{-1} \beta_{\text {pre }, k}\left(\text { Received } \mathrm{SS}_{i} \times \text { Preann }_{t, k}\right) \\
& +\beta_{\text {ann }}\left(\text { Received } \mathrm{SS}_{i} \times \text { Anntopay }_{t}\right)+\beta_{\text {disb }}\left(\text { Received } \mathrm{SS}_{i} \times \text { Postpay }_{t}\right) \\
& +\alpha_{i}+\gamma_{t}+\epsilon_{i t}
\end{aligned}
$$

where $Y_{i t}$ is the outcome variable for respondent $i$ at time $t$; Received $S S_{i}$ is a dummy variable that takes value 1 if the individual received at least one payout for the year 2016 (described in Section 3.2); Preann $_{t,-3}, \operatorname{Preann}_{t,-}, \operatorname{Preann}_{t,-1}$ are dummy variables that take value 1 if time $t$ corresponds to January, February, and March 2016 respectively; Anntopay is a dummy for the period between announcement and payment (waves 9-12, Apr-Jul 2016) and Postpay is a dummy for the period after disbursement (waves 13-23, Aug 2016-Jun 2017). $\alpha_{i}$ and $\gamma_{t}$ are individual and time fixed-effects respectively. The baseline/suppressed period consists of waves two to five (Sep-Dec 2015). ${ }^{17}$ We cluster the standard errors at the household level.

$\beta_{\mathrm{ann}}$ and $\beta_{\mathrm{disb}}$ are our main coefficients of interest, capturing the treatment effects during the announcement and disbursement periods respectively. $\beta_{\text {pre, }}-$ the coefficients for our placebo leads-are used to test the validity of the difference-indifferences (DiD) identifying assumption in our study. A statistically insignificant $\beta_{\text {pre, } k}$ would give us more confidence that the assumption is valid.

As individuals' behaviour may take time to adjust, we also estimate Eq. (2) to study the dynamics of the effect over time:

$$
\begin{aligned}
Y_{i t}= & \sum_{k=-3}^{-1} \beta_{\text {pre }, k}\left(\text { Received } \mathrm{SS}_{i} \times \text { Preann }_{t, k}\right) \\
& +\beta_{\text {ann }}\left(\text { Received } \mathrm{SS}_{i} \times \text { Anntopay }_{t}\right) \\
& +\sum_{p \in P} \beta_{\text {disb }, p}(\text { Received SS } \\
& \left.+ \text { Postpay }_{t} \times \text { Quarter }_{t, p}\right) \\
& +\alpha_{i}+\gamma_{t}+\in_{i t}
\end{aligned}
$$

where Quarter $_{t, p}$ is a dummy variable that takes value 1 if month $t$ belongs to quarter $p$. We split the post-disbursement period into quarters, such that $P$ includes dummies for the periods August-September 2016, Oct-December 2016, January-March 2017, and April-May 2017. ${ }^{18}$

Lastly, we carry out a series of heterogeneity analyses, to examine if the SSS's effects vary by net assets, subjective financial preparedness for retirement, flat-type (a proxy for wealth and the determinant of payout quantum), and gender. We do so by interacting the treatment variables Received $\mathrm{SS}_{i} \times$ Anntopay $_{t}$ and Received $\mathrm{SS}_{i} \times$ Postpay $_{t}$ with the variables listed above. The variables for the heterogeneity analyses were chosen as the effects of permanent income shocks on the outcomes we study are likely to vary by wealth/liquidity constraints, amount received, and gender (see, e.g. Hernani-Limarino and Mena 2015; Jappelli and Pistaferri 2010; Kaushal 2014). 


\section{Potential threats to identification and robustness checks}

While we have attempted to construct sufficiently similar treatment and control groups that are likely to satisfy the DiD identifying assumptions, some identification issues may remain. Here, we describe a series of robustness checks designed to address these potential issues. These checks include the use of different control/treatment groups and different re-weighting techniques to address potential failures of the parallel trends assumption and mismeasurement issues, as well as the use of different specifications of Eq. (1) to test the sensitivity of our main estimates. The results of these checks are summarised in Section 6; full results are in Appendices 1, 2, and 3.

First, there may be measurement error with respect to our treatment variable. A significant proportion of individuals defined as treated reported that they received at least one payout for 2016, but not for 2017. This is likely to be driven by misreporting, as the nature of the eligibility criteria make it unlikely for SSS receipt status to change dramatically in the short run. In addition, some control individuals may have received SSS payouts, as they reported that they received SSS payouts in 2017 but not 2016. Both types of measurement error may attenuate the estimated effects of receiving SSS payouts.

To study whether attenuation from the sources above is an issue, we estimate the following regression:

$$
\begin{aligned}
Y_{i t}= & \sum_{k=-3}^{-1} \beta_{\text {pre }, k}\left(\text { Received } \mathrm{SS}_{i} \times \text { Preann }_{t, k}\right) \\
& +\sum_{g \in G} \beta_{\text {ann }, g}\left(\text { Anntopay }_{t} \times \text { Subset }_{i, g}\right) \\
& +\sum_{g \in G} \beta_{\text {disb }, g}\left(\text { Postpay }_{t} \times \text { Subset }_{i, g}\right) \\
& +\alpha_{i}+\gamma_{t}+\epsilon_{i t}
\end{aligned}
$$

where Subset $_{i, g}$ is a dummy variable that takes value 1 if the individual belongs to subset $g$. $G$ includes the following subsets: individuals who (i) received payouts in 2016 and 2017; (ii) received payouts in 2016 but not 2017; (iii) received payouts in 2016; payout status in 2017 is missing; (iv) received payouts in 2017 but not 2016 (this subset is part of the control group in the main specification ${ }^{19}$ ); and (v) did not receive payouts in 2016; payout status in 2017 is missing. The suppressed subset (i.e. control group) comprises individuals who reported that they did not receive SSS payouts in either 2016 or 2017.

Our coefficients of interest are those related to subset (i)-the subset least likely to suffer from misreporting. These coefficients are based on the comparison between those who almost certainly received SSS payouts (i.e. subset (i)) and those who almost certainly did not receive SSS payouts (i.e. suppressed subset), thus reducing potential attenuation from the sources of mismeasurement described above. If these estimates are similar to those from our main regression, attenuation is less likely to be a major issue in our study.

Second, even though respondents in our control group do not receive SSS payouts, their outcomes may still be affected by the SSS if his/her spouse receives SSS payouts. ${ }^{20}$ This may attenuate our main estimates. 
To account for this, we re-define our treatment groups so that they are based on the number and identity of SSS recipients within a household, and estimate the following equation $^{21}$ :

$$
\begin{aligned}
Y_{i t}= & \sum_{k=-3}^{-1} \beta_{\text {pre }, k}(\text { At least one treated } \\
& \left.\times \text { Preann }_{t, k}\right) \\
& +\sum_{g \in G} \beta_{\text {ann }, g}\left(\text { Who_treated }_{i, g} \times \text { Anntopay }_{t}\right) \\
& +\sum_{g \in G} \beta_{\text {disb }, g}\left(\text { Who_treated }_{i, g} \times \text { Postpay }_{t}\right)
\end{aligned}
$$

where At least one treated ${ }_{i}$ is a dummy variable that takes value 1 if either respondent $i$ or respondent $i$ 's spouse received SSS; Who_treated ${ }_{i, g}$ can be a dummy variable indicating that (i) only the respondent received SSS, (ii) only the respondent's spouse received SSS, or (iii) both the respondent and his/her spouse received SSS. The control group in this regression is thus made up of respondents who did not receive SSS payouts and whose spouse did not receive SSS payouts either.

To give us a sense of whether attenuation is a major problem for our main estimates, we compare our main estimates to the coefficients related to the subset in which only the respondent received SSS payouts. Other coefficients in this specification allow us to explore whether effects vary when the number of people in a household receiving SSS increases.

Third, to address concerns that our main specification's control group is not ideal, we re-estimate Eq. (1) using an alternative control group selected from younger individuals who are not age-eligible for SSS payouts yet (i.e. those aged 56 to $63^{22}$ in 2016). ${ }^{23} \mathrm{We}$ estimate the propensity of receiving SSS payouts for these younger individuals (using the coefficient estimates from our earlier logistic regression described in Section 4.1) and define the alternative control group as those with propensity scores of $0.2-0.8$, to match the propensity scores for our treatment group in our main regression. In addition to using younger respondents as an alternative control group, we also apply different re-weighting techniques on our original control group to address differences in baseline covariates between the control and treatment groups. (More details at the end of the next paragraph.)

Fourth, using the original control group, we test the sensitivity of our results by estimating different variations of Eq. (1) where we (i) remove placebo leads to check if our results are sensitive to our choice of the baseline period; (ii) restrict the sample to individuals with at least one observation in each of the preannouncement, announcement-to-disbursement, and post-disbursement periods, to check that compositional differences are not driving our results; (iii) add groupspecific time fixed effects (based on ethnicity and flat-types) to allow for differential time trends in different groups; (iv) add age fixed effects; (v) add control covariates for other welfare payments ${ }^{24}$; and (vi) implement Abadie (2005)'s semiparametric $\mathrm{DiD}^{25}$ and $\mathrm{DiD}$ matching using 1-to-1 nearest neighbour matching to check if our results are robust to different re-weighting methods used to address imbalances in baseline characteristics. 


\section{Results and discussion}

In this section, we discuss the effects of receiving SSS on each type of outcome variable-labour decisions, private cash transfers, and expenditure.

\subsection{Labour decisions}

Receiving SSS payouts appears to have had little, if any, effect on the labour-related outcomes we study in this section.

Table 2 reports the overall effect of receiving SSS payouts on labour-related outcomes (specified at top of each column). The coefficients for the placebo leads are statistically insignificant. This observation, together with the similar pre-treatment trends we observe in Fig. 2, suggest that the parallel trends assumption is likely to hold for this set of variables. The coefficients for the announcement and disbursement effects of SSS, $\beta_{\mathrm{ann}}$ and $\beta_{\mathrm{disb}}$, are statistically insignificant across all variables studied. These coefficients are also close to zero for column (1) (which looks at whether an individual received income from work in the last month), and positive for columns (2) and (3) (which look at the amount of income received from work). ${ }^{26}$ Our point estimate for the probability of engaging in paid work is lower than the fall of 4 to 6 percentage points that many other studies on non-contributory pensions find (Aguila et al. 2011; Bando et al. 2016; Cheng et al. 2018; Fetter and Lockwood 2016; Galiani et al. 2016; Hernani-Limarino and Mena 2015; Juárez and Pfutze 2015), ${ }^{27}$ while our results related

Table 2 Overall impact of receiving SSS payouts on labour decisions

\begin{tabular}{|c|c|c|c|c|}
\hline & (1) & (2) & (3) & (4) \\
\hline VARIABLES & $\begin{array}{l}\text { Whether received } \\
\text { income }\end{array}$ & $\begin{array}{l}\text { Amount } \\
\text { received }\end{array}$ & $\begin{array}{l}\text { Amount received } \\
\text { (positive) }\end{array}$ & $\begin{array}{l}\text { Probability of working } \\
\text { full- time after age } 70\end{array}$ \\
\hline \multirow[t]{2}{*}{ Received SS $\times$ Jan } & 0.006 & 24.920 & -182.536 & -2.311 \\
\hline & $(0.021)$ & $(69.479)$ & $(154.643)$ & (3.304) \\
\hline \multirow[t]{2}{*}{ Received SS × Feb } & 0.010 & 29.468 & 7.444 & - \\
\hline & $(0.020)$ & $(34.471)$ & (91.964) & - \\
\hline \multirow[t]{2}{*}{ Received SS $\times$ Mar } & 0.021 & 57.272 & -118.865 & - \\
\hline & $(0.020)$ & $(48.284)$ & $(217.277)$ & - \\
\hline \multirow[t]{2}{*}{ Received SS $\times$ announce-to-pay } & 0.012 & 97.578 & 66.047 & -2.117 \\
\hline & $(0.018)$ & $(78.829)$ & $(92.580)$ & (3.194) \\
\hline \multirow[t]{2}{*}{ Received SS $\times$ post-pay } & -0.010 & 67.668 & 44.921 & -4.335 \\
\hline & $(0.017)$ & $(68.360)$ & (98.466) & $(2.950)$ \\
\hline Mean & 0.27 & 331 & 1229 & 18.55 \\
\hline S.D. & 0.45 & 894 & 1366 & 30.38 \\
\hline Observations & 16,062 & 15,997 & 4596 & 3536 \\
\hline R-squared & 0.81 & 0.70 & 0.75 & 0.64 \\
\hline \multicolumn{5}{|c|}{$\begin{array}{l}\text { Notes: } \\
\text { 'Standard errors clustered at the household level in parentheses. }{ }^{* * *},{ }^{* *}, \text { and }{ }^{*} \text { represent statistical significance at the } 1, \\
5 \text {, and } 10 \% \text { level of significance respectively } \\
\text { 2Dependent variables are shown at the top of each column. Values in columns (1)-(3) are reported at the individual and } \\
\text { monthly level, with column (3) including only responses with positive values. Values in column (4) are collected at the } \\
\text { individual level every quarter } \\
{ }^{3} \text { Results are estimates of coefficients in Eq. (1). The sample is restricted to respondents who are age-eligible for SSS } \\
\text { (i.e. aged } 65 \text { and above in } 2016) \text {, Singapore citizens, live in public housing flats, and with a propensity score of } 0.2-0.8 \\
{ }^{4} \text { Mean and standard deviation statistics are based on pre-announcement levels of the dependent variable for respondents } \\
\text { who received SSS payouts }\end{array}$} \\
\hline
\end{tabular}




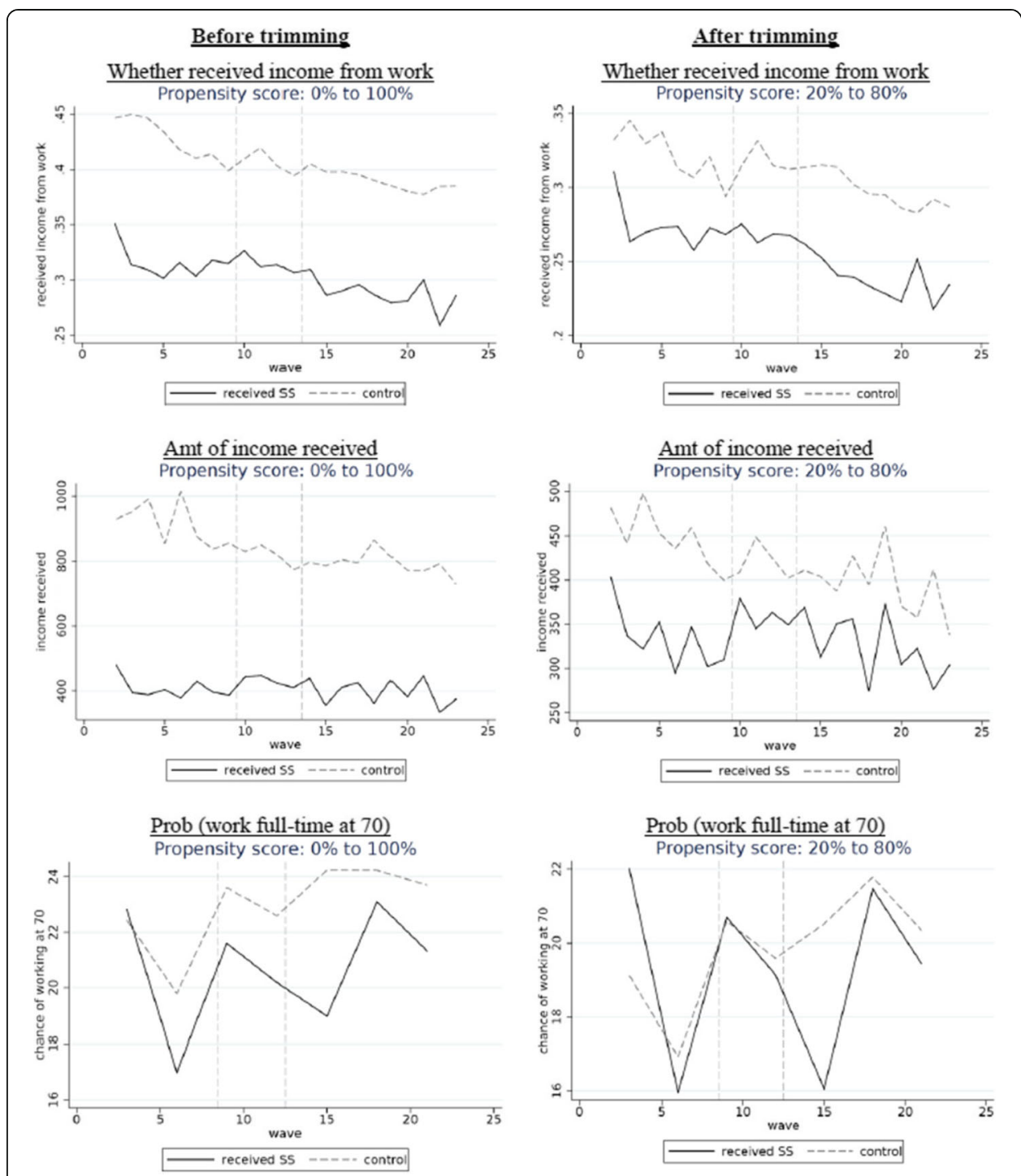

Fig. 2 Trends of key labour-related variables (The periods to the left of the first and second dotted vertical lines refer to the pre-announcement and pre-disbursement periods respectively)

to amount of income received from work suggest that it is unlikely that labour supply fell along the intensive margin. Finally, column (4) shows that there is little evidence of any persistent changes in recipients' subjective probability of working full-time at age 70 .

Table 3 studies how individuals' behaviour might have changed over time. We highlight two interesting trends. First, while our results for whether an individual received income from work (column (1)) remain statistically insignificant, the coefficients of the treatment-related variables fall almost monotonically as time goes by. Second, there was a sharp fall in SSS recipients' subjective probability of working full-time at age 70 immediately after receiving their first SSS payout (column (4)). However, recipients' expectations readjusted very quickly-SSS recipients' self-assessed probability of working full-time at 70 rose quickly soon after and was no longer statistically significant in 2017. In addition, we find little evidence that these effects vary substantially by 
Table 3 Temporal impact of receiving SSS payouts on labour decisions

\begin{tabular}{|c|c|c|c|c|}
\hline & (1) & (2) & (3) & (4) \\
\hline VARIABLES & $\begin{array}{l}\text { Whether received } \\
\text { income }\end{array}$ & $\begin{array}{l}\text { Amount } \\
\text { received }\end{array}$ & $\begin{array}{l}\text { Amount received } \\
\text { (positive) }\end{array}$ & $\begin{array}{l}\text { Probability of working full- } \\
\text { time after age } 70\end{array}$ \\
\hline \multirow[t]{2}{*}{ Received SS $\times$ Jan } & 0.00631 & 24.92 & -182.6 & -2.324 \\
\hline & $(0.0206)$ & $(69.49)$ & $(154.8)$ & (3.304) \\
\hline \multirow[t]{2}{*}{ Received SS × Feb } & 0.00981 & 29.45 & 7.016 & - \\
\hline & $(0.0201)$ & $(34.46)$ & $(92.33)$ & - \\
\hline \multirow[t]{2}{*}{ Received SS $\times$ Mar } & 0.0211 & 57.28 & -119.1 & - \\
\hline & $(0.0196)$ & $(48.28)$ & $(217.6)$ & - \\
\hline \multirow[t]{2}{*}{ Received SS $\times$ announce-to-pay } & 0.0123 & 97.70 & 65.48 & -2.125 \\
\hline & $(0.0178)$ & $(78.85)$ & $(92.73)$ & (3.194) \\
\hline \multirow[t]{2}{*}{ Received SS × Aug-Sep 2016} & 0.00912 & 90.89 & 21.95 & - \\
\hline & $(0.0189)$ & $(74.75)$ & $(84.50)$ & - \\
\hline \multirow[t]{2}{*}{ Received SS × Oct-Dec 2016} & -0.0137 & 70.53 & 47.54 & $-7.164^{* *}$ \\
\hline & $(0.0189)$ & $(85.19)$ & $(134.2)$ & (3.308) \\
\hline \multirow[t]{2}{*}{ Received SS × Jan-Mar 2017} & -0.0115 & 62.68 & 32.63 & -2.330 \\
\hline & $(0.0187)$ & $(66.13)$ & $(134.3)$ & (3.384) \\
\hline \multirow[t]{2}{*}{ Received SS × Apr-May 2017} & -0.0221 & 46.39 & 86.42 & -3.185 \\
\hline & $(0.0209)$ & $(62.31)$ & (146.6) & (3.413) \\
\hline Observations & 16,062 & 15,997 & 4596 & 3536 \\
\hline R-squared & 0.808 & 0.701 & 0.751 & 0.638 \\
\hline \multicolumn{5}{|c|}{ 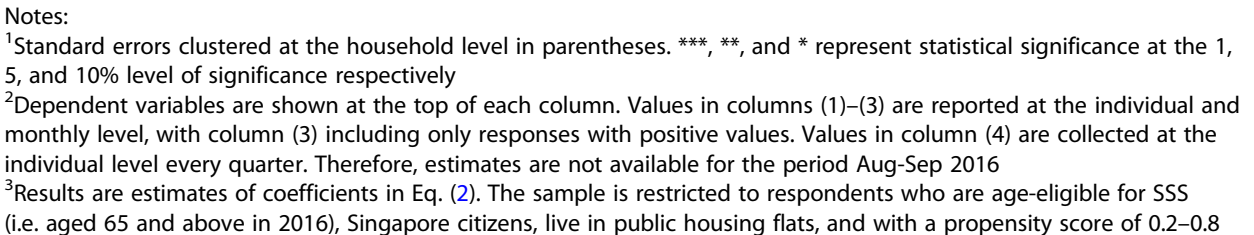 } \\
\hline
\end{tabular}

recipients' net assets, subjective financial preparedness for retirement, flat-type, or gender. (Results available on request.)

These results are robust to the series of robustness checks we described in Section 5 (see Tables 8, 9, 10, 11, 12 and 13 in Appendix 1 for results). In particular, attenuation of our results due to mismeasurement/having a spouse receive SSS payouts does not seem to be an important issue for this set of outcomes, as the treatment effects estimated from regressions where we try to address attenuation (Eqs. (3) and (4)) are similar to or smaller than treatment effects we estimate using our main specification (Eq. (1)).

In all, we find no evidence that receiving SSS reduced labour supply along either the extensive or intensive margins in the first year of the SSS's implementation-our estimates are statistically insignificant and either negative and close to zero, or positive, which imply a short-run labour supply elasticity (with respect to income) of zero. The lack of a short-run response in labour supply is not too surprising given the relatively modest payout levels, ${ }^{28}$ and the fact that those who receive the highest payouts are also the least able to reduce labour supply (i.e. those who stay in the smallest flats, who are likely to be poorer). In addition, receiving SSS does not appear to have a persistent impact on future work expectations. However, there is suggestive evidence that SSS recipients' behaviour may not have fully adjusted yet and that their labour supply may fall further in future. 


\subsection{Private cash transfers}

Receiving SSS payouts appears to have had little impact on whether recipients gave or received private cash transfers. A concern for this set of results is that our identifying assumption may not hold as well for variables related to whether SSS recipients received private cash transfers. While the placebo leads in Table 4 are statistically insignificant, Fig. 3 shows that there seems to be a spike in the variables related to transfers received by SSS recipients, at approximately 1 or 2 months before the SSS announcement. Nonetheless, as we will see later in this sub-section, our robustness checks give us similar results, giving us more confidence that receiving SSS payouts has had little effect on private transfers.

Table 4 reports the effect of receiving SSS payouts on whether (and how much) an individual received and gave cash transfers to their family and friends. The coefficients for the announcement and disbursement effects of SSS, $\beta_{\text {ann }}$ and $\beta_{\text {disb }}$, are statistically insignificant across all transfer-related variables. These coefficients are also close to zero for the variables related to whether an individual received or gave private cash transfers (columns (1) and (4) respectively), and positive for variables related to the amount of private transfers received (columns (2) and (3)). ${ }^{29}$ Our results on the probability of receiving private cash transfers (the extensive margin) are similar to results from papers studying non-contributory pensions in Bolivia, Chile, and China (Behrman et al. 2011; Cheng et al. 2018; Hernani-Limarino and Mena 2015), and precise enough to exclude falls of the magnitude (7-8 percentage points) seen in Peru and Mexico (Amuedo-Dorantes and Juarez 2015; Bando et al. 2016), while our results related to the

Table 4 Overall impact of receiving SSS payouts on private cash transfers

\begin{tabular}{|c|c|c|c|c|c|c|}
\hline & (1) & $(2)$ & (3) & (4) & (5) & (6) \\
\hline VARIABLES & $\begin{array}{l}\text { Whether } \\
\text { received }\end{array}$ & $\begin{array}{l}\text { Amount } \\
\text { received }\end{array}$ & $\begin{array}{l}\text { Amount received } \\
\text { (positive) }\end{array}$ & $\begin{array}{l}\text { Whether } \\
\text { gave }\end{array}$ & $\begin{array}{l}\text { Amount } \\
\text { given }\end{array}$ & $\begin{array}{l}\text { Amount given } \\
\text { (positive) }\end{array}$ \\
\hline \multirow[t]{2}{*}{ Received SS $\times$ Jan } & -0.007 & 13.920 & 12.428 & 0.021 & 6.843 & 154.235 \\
\hline & $(0.030)$ & $(37.129)$ & $(48.749)$ & $(0.029)$ & $(27.856)$ & $(163.458)$ \\
\hline \multirow[t]{2}{*}{ Received SS × Feb } & 0.008 & 29.747 & 61.918 & 0.040 & 0.547 & 9.913 \\
\hline & $(0.029)$ & $(33.602)$ & $(41.753)$ & $(0.033)$ & $(28.959)$ & $(184.678)$ \\
\hline \multirow[t]{2}{*}{ Received SS $\times$ Mar } & 0.041 & 37.983 & 34.748 & 0.008 & -25.217 & -13.378 \\
\hline & $(0.026)$ & $(28.675)$ & $(36.247)$ & $(0.027)$ & $(23.662)$ & $(121.744)$ \\
\hline \multirow[t]{2}{*}{ Received SS $\times$ announce-to-pay } & -0.017 & 0.121 & 31.817 & 0.021 & 4.623 & 32.431 \\
\hline & $(0.021)$ & $(22.432)$ & $(29.931)$ & $(0.018)$ & $(16.486)$ & $(114.317)$ \\
\hline \multirow[t]{2}{*}{ Received SS $\times$ post-pay } & -0.014 & 14.711 & 54.170 & 0.011 & -5.946 & 20.925 \\
\hline & $(0.021)$ & $(27.121)$ & (34.599) & $(0.020)$ & $(18.265)$ & $(95.438)$ \\
\hline Mean & 0.63 & 542.78 & 860.12 & 0.16 & 63.16 & 397.36 \\
\hline S.D. & 0.48 & 669.69 & 661.61 & 0.37 & 325.42 & 731.46 \\
\hline Observations & 15,486 & 15,451 & 9100 & 15,424 & 15,400 & 1940 \\
\hline R-squared & 0.73 & 0.77 & 0.77 & 0.43 & 0.20 & 0.52 \\
\hline
\end{tabular}

Notes:

${ }^{1}$ Standard errors clustered at the household level in parentheses. ${ }^{* * *}, *^{*}$, and ${ }^{*}$ represent statistical significance at the 1 , 5 , and $10 \%$ level of significance respectively

${ }^{2}$ Dependent variables are shown at the top of each column. All transfer values are reported at the couple (respondent and spouse if respondent is married) and monthly level. Columns (3) and (6) include only responses with positive values ${ }^{3}$ Results are estimates of coefficients in Eq. (1). The sample is restricted to respondents who are age-eligible for SSS (i.e. aged 65 and above in 2016), Singapore citizens, live in public housing flats, and with a propensity score of $0.2-0.8$ ${ }^{4}$ Mean and standard deviation statistics are based on pre-announcement levels of the dependent variable for respondents who received SSS payouts 

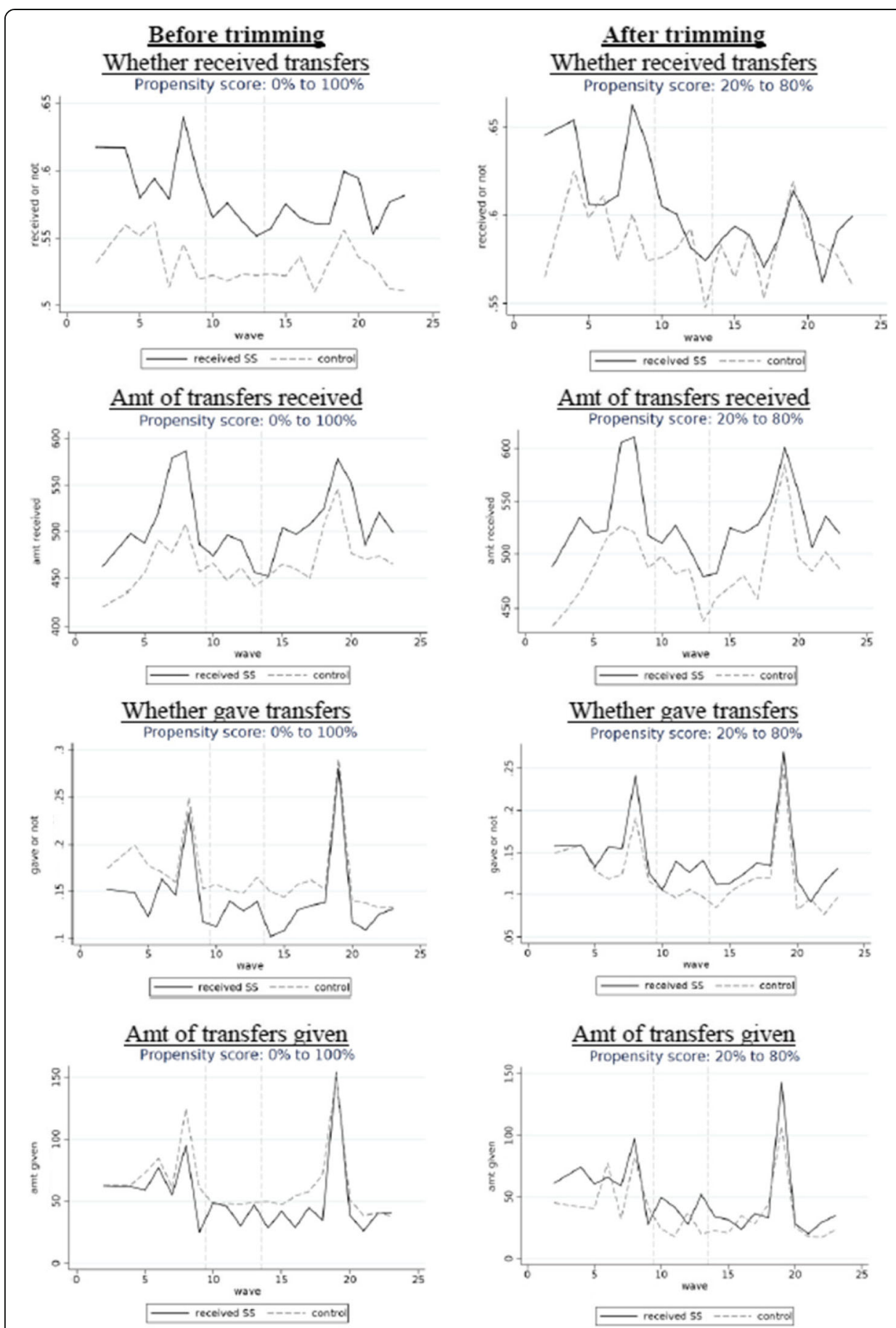

Fig. 3 Trends of key private transfer-related variables (The periods to the left of the first and second dotted vertical lines refer to the pre-announcement and pre-disbursement periods respectively)

amount of private transfers received suggest that it is unlikely that private transfers to SSS recipients fell along the intensive margin.

There does not appear to be a clear pattern in how transfers received and given by SSS recipients change over time (Table 5), and the effect does not appear to vary substantially by recipients' net assets, subjective financial preparedness for retirement, flat-type, or gender (results available on request). 
Table 5 Temporal impact of receiving SSS payouts on private cash transfers

\begin{tabular}{|c|c|c|c|c|c|c|}
\hline & (1) & $(2)$ & (3) & (4) & (5) & (6) \\
\hline VARIABLES & $\begin{array}{l}\text { Whether } \\
\text { received }\end{array}$ & $\begin{array}{l}\text { Amount } \\
\text { received }\end{array}$ & $\begin{array}{l}\text { Amount received } \\
\text { (positive) }\end{array}$ & $\begin{array}{l}\text { Whether } \\
\text { gave }\end{array}$ & $\begin{array}{l}\text { Amount } \\
\text { given }\end{array}$ & $\begin{array}{l}\text { Amount given } \\
\text { (positive) }\end{array}$ \\
\hline \multirow[t]{2}{*}{ Received SS $\times$ Jan } & -0.00685 & 13.92 & 12.43 & 0.0213 & 6.852 & 154.7 \\
\hline & $(0.0305)$ & (37.13) & $(48.75)$ & $(0.0295)$ & $(27.86)$ & $(163.7)$ \\
\hline \multirow[t]{2}{*}{ Received SS $\times$ Feb } & 0.00764 & 29.75 & 61.90 & 0.0395 & 0.581 & 11.06 \\
\hline & $(0.0288)$ & $(33.60)$ & $(41.75)$ & $(0.0330)$ & $(28.96)$ & $(185.1)$ \\
\hline \multirow[t]{2}{*}{ Received SS $\times$ Mar } & 0.0414 & 38.00 & 34.67 & 0.00832 & -25.21 & -12.04 \\
\hline & $(0.0264)$ & $(28.67)$ & $(36.20)$ & $(0.0265)$ & $(23.66)$ & $(122.2)$ \\
\hline \multirow[t]{2}{*}{ Received SS $\times$ announce-to-pay } & -0.0171 & 0.175 & 31.87 & 0.0212 & 4.667 & 31.41 \\
\hline & $(0.0214)$ & $(22.44)$ & $(29.97)$ & $(0.0185)$ & $(16.49)$ & $(113.9)$ \\
\hline \multirow[t]{2}{*}{ Received SS × Aug-Sep 2016} & -0.0123 & 23.89 & $65.22^{*}$ & 0.0123 & 0.121 & 25.07 \\
\hline & $(0.0243)$ & $(28.03)$ & $(36.40)$ & $(0.0208)$ & $(18.25)$ & $(106.9)$ \\
\hline \multirow[t]{2}{*}{ Received SS × Oct-Dec 2016} & -0.0164 & 16.85 & $65.89^{*}$ & 0.00452 & -18.57 & -53.73 \\
\hline & $(0.0231)$ & $(28.93)$ & $(36.85)$ & $(0.0225)$ & $(19.41)$ & $(119.4)$ \\
\hline \multirow[t]{2}{*}{ Received SS × Jan-Mar 2017} & -0.0251 & 9.136 & 54.25 & 0.00879 & 0.377 & 101.7 \\
\hline & $(0.0232)$ & $(31.40)$ & $(41.33)$ & $(0.0240)$ & $(21.11)$ & $(114.0)$ \\
\hline \multirow[t]{2}{*}{ Received SS × Apr-May 2017} & 0.00256 & 10.20 & 24.28 & 0.0215 & -2.106 & -11.14 \\
\hline & $(0.0252)$ & $(31.16)$ & $(39.70)$ & $(0.0233)$ & (18.73) & $(99.97)$ \\
\hline Observations & 15,486 & 15,451 & 9100 & 15,424 & 15,400 & 1940 \\
\hline R-squared & 0.733 & 0.773 & 0.773 & 0.425 & 0.196 & 0.523 \\
\hline
\end{tabular}

Lastly, our results are robust to the series of checks we describe in Section 5 (see Appendix 2 for results). In particular, robustness checks that partially address our concern of potentially different time trends between the treated and control groups in our main specification produce similar results (see Table 16 and columns (7) and (8) of Tables 17, 18, 19, and 20 where an alternative control group and other reweighting schemes are considered ${ }^{30}$ ). The estimated coefficients of the placebo leads from these checks are generally similar or smaller in magnitude than those from our main estimates, suggesting that the parallel trends assumption may hold better in these specifications. Among the robustness checks where the parallel trends assumption appears to hold better, the estimated announcement and disbursement effects are generally similar to or smaller in magnitude than estimates from our main regression. In addition to the robustness checks we describe in Section 5, we study the SSS's effects on transfers using a separate set of questions on annual transfers (results available on request). As these questions are asked annually, they may be subject to less of the month-to-month variability we observe for our main set of transfer-related variables. Our results in this sub-section are robust to estimations from this separate set of annual questions. Finally, our robustness checks designed to deal with potential attenuation of the estimated SSS effects also show that attenuation is unlikely to be a serious issue in this case (Tables 14 and 15). 
In all, our results suggest that in the first year of the SSS's implementation, receipt of SSS payouts was unlikely to have crowded out private cash transfers from friends and family to SSS recipients and was unlikely to have led to a rise in recipients giving cash transfers to others. This lack of crowding out of private transfers in our sample is not too surprising, given the relatively modest SSS payouts, ${ }^{31}$ when other studies which look at non-contributory pensions with higher payout levels have found a similar lack of crowding-out (Behrman et al. 2011; Cheng et al. 2018; Hernani-Limarino and Mena 2015). ${ }^{32}$

\subsection{Expenditure}

Our ability to make definitive statements about the effect of the SSS on expenditure is hampered by the imprecision of our estimates. We therefore relegate our detailed discussion of our expenditure-related results to Appendix 3 in the interest of space. Briefly, our ability to make definitive statements about the effect of SSS on total and non-durables expenditure is hampered by the imprecision of our estimates-our point estimates are positive and quite large in magnitude, but statistically insignificant. In addition, our identifying assumption does not seem to hold well for durables expenditure, even though the effects are positive and statistically significant. Therefore, these expenditure-related results need to be interpreted with caution and corroborated by studies using other datasets before a more definitive conclusion can be made.

\section{Supplementary analyses on anticipation effects}

Finally, we carry out supplementary analyses to explore whether younger individuals, who are not age eligible to receive SSS payouts yet, change their behaviour when they expect to receive SSS payouts in the future. Our sample for this analysis is restricted to those who are aged 56-63 in 2016, and therefore age-ineligible for the SSS over the period we study. ${ }^{33}$ Our estimation strategy in this section follows the strategy we laid out for our main results in Section 4, with the treated group being defined as those who expect to receive SSS payouts in future.

We estimate the effect of expecting to receive SSS payouts in the future by replacing the "Received SS" dummy in Eq. (1) with the "Expect SS" dummy:

$$
\begin{aligned}
Y_{i t}= & \sum_{k=-3}^{-1} \beta_{\text {pre }, k}\left(\text { Expect }_{\mathrm{SS}_{i}} \times \text { Preann }_{t, k}\right) \\
& +\beta_{\text {ann }}\left(\text { Expect }_{\mathrm{SS}_{i}} \times \text { Anntopay }_{t}\right)+\beta_{\text {disb }}\left(\text { Expect } \mathrm{SS}_{i} \times \text { Postpay }_{t}\right) \\
& +\alpha_{i}+\gamma_{t}+\epsilon_{i t}
\end{aligned}
$$

where Expect $\mathrm{SS}_{i}$ is a dummy variable that takes value 1 if the individual reported at least once in 2016 or 2017 that they expect to receive SSS payouts in the future. As in our main analyses, $\beta_{\text {ann }}$ and $\beta_{\text {disb }}$ are our main coefficients of interest, capturing the treatment effects during the announcement and disbursement periods respectively. $\beta_{\text {pre, }}$ $k$-the coefficients for our placebo leads-are used to test the validity of the differencein-differences (DiD) identifying assumption.

We acknowledge that identification may be problematic in this section, as those who report that they expect to receive the SSS may have inherently different time trends from those who do not. Having said this, our pre-treatment placebo leads are generally statistically insignificant (see Tables 6 and 7 and Table 32), giving us a more confidence 
Table 6 Overall impact of expecting to receive SSS payouts on labour decisions

\begin{tabular}{|c|c|c|c|c|c|c|}
\hline & (1) & (2) & (3) & (4) & (5) & (6) \\
\hline VARIABLES & $\begin{array}{l}\text { Whether } \\
\text { received income }\end{array}$ & $\begin{array}{l}\text { Amount } \\
\text { received }\end{array}$ & $\begin{array}{l}\text { Amount } \\
\text { received } \\
\text { (positive) }\end{array}$ & $\begin{array}{l}\text { Probability of } \\
\text { working full- time } \\
\text { after age } 62\end{array}$ & $\begin{array}{l}\text { Probability } \\
\text { of working full- time } \\
\text { after age } 65\end{array}$ & $\begin{array}{l}\text { Probability } \\
\text { of working full- time } \\
\text { after age } 70\end{array}$ \\
\hline \multirow[t]{2}{*}{$\begin{array}{l}\text { Expect SS } \times \\
\text { Jan }\end{array}$} & 0.001 & -55.220 & $\begin{array}{l}- \\
109.955\end{array}$ & -0.752 & -0.786 & 0.594 \\
\hline & $(0.010)$ & (54.173) & (68.180) & $(1.740)$ & (1.519) & $(1.407)$ \\
\hline \multirow{2}{*}{$\begin{array}{l}\text { Expect SS } \times \\
\text { Feb }\end{array}$} & -0.013 & -34.121 & 15.826 & - & - & - \\
\hline & $(0.011)$ & (52.164) & (61.606) & - & - & - \\
\hline \multirow[t]{2}{*}{$\begin{array}{l}\text { Expect SS } \times \\
\text { Mar }\end{array}$} & -0.002 & $-\overline{139.445^{* *}}$ & ${ }^{-}$ & - & - & - \\
\hline & $(0.011)$ & $(64.163)$ & (83.188) & - & - & - \\
\hline \multirow{2}{*}{$\begin{array}{l}\text { Expect SS } \times \\
\text { announce- } \\
\text { to-pay }\end{array}$} & -0.001 & -21.650 & -11.847 & -1.467 & -1.031 & -1.887 \\
\hline & $(0.010)$ & (40.859) & (42.438) & $(1.623)$ & $(1.421)$ & $(1.362)$ \\
\hline \multirow{2}{*}{$\begin{array}{l}\text { Expect SS } \times \\
\text { post-pay }\end{array}$} & -0.002 & -26.508 & -30.540 & -0.949 & -0.287 & 0.117 \\
\hline & $(0.011)$ & (45.552) & (44.553) & (1.650) & $(1.429)$ & $(1.342)$ \\
\hline Mean & 0.70 & 1951 & 2783 & 48.45 & 37.68 & 22.27 \\
\hline S.D. & 0.46 & 2514 & 2588 & 34.68 & 33.48 & 29.04 \\
\hline Observations & 51,578 & 51,432 & 35,475 & 13,581 & 16,490 & 16,502 \\
\hline R-squared & 0.76 & 0.81 & 0.82 & 0.67 & 0.67 & 0.63 \\
\hline \multicolumn{7}{|c|}{$\begin{array}{l}\text { Notes: } \\
{ }^{1} \text { Standard errors clustered at the household level in parentheses. }{ }^{* * *}, * *, \text { and }{ }^{*} \text { represent statistical significance at } \\
\text { the } 1,5 \text {, and } 10 \% \text { level of significance respectively } \\
{ }^{2} \text { Dependent variables are shown at the top of each column. Values in columns (1)-(3) are reported at the } \\
\text { individual and monthly level, with column (3) including only responses with positive values. Values in columns } \\
\text { (4)-(6) are collected at the individual level every quarter } \\
{ }^{3} \text { Results are estimates of coefficients in Eq. (1). The sample is restricted to respondents who are not age-eligible } \\
\text { for SSS (i.e. aged } 56 \text { to } 63 \text { in 2016), Singapore citizens, live in public housing flats, and with a propensity score } \\
\text { of } 0.2-0.8\end{array}$} \\
\hline
\end{tabular}

in the results reported in this section. In the end, however, we recommend that our results in this section be interpreted with caution.

We do not find any evidence that expecting to receive the SSS led to changes in labour-related decisions (see Table 6), private cash transfers (see Table 7) or expenditure (see Table 32 in Appendix 4)-our estimated announcement and disbursement effects are all statistically insignificant and close to zero (especially for labour-related decisions and private cash transfers). This result is not too surprising, as individuals who expect to receive SSS payouts in future are likely to be liquidity/credit constrained and are unlikely to be able to adjust their behaviour before they start receiving SSS payouts when they become age-eligible (see, e.g. Galiani et al. 2016; Jappelli and Pistaferri 2010).

\section{Conclusions}

This paper adds to the literature on the effects of non-contributory pensions on labour decisions and private cash transfers, by using a difference-in-differences strategy and a new high-frequency panel dataset to evaluate the effect of a new non-contributory pension from Singapore (the Silver Support Scheme, or SSS). We find no evidence that SSS recipients reduced their labour supply, experienced persistent changes in the subjective probability that they will be working full-time past age 70 , received fewer cash 
Table 7 Overall impact of expecting to receive SSS payouts on private cash transfers

\begin{tabular}{|c|c|c|c|c|c|c|}
\hline & (1) & (2) & (3) & (4) & (5) & (6) \\
\hline VARIABLES & $\begin{array}{l}\text { Whether } \\
\text { received }\end{array}$ & $\begin{array}{l}\text { Amount } \\
\text { received }\end{array}$ & $\begin{array}{l}\text { Amount received } \\
\text { (positive) }\end{array}$ & $\begin{array}{l}\text { Whether } \\
\text { gave }\end{array}$ & $\begin{array}{l}\text { Amount } \\
\text { given }\end{array}$ & $\begin{array}{l}\text { Amount given } \\
\text { (positive) }\end{array}$ \\
\hline \multirow[t]{2}{*}{ Expect SS $\times$ Jan } & $-0.024^{*}$ & -13.486 & 13.934 & 0.012 & -4.007 & -35.206 \\
\hline & $(0.014)$ & $(15.110)$ & $(30.477)$ & $(0.016)$ & (12.908) & (39.509) \\
\hline \multirow[t]{2}{*}{ Expect SS $\times$ Feb } & -0.011 & -11.979 & -25.963 & -0.021 & -26.840 & -14.883 \\
\hline & $(0.014)$ & $(16.002)$ & $(39.657)$ & $(0.018)$ & (20.483) & $(54.700)$ \\
\hline \multirow[t]{2}{*}{ Expect SS $\times$ Mar } & 0.002 & 21.790 & 36.309 & 0.016 & -13.168 & -34.825 \\
\hline & $(0.013)$ & $(13.486)$ & $(28.706)$ & $(0.016)$ & $(14.962)$ & $(42.608)$ \\
\hline \multirow[t]{2}{*}{ Expect SS $\times$ announce-to-pay } & -0.005 & 4.486 & 4.767 & 0.007 & -3.572 & -4.403 \\
\hline & $(0.011)$ & $(11.380)$ & $(23.437)$ & $(0.012)$ & $(10.240)$ & (35.883) \\
\hline \multirow[t]{2}{*}{ Expect SS $\times$ post-pay } & -0.007 & 2.602 & 18.775 & -0.004 & -11.093 & -17.312 \\
\hline & $(0.012)$ & $(12.084)$ & (25.973) & $(0.013)$ & $(9.670)$ & $(31.965)$ \\
\hline Mean & 0.33 & 231.35 & 707.28 & 0.29 & 122.02 & 427.49 \\
\hline S.D. & 0.47 & 461.00 & 559.60 & 0.45 & 354.73 & 557.09 \\
\hline Observations & 49,565 & 49,471 & 15,293 & 49,313 & 49,274 & 13,278 \\
\hline R-squared & 0.74 & 0.74 & 0.78 & 0.61 & 0.42 & 0.50 \\
\hline \multicolumn{7}{|c|}{$\begin{array}{l}\text { Notes: } \\
\text { 'Standard errors clustered at the household level in parentheses. }{ }^{* * *},{ }^{* *}, \text { and }{ }^{*} \text { represent statistical significance at the } 1, \\
5 \text {, and } 10 \% \text { level of significance respectively } \\
{ }^{2} \text { Dependent variables are shown at the top of each column. All transfer values are reported at the couple (respondent } \\
\text { and spouse if respondent is married) and monthly level. Columns (3) and (6) include only responses with positive values } \\
\text { 32} \text { Results are estimates of coefficients in Eq. (1). The sample is restricted to respondents who are not age-eligible for SSS } \\
\text { (i.e. aged } 56 \text { to } 63 \text { in } 2016), \text { Singapore citizens, live in public housing flats, and with a propensity score of } 0.2-0.8 \\
{ }^{4} \text { Mean and standard deviation statistics are based on pre-announcement levels of the dependent variable for respondents } \\
\text { who expected to receive SSS payouts }\end{array}$} \\
\hline
\end{tabular}

transfers from, or gave more cash transfers to family and friends. Our results are robust to the battery of robustness checks described in Section 5 that include the use of different control groups, different reweighting methods, and the addition of group-specific time fixed effects. However, we do find weak evidence that the adjustment in recipients' labour supply may not be complete yet. Lastly, we do not find any evidence of anticipatory effects-individuals who are not yet age-eligible for the SSS but expect to receive the SSS in future do not exhibit changes in labour supply, work expectations, private transfers, or expenditure.

We emphasise that these are results for the first year of the SSS's implementation and individuals' behaviour may not have fully adjusted yet. It would therefore be useful to revisit this question in the future, to study the SSS's effects in the medium and long run. In addition, it would be useful to evaluate the effect of the SSS using larger datasets (e.g. administrative datasets), to improve the precision of the estimated effects. Nonetheless, we highlight that the magnitude of the SSS's effects we observe in its first year of implementation are substantially lower than the magnitude of the effects of other non-contributory pensions assessed 1 year after implementation (e.g. AmuedoDorantes and Juarez 2015; Bando et al. 2016), suggesting that the institutional and socio-economic context in Singapore, as well as the design of the SSS, may mitigate any falls in labour supply or private cash transfers.

In all, our results, when coupled with the finding in a companion paper that the SSS improved recipients' subjective well-being (Chen and Tan 2017), ${ }^{34}$ suggest that the SSS was successful in improving recipients' welfare without substantial reductions in labour 
supply, crowding out of private transfers, or changes in the behaviour of younger individuals who expect to receive SSS payouts in future. In addition, our results from this paper suggest that the effects of non-contributory pensions are likely to vary by institutional and socio-economic context as well as payout levels. It will thus remain important to evaluate introductions of or reforms to non-contributory pensions, to obtain more generalizable evidence on the effects of non-contributory pensions.

\section{Endnotes}

${ }^{1}$ For more on context dependence and the importance of accumulating evidence to move towards external validity, see, e.g. Angrist and Pischke (2010) and Banerjee et al. (2017).

${ }^{2}$ We also carry out a supplementary analysis on the effects of expecting to receive the SSS on younger individuals who are not age-eligible for payouts yet (i.e. individuals aged 56-63 in 2016). For clarity of our exposition, this supplementary analysis is discussed in more detail only in Section 7. All other sections describe our main analysis on the effect of receiving SSS payouts, using a sample of individuals who can already start to receive payouts, i.e. aged 65 and above in 2016.

${ }^{3}$ This delayed adjustment is unlikely to be driven by workers' inability to resign due to binding contracts, as the typical resignation notice period in Singapore is 1 month for full-time jobs (Ministry of Manpower, 2017) - a period far shorter than the 1 year post-implementation period we study.

${ }^{4}$ As an aside, while we also examine SSS's effect on recipients' expenditure, we are unable to make definitive conclusions. Our estimated treatment effects are quite large and positive but imprecise, and the DiD identifying assumption may be violated for expenditure on durables.

${ }^{5}$ These improvements in subjective well-being may be due to reasons unrelated to current consumption (e.g. improved retirement security arising from an unexpected increase in permanent income). In addition, we are unable to rule out the possibility of these changes being due to increases in current consumption. While our expenditure-related results are statistically insignificant, the point estimates are positive and quite large.

${ }^{6}$ Some have found bigger effects (e.g. Danzer, 2013; Juárez and Pfutze, 2015).

${ }^{7}$ The average SSS payout in our sample is about $14 \%$ of the pre-announcement mean monthly wage among SSS recipients who worked, lower than payouts from many other non-contributory pensions studied in the literature. For example, payouts were equivalent to more than twice the median per capita income in South Africa (Case and Deaton, 1998; Jensen, 2004), 96 and 76\% of mean labour income for eligible individuals in Mexico (Galiani et al., 2016; Juárez and Pfutze, 2015) and Peru (Bando et al. 2016) respectively, and about $25 \%$ of the 1939 median wage for 60-64-year-olds for the US Old Age Assistance program (Fetter and Lockwood, 2016).

${ }^{8}$ For example, SSS recipients in our sample receive payouts equivalent to about $14 \%$ of their mean pre-announcement wage. This is lower than, e.g. the $76 \%$ of mean peradult-equivalent labour income that recipients in Bando et al. (2016)'s study receive.

${ }^{9}$ Most of the details in this section can also be found in our companion paper which looks at the effect of the SSS on subjective well-being (Chen and Tan, 2017).

${ }^{10}$ The monthly retirement payouts from Singapore's defined contribution scheme does not depend on current work status, but starts at a pre-determined payout eligibility age 
(65 as of 2018, but can be deferred by choice). The receipt of retirement payouts from the scheme does not require one to stop work or earn less income.

${ }^{11}$ The Government first announced the introduction of the Silver Support Scheme (SSS) in early 2015, but details on qualifying criteria were not announced then. This implies that even if Singaporeans had some expectations about whether they would receive payouts from SSS, these expectations were probably weak.

${ }^{12} 80 \%$ of Singaporeans (as of 2016-see Department of Statistics (2017)) live in public housing apartments (flats) which come in different sizes, and $90 \%$ of these households own their flat (Housing and Development Board 2017). Flat sizes or flat-types are often used as a proxy for socio-economic status by the government to target subsidies and transfers. The SSS payout quantum schedule for individuals living in each type of flat is: 1- and 2-room flats: $S \$ 750$; 3-room flats: $\$ \$ 600$; 4-room flats: $\$ \$ 450$; 5-room flats: $S \$ 300$.

${ }^{13}$ This implies that SSS recipients can continue working, and their monthly income can even exceed $S \$ 1100$. As long their per-capita household income does not exceed S $\$ 1100$, SSS payouts will continue to be made to these recipients.

${ }^{14}$ Briefly, we restrict the treatment group to only those who received SSS in 2016. This may attenuate our treatment effects; we address this by performing a robustness check where we restrict the control group to those who definitely did not receive SSS payouts in either 2016 or 2017 (see Section 5).

${ }^{15} 80 \%$ of Singaporeans (as of 2016-see Department of Statistics (2017)) live in public housing apartments (flats).

${ }^{16} \mathrm{We}$ include only outcome values from wave two onwards as wave zero was the baseline survey, and wave one was a pilot survey that included only a subset of respondents. We also exclude transfers-related data that were collected in wave three as the data collected was affected by a technical glitch.

${ }^{17}$ We include only outcome values from wave two onwards as wave zero was the baseline survey, and wave one was a pilot survey that included only a subset of respondents. We also exclude transfers-related data that were collected in wave three as the data collected was affected by a glitch.

${ }^{18}$ The last quarter ends in May instead of June 2017 because the Jun 2017 wave of the SLP captures outcome values that correspond to behaviours in May 2017 (e.g. respondents were asked whether they received income from work in the previous month).

${ }^{19}$ The presence of this subset within the control group in the main specification may lead to attenuation bias, since individuals in this subset may suffer from self-selection problems. Allowing a separate coefficient for this subset can help to address the attenuation bias.

${ }^{20}$ We can define the respondent's spouse's treatment status because respondents also answered questions on their spouse's SSS receipt.

${ }^{21}$ We do not use this as our main specification as not all respondents answer questions on whether their spouse receives SSS payouts, and also due to potentially greater mismeasurement in respondents' reports of whether their spouse received SSS payouts.

${ }^{22}$ We excluded individuals aged 64 in 2016 as some of them would be receiving SSS payouts for the year 2017.

${ }^{23}$ Using age-ineligible controls may lead to attenuation of our results if individuals who are age-ineligible but expect to receive SSS payouts in future start adjusting their behaviour even before they are age-eligible. This is unlikely to be an issue in our case-our results in Section 7 suggest that such anticipatory behaviour does not exist in our sample. 
${ }^{24}$ These welfare payments include payments from Workfare Income Supplement (WIS) and GST Vouchers. WIS encourages lower income workers to work by supplementing their income and retirement savings through cash payments and contributions to the defined contribution scheme, CPF. GST vouchers can come in the form of cash. These controls are not included in our main specification as these questions are posed at lower frequency and therefore, not all respondents reply to these questions. This leads to a considerable decrease in our sample size.We argue that other government policies are unlikely to drive our results. Two major policies that affect elderly Singaporeans in the age group we study, are the Pioneer Generation Package (PGP) and eligibility for CPF payouts. All individuals aged 65 or above in 2014 are eligible for the Pioneer Generation Package (PGP) which provides healthcare subsidies that vary only by age cohort, not socioeconomic status. As the age distribution of our trimmed sample is similar across the treatment and control groups, this policy is unlikely to affect our analyses. We also note that PGP was already in place before the start of the SSS. The CPF payout eligibility age is also unlikely to affect our analyses, as the eligibility age also varies only by age cohort and not socioeconomic status. Furthermore, there is no change in CPF eligibility status within the period of our study for both our main and supplementary samples. All individuals in our main sample are already age-eligible for CPF payouts at the start of our study period; all individuals in our supplementary analyses will not be old enough to reach CPF payout eligibility age by the end of the period studied.

${ }^{25}$ This method addresses the imbalance of baseline characteristics between the treated and control groups by reweighting control observations based on their propensity score; control observations with a higher propensity score are given a higher weight. We use the Stata package absdid described in Houngbedji (2015) to implement this estimator.

${ }^{26}$ Column (2) includes individuals who did not work; the income for these individuals are taken to be zero. The results for column (2) thus capture effects from both the extensive and intensive margin. Column (3) includes only individuals who worked, and thus captures mainly effects from the intensive margin.

${ }^{27}$ Having said this, we acknowledge that our estimates are not sufficiently precise to exclude falls of approximately 4 percentage points in labour supply, which is within the range of 4-6 percentage points estimated in the literature. However, the lack of a response on the intensive margin, the fact that SSS payouts can only cover a fraction of recipients' monthly household expenditure, and the fact that SSS payouts are lower in Singapore than in many other countries with non-contributory pensions (see footnote 7 for a brief comparison) lead us to conclude that similarly sized falls in labour supply are unlikely to have occurred in our context.

${ }^{28}$ The average SSS payout in our sample is about $14 \%$ of the pre-announcement mean monthly wage among SSS recipients who worked, lower than payouts from many other non-contributory pensions studied in the literature. (See footnote 7 for more details on payout levels in other studies.)

${ }^{29}$ Column (2) includes individuals who did not receive transfers, and thus captures both intensive and extensive margin effects. Column (3) includes only individuals who received transfers, and thus captures intensive margin effects.

${ }^{30}$ To recap, we use a control group from the age-ineligible cohort (Table 16) and different reweighting methods (Abadie (2005)'s semi-parametric $\mathrm{DiD}$ and 1:1 matching 
DiD in columns (7) and (8) of Tables 17, 18, 19, and 20) to address potential issues with the parallel trends assumption in our main specification.

${ }^{31}$ The average SSS payout in our sample is about $14 \%$ of the pre-announcement mean monthly wage among SSS recipients who worked, lower than payouts from many other non-contributory pensions studied in the literature. (See footnote 7 for more details on payout levels in other studies.)

${ }^{32} \mathrm{~A}$ detailed analysis of the reasons underlying the lack of crowding out is beyond the scope of our paper. Having said this, understanding why there is no crowding out here is interesting, and we engage in some preliminary speculation about the underlying reasons.A possible reason for the lack of crowding out could be the design of the SSS. Recall that individuals who stay in one-/two-room flats receive the highest payout quantum. These individuals, who are likely to be the least financially able, are also likely to have family and friends who are less able to provide cash support. Since they do not receive much cash transfers to start with, it is not surprising if SSS has no effect on cash transfers. On the other hand, individuals who stay in larger flats (they receive the lowest SSS payout quantum) may have more well-to-do relatives and friends who may not reduce their cash transfers due to the relatively small SSS payouts.In our view, this line of reasoning is more plausible for the lack of crowding out among SSS recipients who stay in larger flats. While the lack of crowding out among poorer SSS recipients may be due in part to the fact that fewer of them receive private cash transfers in the first place, this explanation is unlikely to be the only reason, since substantial proportions of those living in smaller flat-types (who receive the highest payouts) receive private cash transfers as well. For example, during the period before the announcement of SSS details, 26, 36, and 59\% of SSS recipients in one-, two-, three-room flats receive private cash transfers respectively monthly. Conditional on receipt, they receive monthly averages of $\$ \$ 693, S \$ 434$, and $S \$ 817$. These statistics suggest that our finding of no effect on the receipt of private cash transfer can also be driven by a lack of response from "donors" to SSS recipients.

${ }^{33}$ Summary statistics for this sample of younger individuals can be found in Tables 30 and 31 of Appendix 4.

${ }^{34}$ These improvements in subjective well-being may be due to reasons unrelated to current consumption (e.g. improved retirement security arising from an unexpected increase in permanent income). In addition, we are unable to rule out the possibility of these changes being due to increases in current consumption. While our expenditure-related results are statistically insignificant, the point estimates are positive and quite large.

${ }^{35}$ Respondent and spouse if the respondent is married.

${ }^{36}$ To a lesser extent, this may be a potential issue for total and non-durable expenditure as well. This issue biases our results upwards and means that SSS receipt is even less likely to have had much of an effect on these total and non-durable expenditure.

${ }^{37}$ To recap, we use age-ineligible controls (Table 25) and different reweighting methods (Abadie (2005)'s semi-parametric DiD and 1:1 matching DiD in columns (7) and (8) of Tables 26, 27, 28, and 29) to address potential issues with the parallel trends assumption in our main estimates.

${ }^{38}$ To a lesser extent, total and non-durables expenditure face this issue as well. 


\section{Appendix 1}

\subsection{Robustness checks for labour}

Table 8 Robustness check for labour decisions-accounting for misreporting of SSS payout receipt

\begin{tabular}{lllll}
\hline \multirow{2}{*}{ VARIABLES } & $(1)$ & $(2)$ & $(3)$ & $(4)$ \\
& $\begin{array}{l}\text { Whether } \\
\text { received income }\end{array}$ & $\begin{array}{l}\text { Amount } \\
\text { received }\end{array}$ & $\begin{array}{l}\text { Amount } \\
\text { received (positive) }\end{array}$ & $\begin{array}{l}\text { Probability of working } \\
\text { full- time after age 70 }\end{array}$ \\
\hline Received SS $\times$ Jan & 0.00542 & 22.73 & -183.1 & -2.383 \\
& $(0.0207)$ & $(68.19)$ & $(156.2)$ & $(3.313)$ \\
Received SS $\times$ Feb & 0.00959 & 28.99 & 3.922 & - \\
& $(0.0201)$ & $(34.37)$ & $(91.62)$ & - \\
Received SS $\times$ Mar & 0.0180 & 52.71 & -125.8 & - \\
& $(0.0197)$ & $(47.40)$ & $(220.2)$ & - \\
Received SS $\times$ announce-to-pay $\times$ re- & 0.0268 & 123.6 & 32.67 & -2.297 \\
ceived in 2016 and 2017 & $(0.0209)$ & $(121.4)$ & $(101.1)$ & $(3.579)$ \\
Received SS $\times$ post-pay $\times$ received in & -0.00415 & 82.01 & 21.38 & -4.259 \\
2016 and 2017 & $(0.0204)$ & $(99.73)$ & $(95.84)$ & $(3.264)$ \\
Observations & 16,062 & 15,997 & 4596 & 3536 \\
R-squared & 0.808 & 0.701 & 0.751 & 0.638 \\
\hline
\end{tabular}

Notes:

${ }^{1}$ Standard errors clustered at the household level in parentheses. ${ }^{* *},{ }^{* *}$, and ${ }^{*}$ represent statistical significance at the 1 , 5 , and $10 \%$ level of significance respectively

${ }^{2}$ Dependent variables are shown at the top of each column. Values in columns (1)-(3) are reported at the individual and monthly level, with column (3) including only responses with positive values. Values in column (4) are collected at the individual level every quarter

${ }^{3}$ Results are estimates of coefficients in Eq. (3). In the interest of space, we show only the coefficients from interacting the policy variables with the dummy which represents the subset of individuals who reported receiving SSS payout at least once in 2016 and at least once in 2017. The suppressed category of individuals are those who reported not receiving SSS payout in 2016 and 2017. The sample is restricted to respondents who are age-eligible for SSS (i.e. aged 65 and above in 2016), Singapore citizens, live in public housing flats, and with a propensity score of $0.2-0.8$ 
Table 9 Robustness check for labour decisions_-accounting for spousal receipt of SSS payout

\begin{tabular}{lllll}
\hline \multirow{2}{*}{ VARIABLES } & $(1)$ & $(2)$ & $(3)$ & $(4)$ \\
& $\begin{array}{l}\text { Whether received } \\
\text { income }\end{array}$ & $\begin{array}{l}\text { Amount } \\
\text { received }\end{array}$ & $\begin{array}{l}\text { Amount received } \\
\text { (positive) }\end{array}$ & $\begin{array}{l}\text { Probability of working } \\
\text { full- time after age 70 }\end{array}$ \\
\hline Only respondent rcv SS $\times$ announce-to- & 0.0182 & 160.4 & 91.45 & -2.008 \\
pay & $(0.0223)$ & $(126.6)$ & $(120.3)$ & $(3.842)$ \\
Only spouse rcv SS $\times$ announce-to-pay & 0.0341 & $98.83^{* *}$ & 56.89 & 0.358 \\
& $(0.0298)$ & $(44.73)$ & $(88.78)$ & $(9.202)$ \\
Both rcv SS $\times$ announce-to-pay & 0.0186 & 53.09 & 69.12 & -3.614 \\
& $(0.0200)$ & $(43.77)$ & $(121.5)$ & $(3.919)$ \\
Only respondent rcv SS $\times$ post-pay & -0.0127 & 144.8 & 165.4 & -4.396 \\
& $(0.0227)$ & $(106.2)$ & $(132.6)$ & $(3.375)$ \\
Only spouse rcv SS $\times$ post-pay & 0.0467 & $129.8^{* *}$ & 106.3 & 0.318 \\
Both rcv SS $\times$ post-pay & $(0.0451)$ & $(58.53)$ & $(102.5)$ & $(7.000)$ \\
Observations & 0.00888 & 20.69 & -54.55 & -5.013 \\
R-squared & $(0.0184)$ & $(39.37)$ & $(87.64)$ & $(3.785)$ \\
\hline
\end{tabular}

Notes:

${ }^{1}$ Standard errors clustered at the household level in parentheses. ${ }^{* *},{ }^{* *}$, and ${ }^{*}$ represent statistical significance at the 1 , 5 , and $10 \%$ level of significance respectively

${ }^{2}$ Dependent variables are shown at the top of each column. Values in columns (1)-(3) are reported at the individual and monthly level, with column (3) including only responses with positive values. Values in column (4) are collected at the individual level every quarter

${ }^{3}$ Results are estimates of coefficients in Eq. (4). In the interest of space, we do not show the coefficients from the placebo leads. The sample is restricted to respondents who are age-eligible for SSS (i.e. aged 65 and above in 2016), Singapore citizens, live in public housing flats, and with a propensity score of $0.2-0.8$ 
Table 10 Robustness check for labour decisions-using non-age-eligible sample as a control group (propensity score 0.2-0.8)

\begin{tabular}{lllll}
\hline \multirow{2}{*}{ VARIABLES } & $(1)$ & $(2)$ & $(3)$ & $(4)$ \\
& $\begin{array}{l}\text { Whether received } \\
\text { income }\end{array}$ & $\begin{array}{l}\text { Amount } \\
\text { received }\end{array}$ & $\begin{array}{l}\text { Amount received } \\
\text { (positive) }\end{array}$ & $\begin{array}{l}\text { Probability of working full- time } \\
\text { after age 70 }\end{array}$ \\
\hline Received SS $\times$ Jan & -0.00291 & 88.68 & -3.822 & -3.999 \\
& $(0.0213)$ & $(70.25)$ & $(135.6)$ & $(3.207)$ \\
Received SS $\times$ Feb & 0.0131 & $103.3^{* *}$ & 132.3 & - \\
& $(0.0202)$ & $(42.31)$ & $(89.68)$ & - \\
Received SS $\times$ Mar & -0.000928 & 23.89 & -84.87 & - \\
& $(0.0196)$ & $(60.51)$ & $(216.4)$ & - \\
Received SS $\times$ announce-to- & -0.00325 & 106.4 & 116.0 & -1.452 \\
pay & $(0.0177)$ & $(83.44)$ & $(93.47)$ & $(3.167)$ \\
Received SS $\times$ post-pay & -0.0257 & 50.34 & 45.48 & -3.421 \\
& $(0.0166)$ & $(71.65)$ & $(91.28)$ & $(2.827)$ \\
Observations & 17,500 & 17,458 & 8234 & 4962 \\
R-squared & 0.806 & 0.740 & 0.731 & 0.623 \\
\hline
\end{tabular}

Notes:

${ }^{1}$ Standard errors clustered at the household level in parentheses. ${ }^{* *},{ }^{* *}$, and * represent statistical significance at the 1, 5 , and $10 \%$ level of significance respectively

${ }^{2}$ Dependent variables are shown at the top of each column. Values in columns (1)-(3) are reported at the individual and monthly level, with column (3) including only responses with positive values. Values in column (4) are collected at the individual level every quarter

${ }^{3}$ Results are estimates of coefficients in Eq. (1). The sample is restricted to respondents who are Singapore citizens, live in public housing flats, and with a propensity score of $0.2-0.8$. The treated group consists of individuals aged 65 and above in 2016 who received SSS payouts, while the control group consists of younger individuals aged 56 to 63 in 2016 who are not age eligible to receive SSS payouts yet 
Table 11 Robustness check for impact of receiving SSS payouts on receiving income from work

\begin{tabular}{|c|c|c|c|c|c|c|c|c|}
\hline & (1) & (2) & (3) & (4) & (5) & (6) & (7) & (8) \\
\hline VARIABLES & No leads & Balanced & $\begin{array}{l}\text { Ethnic } \\
\text { trends }\end{array}$ & $\begin{array}{l}\text { Flat-type } \\
\text { trends }\end{array}$ & Age FE & WIS/ GST & Abadie & 1-1 matching \\
\hline \multirow[t]{2}{*}{ Received SS $\times$ Jan } & - & 0.00601 & 0.00556 & 0.00581 & 0.00770 & 0.0143 & 0.0128 & - \\
\hline & - & $(0.0206)$ & $(0.0205)$ & $(0.0205)$ & $(0.0206)$ & $(0.0251)$ & $(0.0162)$ & - \\
\hline \multirow[t]{2}{*}{ Received SS × Feb } & - & 0.00805 & 0.0106 & 0.00745 & 0.0116 & 0.0264 & 0.0147 & - \\
\hline & - & $(0.0200)$ & $(0.0199)$ & $(0.0201)$ & $(0.0201)$ & $(0.0218)$ & $(0.0157)$ & - \\
\hline \multirow[t]{2}{*}{ Received SS $\times$ Mar } & - & 0.0184 & 0.0216 & 0.0177 & 0.0226 & 0.0183 & $0.0331^{* *}$ & - \\
\hline & - & $(0.0196)$ & $(0.0194)$ & $(0.0197)$ & $(0.0197)$ & $(0.0226)$ & $(0.0151)$ & - \\
\hline \multirow{2}{*}{$\begin{array}{l}\text { Received SS } \times \\
\text { Jan-Mar }\end{array}$} & - & - & - & - & - & - & - & 0.0117 \\
\hline & - & - & - & - & - & - & - & $P=0.45$ \\
\hline \multirow{2}{*}{$\begin{array}{l}\text { Received SS } \times \\
\text { announce-to-pay }\end{array}$} & 0.00710 & 0.0109 & 0.0125 & 0.00685 & 0.0142 & 0.0336 & 0.0178 & 0.0145 \\
\hline & $(0.0143)$ & $(0.0179)$ & $(0.0177)$ & $(0.0177)$ & $(0.0179)$ & $(0.0206)$ & $(0.0149)$ & $P=0.43$ \\
\hline \multirow{2}{*}{$\begin{array}{l}\text { Received SS } \times \text { post- } \\
\text { pay }\end{array}$} & -0.0151 & -0.00952 & -0.0100 & -0.0129 & -0.00758 & -0.00109 & -0.00122 & -0.0018 \\
\hline & $(0.0148)$ & $(0.0172)$ & $(0.0170)$ & $(0.0173)$ & $(0.0169)$ & $(0.0203)$ & $(0.0145)$ & $P=0.92$ \\
\hline Observations & 16,062 & 15,769 & 16,062 & 16,062 & 16,062 & 11,213 & 1468 & 369 \\
\hline R-squared & 0.808 & 0.808 & 0.808 & 0.810 & 0.809 & 0.813 & - & - \\
\hline
\end{tabular}

Notes:

${ }^{1}$ Standard errors clustered at the household level in parentheses. ${ }^{* *},{ }^{* *}$, and ${ }^{*}$ represent statistical significance at the 1 , 5 , and $10 \%$ level of significance respectively

${ }^{2}$ All values are reported at the individual and monthly level

${ }^{3}$ Columns (1)-(8) show results from additional robustness checks carried out. These checks are: (1) removal of the lead terms; (2) restricting the sample to a "balanced" panel, where each individual has at least one observation in the preannouncement, announcement-to-disbursement, and post-disbursement periods; (3) allowing for ethnicity-specific time fixed effects; (4) allowing for flat-type-specific time fixed effects; (5) adding age fixed effects as a control; (6) adding receipt of additional welfare payments (Workfare Income Supplement; GST Vouchers) as a control—sample is smaller because this data is not collected every wave and not everyone responds every wave; (7) reweighting each observation by their propensity of receiving SSS as in Abadie (2005); and (8) DiD matching with a 1-1 nearest neighbour match. Eq. (1) describes the baseline model used in these checks

${ }^{4}$ For columns (1)-(6), the sample is restricted to respondents who are age-eligible for SSS (i.e. aged 65 and above in 2016), Singapore citizens, live in public housing flats, and with a propensity score of $0.2-0.8$. The number of observations in these columns refers to the number of individual-month observations. For columns (7) and (8), the number of observations refers to number of respondents, and the sample is not restricted by the propensity score. The sample, however, is smaller than the full sample due to data availability issues specific to the estimation of (7) and (8) 
Table 12 Robustness check for impact of receiving SSS payouts on amount of income received from work

\begin{tabular}{|c|c|c|c|c|c|c|c|c|}
\hline & (1) & (2) & (3) & (4) & (5) & (6) & (7) & (8) \\
\hline VARIABLES & No leads & Balanced & $\begin{array}{l}\text { Ethnic } \\
\text { trends }\end{array}$ & $\begin{array}{l}\text { Flat-type } \\
\text { trends }\end{array}$ & Age FE & WIS/ GST & Abadie & 1-1 matching \\
\hline \multirow[t]{2}{*}{ Received SS $\times$ Jan } & - & 25.11 & 25.67 & 31.62 & 27.42 & 38.28 & 66.82 & - \\
\hline & - & $(69.84)$ & $(70.04)$ & $(71.56)$ & $(69.72)$ & (93.44) & $(52.85)$ & - \\
\hline \multirow[t]{2}{*}{ Received SS × Feb } & - & 24.20 & 29.53 & 28.24 & 32.68 & 42.70 & $59.67^{* *}$ & - \\
\hline & - & $(34.10)$ & $(34.60)$ & $(34.30)$ & $(34.52)$ & (38.15) & $(25.02)$ & - \\
\hline \multirow[t]{2}{*}{ Received SS $\times$ Mar } & - & 52.37 & 57.93 & 54.91 & 60.46 & 58.73 & $61.11^{*}$ & - \\
\hline & - & $(48.36)$ & $(48.56)$ & $(49.37)$ & $(48.96)$ & $(62.60)$ & $(34.55)$ & - \\
\hline \multirow[t]{2}{*}{ Received SS $\times$ Jan-Mar } & - & - & - & - & - & - & - & 40.73 \\
\hline & - & - & - & - & - & - & - & $P=0.23$ \\
\hline \multirow{2}{*}{$\begin{array}{l}\text { Received SS } \times \text { announce- } \\
\text { to-pay }\end{array}$} & 82.24 & 97.51 & 97.31 & 97.72 & 102.0 & 148.6 & $93.11^{*}$ & $94.84^{*}$ \\
\hline & (66.19) & $(79.63)$ & $(79.70)$ & $(82.68)$ & $(80.54)$ & $(111.1)$ & $(50.79)$ & $P=0.06$ \\
\hline \multirow[t]{2}{*}{ Received SS $\times$ post-pay } & 52.42 & 69.03 & 67.14 & 70.97 & 75.13 & 101.6 & $83.42^{*}$ & 55.12 \\
\hline & $(55.47)$ & $(68.67)$ & (69.09) & (71.39) & $(70.13)$ & (93.64) & $(45.21)$ & $P=0.30$ \\
\hline Observations & 15,997 & 15,706 & 15,997 & 15,997 & 15,997 & 11,173 & 1468 & 369 \\
\hline R-squared & 0.701 & 0.701 & 0.701 & 0.703 & 0.702 & 0.691 & - & - \\
\hline
\end{tabular}

Notes:

${ }^{1}$ Standard errors clustered at the household level in parentheses. ${ }^{* *}, *^{*}$, and ${ }^{*}$ represent statistical significance at the 1 , 5 , and $10 \%$ level of significance respectively

${ }^{2}$ All values are reported at the individual and monthly level

${ }^{3}$ Columns (1)-(8) show results from additional robustness checks carried out. These checks are: (1) removal of the lead terms; (2) restricting the sample to a "balanced" panel, where each individual has at least one observation in the preannouncement, announcement-to-disbursement, and post-disbursement periods; (3) allowing for ethnicity-specific time fixed effects; (4) allowing for flat-type-specific time fixed effects; (5) adding age fixed effects as a control; (6) adding receipt of additional welfare payments (Workfare Income Supplement; GST Vouchers) as a control-sample is smaller because this data is not collected every wave and not everyone responds every wave; (7) reweighting each observation by their propensity of receiving SSS as in Abadie (2005); and (8) DiD matching with a 1-1 nearest neighbour match. Eq. (1) describes the baseline model used in these checks

${ }^{4}$ For columns (1)-(6), the sample is restricted to respondents who are age-eligible for SSS (i.e. aged 65 and above in 2016), Singapore citizens, live in public housing flats, and with a propensity score of $0.2-0.8$. The number of observations in these columns refers to the number of individual-month observations. For columns (7) and (8), the number of observations refers to number of respondents, and the sample is not restricted by the propensity score. The sample, however, is smaller than the full sample due to data availability issues specific to the estimation of (7) and (8) 
Table 13 Robustness check for impact of receiving SSS payouts on probability of working full-time after age 70

\begin{tabular}{|c|c|c|c|c|c|c|c|c|}
\hline & (1) & (2) & (3) & (4) & (5) & (6) & (7) & (8) \\
\hline VARIABLES & No leads & Balanced & $\begin{array}{l}\text { Ethnic } \\
\text { trends }\end{array}$ & $\begin{array}{l}\text { Flat-type } \\
\text { trends }\end{array}$ & Age FE & WIS/ GST & Abadie & 1-1 matching \\
\hline \multirow[t]{2}{*}{ Received SS $\times$ Jan } & - & -3.459 & -2.346 & -2.617 & -2.218 & -1.444 & -2.019 & - \\
\hline & - & (3.513) & (0) & $(3.267)$ & (3.320) & (3.955) & $(2.536)$ & - \\
\hline \multirow[t]{2}{*}{ Received SS $\times$ Feb } & - & - & - & - & - & - & - & - \\
\hline & - & - & - & - & - & - & - & - \\
\hline \multirow[t]{2}{*}{ Received SS $\times$ Mar } & - & - & - & - & - & - & - & - \\
\hline & - & - & - & - & - & - & - & - \\
\hline \multirow[t]{2}{*}{ Received SS $\times$ Jan-Mar } & - & - & - & - & - & - & - & -2.182 \\
\hline & - & - & - & - & - & - & - & $p=0.469$ \\
\hline \multirow{2}{*}{$\begin{array}{l}\text { Received SS } \times \text { announce- } \\
\text { to-pay }\end{array}$} & -0.766 & -2.697 & -2.215 & -2.352 & -2.070 & -0.0366 & -0.549 & 1.425 \\
\hline & $(2.294)$ & (3.378) & $(0)$ & $(3.160)$ & (3.213) & $(3.840)$ & $(2.518)$ & $p=0.612$ \\
\hline \multirow[t]{2}{*}{ Received SS $\times$ post-pay } & -2.981 & $-5.189 *$ & -4.368 & -4.498 & -4.365 & -4.763 & -3.308 & -1.559 \\
\hline & $(2.179)$ & (3.137) & (0) & $(2.952)$ & $(2.978)$ & $(3.417)$ & $(2.389)$ & $p=0.612$ \\
\hline Observations & 3536 & 3089 & 3536 & 3536 & 3536 & 2401 & 771 & 159 \\
\hline R-squared & 0.637 & 0.618 & 0.640 & 0.640 & 0.638 & 0.639 & - & - \\
\hline
\end{tabular}

Notes:

${ }^{1}$ Standard errors clustered at the household level in parentheses. ${ }^{* *},{ }^{* *}$, and * represent statistical significance at the 1 , 5 , and $10 \%$ level of significance respectively

${ }^{2}$ All values are reported at the individual level, based on data collected every quarter

${ }^{3}$ Columns (1)-(8) show results from additional robustness checks carried out. These checks are: (1) removal of the lead terms; (2) restricting the sample to a "balanced" panel, where each individual has at least one observation in the preannouncement, announcement-to-disbursement, and post-disbursement periods; (3) allowing for ethnicity-specific time fixed effects; (4) allowing for flat-type-specific time fixed effects; (5) adding age fixed effects as a control; (6) adding receipt of additional welfare payments (Workfare Income Supplement; GST Vouchers) as a control-sample is smaller because this data is not collected every wave and not everyone responds every wave; (7) reweighting each observation by their propensity of receiving SSS as in Abadie (2005); and (8) DiD matching with a 1-1 nearest neighbour match. Eq. (1) describes the baseline model used in these checks

${ }^{4}$ For columns (1)-(6), the sample is restricted to respondents who are age-eligible for SSS (i.e. aged 65 and above in 2016), Singapore citizens, live in public housing flats, and with a propensity score of $0.2-0.8$. The number of observations in these columns refers to the number of individual-month observations. For columns (7) and (8), the number of observations refers to number of respondents, and the sample is not restricted by the propensity score. The sample, however, is smaller than the full sample due to data availability issues specific to the estimation of (7) and (8) 


\section{Appendix 2}

\subsection{Robustness checks for private cash transfers}

Table 14 Robustness check for private cash transfers - accounting for misreporting of SSS payout receipt

\begin{tabular}{|c|c|c|c|c|c|c|}
\hline & (1) & (2) & (3) & (4) & (5) & (6) \\
\hline VARIABLES & $\begin{array}{l}\text { Whether } \\
\text { received }\end{array}$ & $\begin{array}{l}\text { Amount } \\
\text { received }\end{array}$ & $\begin{array}{l}\text { Amount } \\
\text { received (positive) }\end{array}$ & $\begin{array}{l}\text { Whether } \\
\text { gave }\end{array}$ & $\begin{array}{l}\text { Amount } \\
\text { given }\end{array}$ & $\begin{array}{l}\text { Amount } \\
\text { given (positive) }\end{array}$ \\
\hline \multirow[t]{2}{*}{ Received SS $\times$ Jan } & -0.00626 & 14.16 & 13.48 & 0.0214 & 7.356 & 164.7 \\
\hline & $(0.0304)$ & $(37.17)$ & $(48.83)$ & $(0.0294)$ & $(27.74)$ & $(162.1)$ \\
\hline \multirow[t]{2}{*}{ Received SS $\times$ Feb } & 0.00809 & 30.29 & 62.82 & 0.0395 & 0.511 & 9.627 \\
\hline & $(0.0287)$ & (33.56) & $(41.73)$ & $(0.0330)$ & $(29.00)$ & (185.8) \\
\hline \multirow[t]{2}{*}{ Received SS $\times$ Mar } & 0.0428 & 37.94 & 35.43 & 0.00900 & -23.07 & -0.651 \\
\hline & $(0.0262)$ & $(28.67)$ & (36.33) & $(0.0266)$ & $(23.51)$ & $(120.2)$ \\
\hline \multirow{2}{*}{$\begin{array}{l}\text { Received SS } \times \text { announce-to-pay } \\
\times \text { received in } 2016 \text { and } 2017\end{array}$} & -0.0112 & 11.46 & 47.62 & $0.0387^{*}$ & 0.134 & -8.465 \\
\hline & $(0.0247)$ & $(24.74)$ & $(36.80)$ & $(0.0201)$ & (19.29) & $(140.1)$ \\
\hline \multirow{2}{*}{$\begin{array}{l}\text { Received SS } \times \text { post-pay } \times \\
\text { received in } 2016 \text { and } 2017\end{array}$} & -0.00349 & 47.11 & $79.30^{*}$ & 0.0134 & -18.00 & -44.57 \\
\hline & $(0.0242)$ & $(31.67)$ & $(47.94)$ & $(0.0221)$ & $(22.42)$ & (112.4) \\
\hline Observations & 15,486 & 15,451 & 9100 & 15,424 & 15,400 & 1940 \\
\hline R-squared & 0.734 & 0.773 & 0.773 & 0.426 & 0.197 & 0.523 \\
\hline
\end{tabular}

Notes:

${ }^{1}$ Standard errors clustered at the household level in parentheses. ${ }^{* *},{ }^{* *}$, and ${ }^{*}$ represent statistical significance at the 1 , 5 , and $10 \%$ level of significance respectively

${ }^{2}$ Dependent variables are shown at the top of each column. All transfer values are reported at the couple (respondent and spouse if respondent is married) and monthly level. Columns (3) and (6) include only responses with positive values ${ }^{3}$ Results are estimates of coefficients in Eq. (3). In the interest of space, we show only the coefficients from interacting the policy variables with the dummy which represents the subset of individuals who reported receiving SSS payout at least once in 2016 and at least once in 2017. The suppressed category of individuals are those who reported not receiving SSS payout in 2016 and 2017. The sample is restricted to respondents who are age-eligible for SSS (i.e. aged 65 and above in 2016), Singapore citizens, live in public housing flats, and with a propensity score of $0.2-0.8$ 
Table 15 Robustness check for private cash transfers - accounting for spousal receipt of SSS payout

\begin{tabular}{lllllll}
\hline \multirow{2}{*}{ VARIABLES } & $(1)$ & $(2)$ & $(3)$ & $(4)$ & $(5)$ & $(6)$ \\
& $\begin{array}{l}\text { Whether } \\
\text { received }\end{array}$ & $\begin{array}{l}\text { Amount } \\
\text { received }\end{array}$ & $\begin{array}{l}\text { Amount received } \\
\text { (positive) }\end{array}$ & $\begin{array}{l}\text { Whether } \\
\text { gave }\end{array}$ & $\begin{array}{l}\text { Amount } \\
\text { given }\end{array}$ & $\begin{array}{l}\text { Amount given } \\
\text { (positive) }\end{array}$ \\
\hline Only respondent rcv SS $\times$ & 0.00104 & 8.499 & 20.78 & 0.00818 & -7.894 & -4.269 \\
announce-to-pay & $(0.0246)$ & $(25.67)$ & $(34.44)$ & $(0.0221)$ & $(20.34)$ & $(141.6)$ \\
Only spouse rcv SS $\times$ announce- & 0.0433 & 86.72 & 17.68 & 0.0310 & 12.43 & 76.94 \\
to-pay & $(0.0551)$ & $(59.43)$ & $(67.01)$ & $(0.0311)$ & $(19.16)$ & $(146.7)$ \\
Both rcv SS $\times$ announce-to-pay & -0.0265 & 37.58 & $79.87^{*}$ & 0.0356 & 25.95 & 125.1 \\
& $(0.0306)$ & $(34.01)$ & $(42.16)$ & $(0.0224)$ & $(17.87)$ & $(117.5)$ \\
Only respondent rcv SS $\times$ post-pay & 0.00567 & 27.55 & 38.39 & -0.00937 & -23.41 & -43.97 \\
Only spouse rcv SS $\times$ post-pay & $(0.0258)$ & $(33.45)$ & $(44.56)$ & $(0.0218)$ & $(23.71)$ & $(105.2)$ \\
& 0.0886 & $161.6^{* * *}$ & 75.10 & 0.0568 & 14.11 & -63.72 \\
Both rcv SS $\times$ post-pay & $(0.0565)$ & $(61.08)$ & $(55.70)$ & $(0.0381)$ & $(15.37)$ & $(173.6)$ \\
& -0.0201 & 61.64 & $120.9^{* * *}$ & 0.0387 & 18.20 & 77.32 \\
Observations & $(0.0296)$ & $(38.56)$ & $(45.72)$ & $(0.0273)$ & $(15.88)$ & $(107.4)$ \\
R-squared & 15,096 & 15,061 & 8861 & 15,038 & 15,014 & 1894 \\
\hline Notes: & 0.732 & 0.771 & 0.771 & 0.429 & 0.195 & 0.521
\end{tabular}

Notes:

${ }^{1}$ Standard errors clustered at the household level in parentheses. ${ }^{* *},{ }^{* *}$, and ${ }^{*}$ represent statistical significance at the 1 , 5 , and $10 \%$ level of significance respectively

${ }^{2}$ Dependent variables are shown at the top of each column. All transfer values are reported at the couple (respondent and spouse if respondent is married) and monthly level. Columns (3) and (6) include only responses with positive values ${ }^{3}$ Results are estimates of coefficients in Eq. (4). In the interest of space, we do not show the coefficients from the placebo leads. The sample is restricted to respondents who are age-eligible for SSS (i.e. aged 65 and above in 2016), Singapore citizens, live in public housing flats, and with a propensity score of 0.2-0.8 
Table 16 Robustness check for private cash transfers - using non-age-eligible sample as a control group (propensity score $0.2-0.8$ )

\begin{tabular}{lllllll}
\hline \multirow{2}{*}{ VARIABLES } & $(1)$ & $(2)$ & $(3)$ & $(4)$ & $(5)$ & $(6)$ \\
& $\begin{array}{l}\text { Whether } \\
\text { received }\end{array}$ & $\begin{array}{l}\text { Amount } \\
\text { received }\end{array}$ & $\begin{array}{l}\text { Amount received } \\
\text { (positive) }\end{array}$ & $\begin{array}{l}\text { Whether } \\
\text { gave }\end{array}$ & $\begin{array}{l}\text { Amount } \\
\text { given }\end{array}$ & $\begin{array}{l}\text { Amount given } \\
\text { (positive) }\end{array}$ \\
\hline Received SS $\times$ Jan & -0.0301 & $62.92^{*}$ & $83.45^{*}$ & 0.0309 & 7.882 & 49.61 \\
& $(0.0301)$ & $(32.81)$ & $(45.29)$ & $(0.0286)$ & $(28.57)$ & $(140.7)$ \\
Received SS $\times$ Feb & 0.0331 & $68.68^{* *}$ & $84.36^{*}$ & 0.0405 & -33.12 & -74.74 \\
& $(0.0283)$ & $(32.12)$ & $(47.67)$ & $(0.0333)$ & $(33.01)$ & $(152.3)$ \\
Received SS $\times$ Mar & 0.0218 & $44.33^{*}$ & 39.39 & -0.00201 & -18.68 & 39.67 \\
& $(0.0250)$ & $(25.09)$ & $(35.54)$ & $(0.0272)$ & $(25.24)$ & $(100.2)$ \\
Received SS $\times$ & -0.0160 & 21.05 & $51.52^{*}$ & 0.00181 & -0.137 & -3.835 \\
announce-to-pay & $(0.0211)$ & $(21.33)$ & $(29.28)$ & $(0.0197)$ & $(18.47)$ & $(106.6)$ \\
Received SS $\times$ post- & -0.0170 & 26.21 & 42.24 & 0.00697 & -4.933 & -26.99 \\
pay & $(0.0209)$ & $(25.12)$ & $(35.87)$ & $(0.0210)$ & $(19.56)$ & $(83.39)$ \\
Observations & 16,846 & 16,818 & 7514 & 16,760 & 16,739 & 3336 \\
R-squared & 0.763 & 0.814 & 0.834 & 0.536 & 0.307 & 0.550 \\
\hline
\end{tabular}

Notes:

${ }^{1}$ Standard errors clustered at the household level in parentheses. ${ }^{* *},{ }^{* *}$, and ${ }^{*}$ represent statistical significance at the 1 , 5 , and $10 \%$ level of significance respectively

${ }^{2}$ Dependent variables are shown at the top of each column. All transfer values are reported at the couple (respondent and spouse if respondent is married) and monthly level. Columns (3) and (6) include only responses with positive values ${ }^{3}$ Results are estimates of coefficients in Eq. (1). The sample is restricted to respondents who are Singapore citizens, live in public housing flats, and with a propensity score of $0.2-0.8$. The treated group consists of individuals aged 65 and above in 2016 who received SSS payouts, while the control group consists of younger individuals aged 56 to 63 in 2016 who are not age eligible to receive SSS payouts yet 
Table 17 Robustness check for impact of receiving SSS payouts on receiving private cash transfers

\begin{tabular}{|c|c|c|c|c|c|c|c|c|}
\hline & (1) & (2) & (3) & (4) & (5) & (6) & (7) & (8) \\
\hline VARIABLES & $\begin{array}{l}\text { No } \\
\text { leads }\end{array}$ & Balanced & $\begin{array}{l}\text { Ethnic } \\
\text { trends }\end{array}$ & $\begin{array}{l}\text { Flat-type } \\
\text { trends }\end{array}$ & Age FE & $\begin{array}{l}\text { WIS/ } \\
\text { GST }\end{array}$ & Abadie & $\begin{array}{l}1-1 \\
\text { matching }\end{array}$ \\
\hline \multirow[t]{2}{*}{ Received SS $\times$ Jan } & - & -0.00947 & -0.00721 & -0.00235 & -0.00815 & 0.00847 & -0.00726 & - \\
\hline & - & $(0.0305)$ & $(0.0307)$ & $(0.0306)$ & $(0.0304)$ & $(0.0348)$ & $(0.0255)$ & - \\
\hline \multirow[t]{2}{*}{ Received SS $\times$ Feb } & - & 0.00414 & 0.00775 & 0.0127 & 0.00614 & -0.0131 & 0.00300 & - \\
\hline & - & $(0.0290)$ & $(0.0289)$ & $(0.0288)$ & $(0.0289)$ & $(0.0330)$ & $(0.0237)$ & - \\
\hline \multirow[t]{2}{*}{ Received SS $\times$ Mar } & - & 0.0370 & 0.0382 & 0.0426 & 0.0387 & 0.00933 & 0.0173 & - \\
\hline & - & $(0.0262)$ & $(0.0263)$ & $(0.0262)$ & $(0.0263)$ & $(0.0301)$ & $(0.0219)$ & - \\
\hline \multirow[t]{2}{*}{ Received SS $\times$ Jan-Mar } & - & - & - & - & - & - & - & 0.0172 \\
\hline & - & - & - & - & - & - & - & $P=0.40$ \\
\hline \multirow[t]{2}{*}{$\begin{array}{l}\text { Received SS } \times \\
\text { announce-to-pay }\end{array}$} & -0.0241 & -0.0179 & -0.0173 & -0.0128 & -0.0203 & $-\overline{0}-0337$ & -0.0155 & -0.0145 \\
\hline & $(0.0170)$ & $(0.0214)$ & $(0.0214)$ & $(0.0213)$ & $(0.0215)$ & $(0.0260)$ & $(0.0183)$ & $P=0.49$ \\
\hline \multirow[t]{2}{*}{ Received SS $\times$ post-pay } & -0.0212 & -0.0173 & -0.0135 & -0.00992 & -0.0182 & $\begin{array}{l}- \\
0.0247\end{array}$ & -0.00077 & -0.00657 \\
\hline & $(0.0175)$ & $(0.0215)$ & $(0.0214)$ & $(0.0214)$ & $(0.0215)$ & $(0.0259)$ & $(0.0191)$ & $P=0.80$ \\
\hline Observations & 15,486 & 15,182 & 15,486 & 15,486 & 15,486 & 10,796 & 1451 & 367 \\
\hline R-squared & 0.733 & 0.734 & 0.735 & 0.735 & 0.734 & 0.757 & - & - \\
\hline
\end{tabular}

Notes:

${ }^{1}$ Standard errors clustered at the household level in parentheses. ${ }^{* *},{ }^{* *}$, and * represent statistical significance at the 1 , 5 , and $10 \%$ level of significance respectively

${ }^{2}$ All transfer values are reported at the couple (respondent and spouse if respondent is married) and monthly level

${ }^{3}$ Columns (1)-(8) show results from additional robustness checks carried out. These checks are: (1) removal of the lead terms; (2) restricting the sample to a "balanced" panel, where each individual has at least one observation in the preannouncement, announcement-to-disbursement, and post-disbursement periods; (3) allowing for ethnicity-specific time fixed effects; (4) allowing for flat-type-specific time fixed effects; (5) adding age fixed effects as a control; (6) adding receipt of additional welfare payments (Workfare Income Supplement; GST Vouchers) as a control—sample is smaller because this data is not collected every wave and not everyone responds every wave; (7) reweighting each observation by their propensity of receiving SSS as in Abadie (2005); and (8) DiD matching with a 1-1 nearest neighbour match. Eq. (1) describes the baseline model used in these checks

${ }^{4}$ For columns (1)-(6), the sample is restricted to respondents who are age-eligible for SSS (i.e. aged 65 and above in 2016), Singapore citizens, live in public housing flats, and with a propensity score of $0.2-0.8$. The number of observations in these columns refers to the number of individual-month observations. For columns (7) and (8), the number of observations refers to number of respondents, and the sample is not restricted by the propensity score. The sample, however, is smaller than the full sample due to data availability issues specific to the estimation of (7) and (8) 
Table 18 Robustness check for impact of receiving SSS payouts on amount of private cash transfers received

\begin{tabular}{lllllllll}
\hline \multirow{2}{*}{ VARIABLES } & $(1)$ & $(2)$ & $(3)$ & $(4)$ & $(5)$ & $(6)$ & $(7)$ & $(8)$ \\
& No leads & Balanced & $\begin{array}{l}\text { Ethnic } \\
\text { trends }\end{array}$ & $\begin{array}{l}\text { Flat-type } \\
\text { trends }\end{array}$ & Age FE & WIS/ GST & Abadie & $1-1$ matching \\
\hline Received SS $\times$ Jan & - & 12.83 & 14.59 & 12.04 & 12.64 & 33.70 & 30.98 & - \\
& - & $(37.20)$ & $(37.14)$ & $(37.90)$ & $(37.11)$ & $(45.78)$ & $(30.39)$ & - \\
Received SS $\times$ Feb & - & 22.94 & 29.55 & 33.32 & 27.42 & -19.56 & 23.62 & - \\
& - & $(33.63)$ & $(33.63)$ & $(33.81)$ & $(33.53)$ & $(38.42)$ & $(27.30)$ & - \\
Received SS $\times$ Mar & - & 35.67 & 35.11 & 39.01 & 34.67 & 48.03 & 9.274 & - \\
& - & $(28.75)$ & $(28.55)$ & $(28.58)$ & $(28.75)$ & $(35.13)$ & $(27.11)$ & - \\
Received SS $\times$ Jan- - & - & - & - & - & - & - & - & 15.66 \\
Mar & - & - & - & - & - & - & - & $P=0.51$ \\
Received SS $\times$ & -12.41 & -1.234 & -1.123 & 1.489 & -3.895 & -5.637 & - & -9.70 \\
announce-to-pay & & & & & & & 10.55 & \\
& $(18.54)$ & $(22.57)$ & $(22.45)$ & $(22.71)$ & $(22.55)$ & $(28.03)$ & $(22.03)$ & $P=0.65$ \\
Received SS $\times$ post- & 2.237 & 13.07 & 14.38 & 17.84 & 11.11 & 12.77 & 20.09 & 2.83 \\
pay & $(23.04)$ & $(27.24)$ & $(27.24)$ & $(27.48)$ & $(26.77)$ & $(34.48)$ & $(22.39)$ & $P=0.92$ \\
Observations & 15,451 & 15,148 & 15,451 & 15,451 & 15,451 & 10,781 & 1451 & 366 \\
R-squared & 0.773 & 0.773 & 0.774 & 0.774 & 0.774 & 0.779 & - & - \\
\hline
\end{tabular}

Notes:

${ }^{1}$ Standard errors clustered at the household level in parentheses. ${ }^{* *},{ }^{* *}$, and * represent statistical significance at the 1 , 5 , and $10 \%$ level of significance respectively

${ }^{2}$ All transfer values are reported at the couple (respondent and spouse if respondent is married) and monthly level ${ }^{3}$ Columns (1)-(8) show results from additional robustness checks carried out. These checks are: (1) removal of the lead terms; (2) restricting the sample to a "balanced" panel, where each individual has at least one observation in the preannouncement, announcement-to-disbursement, and post-disbursement periods; (3) allowing for ethnicity-specific time fixed effects; (4) allowing for flat-type-specific time fixed effects; (5) adding age fixed effects as a control; (6) adding receipt of additional welfare payments (Workfare Income Supplement; GST Vouchers) as a control-sample is smaller because this data is not collected every wave and not everyone responds every wave; (7) reweighting each observation by their propensity of receiving SSS as in Abadie (2005); and (8) DiD matching with a 1-1 nearest neighbour match. Eq. (1) describes the baseline model used in these checks

${ }^{4}$ For columns (1)-(6), the sample is restricted to respondents who are age-eligible for SSS (i.e. aged 65 and above in 2016), Singapore citizens, live in public housing flats, and with a propensity score of $0.2-0.8$. The number of observations in these columns refers to the number of individual-month observations. For columns (7) and (8), the number of observations refers to number of respondents, and the sample is not restricted by the propensity score. The sample, however, is smaller than the full sample due to data availability issues specific to the estimation of (7) and (8) 
Table 19 Robustness check for impact of receiving SSS payouts on giving private cash transfers

\begin{tabular}{|c|c|c|c|c|c|c|c|c|}
\hline & (1) & (2) & (3) & (4) & (5) & (6) & (7) & (8) \\
\hline VARIABLES & No leads & Balanced & $\begin{array}{l}\text { Ethnic } \\
\text { trends }\end{array}$ & $\begin{array}{l}\text { Flat-type } \\
\text { trends }\end{array}$ & Age FE & WIS/ GST & Abadie & 1-1 matching \\
\hline \multirow[t]{2}{*}{ Received SS $\times$ Jan } & - & 0.0245 & 0.0264 & 0.0251 & 0.0202 & 0.00388 & 0.0218 & - \\
\hline & - & $(0.0295)$ & $(0.0296)$ & $(0.0301)$ & $(0.0293)$ & $(0.0336)$ & $(0.0232)$ & - \\
\hline \multirow[t]{2}{*}{ Received SS × Feb } & - & 0.0422 & 0.0411 & 0.0487 & 0.0377 & -0.00108 & 0.0391 & - \\
\hline & - & $(0.0333)$ & $(0.0331)$ & $(0.0338)$ & $(0.0328)$ & $(0.0380)$ & $(0.0255)$ & - \\
\hline \multirow[t]{2}{*}{ Received SS $\times$ Mar } & - & 0.00924 & 0.0104 & 0.0137 & 0.00675 & -0.00481 & -0.00330 & - \\
\hline & - & $(0.0267)$ & $(0.0267)$ & $(0.0274)$ & $(0.0264)$ & $(0.0311)$ & $(0.0211)$ & - \\
\hline \multirow[t]{2}{*}{ Received SS × Jan-Mar } & - & - & - & - & - & - & - & $0.0376^{*}$ \\
\hline & - & - & - & - & - & - & - & 0.081 \\
\hline \multirow{2}{*}{$\begin{array}{l}\text { Received SS } \times \\
\text { announce-to-pay }\end{array}$} & 0.0109 & 0.0219 & 0.0200 & 0.0232 & 0.0185 & 0.0164 & 0.0235 & $0.0415^{* *}$ \\
\hline & $(0.0146)$ & $(0.0186)$ & $(0.0186)$ & $(0.0189)$ & $(0.0184)$ & $(0.0221)$ & $(0.0155)$ & 0.027 \\
\hline \multirow[t]{2}{*}{ Received SS $\times$ post-pay } & 0.000442 & 0.0120 & 0.0108 & 0.0145 & 0.00776 & -0.0108 & 0.0199 & $0.0392^{* *}$ \\
\hline & $(0.0151)$ & $(0.0197)$ & (0.0198) & $(0.0203)$ & $(0.0191)$ & $(0.0239)$ & $(0.0153)$ & 0.035 \\
\hline Observations & 15,424 & 15,113 & 15,424 & 15,424 & 15,424 & 10,767 & 1450 & 366 \\
\hline R-squared & 0.425 & 0.427 & 0.429 & 0.430 & 0.426 & 0.439 & - & - \\
\hline
\end{tabular}

Notes:

${ }^{1}$ Standard errors clustered at the household level in parentheses. ${ }^{* *}, *^{*}$, and * represent statistical significance at the 1 , 5 , and $10 \%$ level of significance respectively

${ }^{2}$ All transfer values are reported at the couple (respondent and spouse if respondent is married) and monthly level

${ }^{3}$ Columns (1)-(8) show results from additional robustness checks carried out. These checks are: (1) removal of the lead terms; (2) restricting the sample to a "balanced" panel, where each individual has at least one observation in the preannouncement, announcement-to-disbursement, and post-disbursement periods; (3) allowing for ethnicity-specific time fixed effects; (4) allowing for flat-type-specific time fixed effects; (5) adding age fixed effects as a control; (6) adding receipt of additional welfare payments (Workfare Income Supplement; GST Vouchers) as a control-sample is smaller because this data is not collected every wave and not everyone responds every wave; (7) reweighting each observation by their propensity of receiving SSS as in Abadie (2005); and (8) DiD matching with a 1-1 nearest neighbour match. Eq. (1) describes the baseline model used in these checks

${ }^{4}$ For columns (1)-(6), the sample is restricted to respondents who are age-eligible for SSS (i.e. aged 65 and above in 2016), Singapore citizens, live in public housing flats, and with a propensity score of $0.2-0.8$. The number of observations in these columns refers to the number of individual-month observations. For columns (7) and (8), the number of observations refers to number of respondents, and the sample is not restricted by the propensity score. The sample, however, is smaller than the full sample due to data availability issues specific to the estimation of (7) and (8) 
Table 20 Robustness check for impact of receiving SSS payouts on amount of private cash transfers given

\begin{tabular}{|c|c|c|c|c|c|c|c|c|}
\hline & (1) & (2) & (3) & (4) & (5) & (6) & (7) & (8) \\
\hline VARIABLES & $\begin{array}{l}\text { No } \\
\text { leads }\end{array}$ & Balanced & $\begin{array}{l}\text { Ethnic } \\
\text { trends }\end{array}$ & $\begin{array}{l}\text { Flat-type } \\
\text { trends }\end{array}$ & $\begin{array}{l}\text { Age } \\
\mathrm{FE}\end{array}$ & $\begin{array}{l}\text { WIS/ } \\
\text { GST }\end{array}$ & Abadie & $\begin{array}{l}\text { 1-1 } \\
\text { matching }\end{array}$ \\
\hline \multirow[t]{2}{*}{ Received SS $\times$ Jan } & - & 7.625 & 6.930 & 10.24 & 6.614 & 8.259 & - & - \\
\hline & - & $(27.97)$ & $(28.38)$ & $(28.80)$ & $(27.87)$ & (36.14) & (23.39) & - \\
\hline \multirow[t]{2}{*}{ Received SS × Feb } & - & 0.762 & 1.451 & 7.220 & -0.113 & -1.176 & $-\overline{-}$ & - \\
\hline & - & $(29.17)$ & $(29.13)$ & (29.33) & $(29.07)$ & $(35.61)$ & $(23.63)$ & - \\
\hline \multirow[t]{2}{*}{ Received SS $\times$ Mar } & - & -25.28 & -25.49 & -22.30 & -25.44 & -24.43 & - & - \\
\hline & - & $(23.82)$ & $(23.76)$ & $(23.87)$ & $(23.63)$ & $(26.76)$ & $(16.45)$ & - \\
\hline \multirow[t]{2}{*}{ Received SS × Jan-Mar } & - & - & - & - & - & - & - & -1.10 \\
\hline & - & - & - & - & - & - & - & 0.95 \\
\hline \multirow{2}{*}{$\begin{array}{l}\text { Received SS } \times \text { announce- } \\
\text { to-pay }\end{array}$} & 7.680 & 5.007 & 4.091 & 7.130 & 4.621 & 0.529 & 1.352 & 14.22 \\
\hline & $(11.57)$ & $(16.59)$ & $(16.64)$ & $(16.36)$ & $(16.53)$ & $(18.14)$ & $(13.73)$ & 0.39 \\
\hline \multirow[t]{2}{*}{ Received SS $\times$ post-pay } & -2.928 & -5.684 & -6.150 & -2.365 & $-\overline{5} \cdot 663$ & -17.94 & 0.308 & 12.33 \\
\hline & $(11.41)$ & (18.37) & (18.45) & $(17.91)$ & (18.25) & $(23.05)$ & $(14.85)$ & 0.47 \\
\hline Observations & 15,400 & 15,091 & 15,400 & 15,400 & 15,400 & 10,753 & 1450 & 366 \\
\hline R-squared & 0.196 & 0.196 & 0.197 & 0.202 & 0.197 & 0.210 & - & - \\
\hline \multicolumn{9}{|c|}{$\begin{array}{l}\text { Notes: } \\
\text { 'Standard errors clustered at the household level in parentheses. }{ }^{* * *}, * * \text {, and * represent statistical significance at the } 1, \\
5 \text {, and } 10 \% \text { level of significance respectively } \\
\text { 2All transfer values are reported at the couple (respondent and spouse if respondent is married) and monthly level } \\
{ }^{3} \text { Columns (1)-(8) show results from additional robustness checks carried out. These checks are: (1) removal of the lead } \\
\text { terms; (2) restricting the sample to a "balanced" panel, where each individual has at least one observation in the pre- } \\
\text { announcement, announcement-to-disbursement, and post-disbursement periods; (3) allowing for ethnicity-specific time } \\
\text { fixed effects; (4) allowing for flat-type-specific time fixed effects; (5) adding age fixed effects as a control; (6) adding } \\
\text { receipt of additional welfare payments (Workfare Income Supplement; GST Vouchers) as a control-sample is smaller } \\
\text { because this data is not collected every wave and not everyone responds every wave; (7) reweighting each observation } \\
\text { by their propensity of receiving SSS as in Abadie (2005); and (8) DiD matching with a 1-1 nearest neighbour match. } \\
\text { Eq. (1) describes the baseline model used in these checks } \\
{ }^{4} \text { For columns (1)-(6), the sample is restricted to respondents who are age-eligible for SSS (i.e. aged } 65 \text { and above in } \\
\text { 2016), Singapore citizens, live in public housing flats, and with a propensity score of } 0.2-0.8 \text {. The number of observations } \\
\text { in these columns refers to the number of individual-month observations. For columns (7) and (8), the number of observations } \\
\text { refers to number of respondents, and the sample is not restricted by the propensity score. The sample, however, is smaller } \\
\text { than the full sample due to data availability issues specific to the estimation of (7) and (8) }\end{array}$} \\
\hline
\end{tabular}




\section{Appendix 3}

\subsection{Expenditure-related results}

In general, we are unable to make definitive statements about this set of outcomes, due to the imprecision of our estimates. There is some evidence of a rise in durables expenditure, but our identifying assumption does not seem to hold well for durables expenditure. These results thus need to be interpreted with caution. The rest of this section discusses our results on the effect of receiving the SSS on expenditure-related outcomes in more detail.

Table 21 reports the effect of receiving SSS payouts on recipients' expenditure (at the couple level ${ }^{35}$ ). The coefficients related to the announcement and disbursement effects are generally quite large in magnitude, but imprecise and thus statistically insignificant across the variables studied. However, there is some evidence of a rise in durables-related expenditure during the announcement-to-payment and post-disbursement periods, as well as a small rise in expenditure related to clothes and personal care in the announcement-to-payment period.

Table 22 shows that there is little evidence that the consumption response to receiving SSS payouts has changed over time, though the increased expenditure on durables may be concentrated in the announcement-to-payment and early disbursement period. In general, the effect does not seem to vary substantially by recipients' flat-type or gender, though there is suggestive evidence that SSS recipients who are more financially prepared for retirement/have higher income may spend more on health-related consumption (results available on request).

A concern with these results, however, is that the identifying assumption may not hold up well for some variables. Our identification assumption appears to hold reasonably well for total and non-durable expenditure-the placebo leads in Table 21 are statistically insignificant, and the trends plotted in Fig. 4 suggest that the pre-treatment trends for the treated and control groups are similar. However, while the placebo leads for expenditure on durables are statistically insignificant, the pre-treatment trends for the treated and control groups look quite different.

Figure 4 suggests that our durables-related results could be driven by the trend difference in the pre-treatment period: the pre-treatment trend for the control group falls much more quickly than that of treated group at the start; this could lead to an overestimation of the effect of SSS on durables expenditure among the treated. ${ }^{36}$ Unfortunately, the robustness checks that could potentially address the issue of differing time trends between the treated and control groups do not appear to be very effective, as the coefficients of the placebo leads are often large and sometimes marginally significant (see Table 25 and columns (7) and (8) of Tables 26, 27, 28 and 2937). Our durables-related estimates in all specifications in this paper may thus be overestimated. $^{38}$

Apart from the potential issue of differing time trends between the control and treatment groups, the other robustness checks designed to address potential attenuation (Tables 23 and 24) and test the sensitivity of our results to other specification (Tables 25, 26, 27, 28 and 29) show that our results seem to be robust to these issues. Our results are also robust to transforming our variables using the inverse hyperbolic sine, which approximates the natural logarithm but maps zero to zero (see e.g. Burbidge et al. 1988; MacKinnon and Magee 1990) (results available on request). 


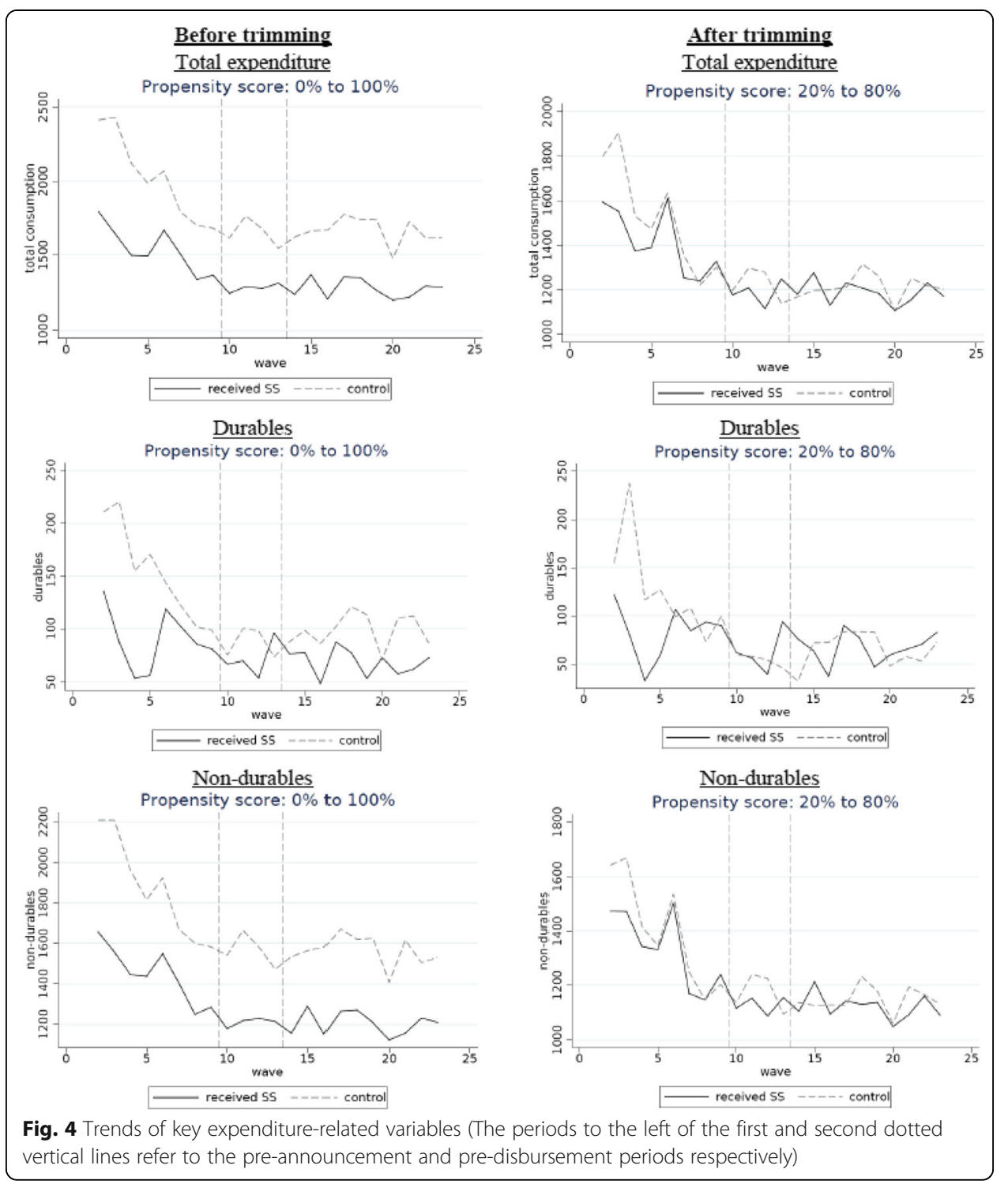

In all, we find little evidence that the SSS led to increases in total and nondurables expenditure, and some suggestive evidence that durables expenditure may have risen in response to SSS receipt. Unfortunately, our ability to make definitive statements about the lack of an effect of the SSS on total and non-durables expenditure is hampered by the imprecision of our estimates. In addition, our identifying assumption does not seem to hold well for durables expenditure; these results thus need to be interpreted with caution. Our expenditure-related results should thus be corroborated by studies using other datasets before a more definitive conclusion can be made. 
Table 21 Overall impact of receiving SSS payouts on expenditure

\begin{tabular}{|c|c|c|c|c|c|c|c|c|c|}
\hline & (1) & (2) & (3) & (4) & (5) & (6) & (7) & (8) & (9) \\
\hline VARIABLES & Total & Durables & $\begin{array}{l}\text { urables } \\
\text { ubset }\end{array}$ & $\begin{array}{l}\text { Non- } \\
\text { durables }\end{array}$ & Food & Tobacco & $\begin{array}{l}\text { Clothes } \\
\text { /Personal c }\end{array}$ & Health & Leisure \\
\hline \multirow{2}{*}{$\begin{array}{l}\text { Received SS } \times \\
\text { Jan }\end{array}$} & & & 17.144 & -13.574 & -10.347 & & -0.111 & & 1.200 \\
\hline & (105.715) & $(47.887)$ & $(44.492)$ & (85.963) & (22.578) & $(1.984)$ & & $(27.815)$ & $(32.623)$ \\
\hline \multirow{2}{*}{$\begin{array}{l}\text { Received SS } \times \\
\text { Feb }\end{array}$} & 170.274 & 78.893 & 50.216 & 91.707 & 18.021 & 1.001 & 7.918 & -12.850 & 39.023 \\
\hline & (117.335) & $(49.606)$ & (41.931) & (100.368) & (21.920) & $(2.097)$ & (8.396) & (26.393) & $(54.562)$ \\
\hline \multirow{2}{*}{$\begin{array}{l}\text { Received SS } \times \\
\text { Mar }\end{array}$} & 221.451 & 52.306 & 50.469 & 170.399 & -9.369 & -2.991 & 1.487 & -14.530 & 40.765 \\
\hline & (179.048) & $(49.028)$ & (46.316) & $(167.223)$ & (19.988) & $(2.499)$ & (7.26 & $(27.417)$ & (53.174) \\
\hline & 93.081 & $62.228^{*}$ & $57.854^{* *}$ & 33.854 & 24.822 & -1.395 & & & 7.342 \\
\hline & 0.00 & & & & $(16.1$ & $(1.89$ & & & \\
\hline \multirow{2}{*}{$\begin{array}{l}\text { Received SS } \times \\
\text { post-pay }\end{array}$} & 113.425 & $57.062^{*}$ & 44.246 & 56.290 & -3.672 & -1.392 & 5.9 & 5.65 & 11.416 \\
\hline & (93.064) & (31.672) & (27.181) & (79.732) & (17.224) & $(2.153)$ & (5.768) & (21.905) & $(26.971)$ \\
\hline eall & & 84 & & 政 & 412 & 8 & & 171 & 122 \\
\hline & & & & & & & & 572 & 662 \\
\hline & 15,970 & & & & & & & & 16,019 \\
\hline k-squarea & & 0.13 & 0.12 & 0.44 & 0.73 & 0.85 & 0.38 & 0.20 & 0.18 \\
\hline \multicolumn{10}{|c|}{$\begin{array}{l}\text { Notes: } \\
{ }^{1} \text { Standard errors clustered at the household level in parentheses. }{ }^{* * *},{ }^{* *} \text {, and }{ }^{*} \text { represent statistical significance } \\
\text { at the } 1,5 \text {, and } 10 \% \text { level of significance respectively } \\
{ }^{2} \text { Dependent variables are shown at the top of each column. All expenditure values are reported at the couple } \\
\text { (respondent and spouse if respondent is married) and monthly level. Total expenditure excludes cash gifts. } \\
\text { Durables include furniture/furnishings, household appliances, home and vehicle repair/maintenance. Durables } \\
\text { subset includes only furniture/furnishings and household appliances. Non-durables are based on the } \\
\text { difference between total expenditure and durables. The sub-categories of non-durables captured in columns } \\
\text { (5)-(9) are not exhaustive } \\
{ }^{3} \text { Results are estimates of coefficients in Eq. (1). The sample is restricted to respondents who are age-eligible } \\
\text { for SSS (i.e. aged } 65 \text { and above in 2016), Singapore citizens, live in public housing flats, and with a propensity } \\
\text { score of } 0.2-0.8 \\
{ }^{4} \text { Mean and standard deviation statistics are based on pre-announcement levels of the dependent variable for } \\
\text { respondents who received SSS payouts }\end{array}$} \\
\hline
\end{tabular}


Table 22 Temporal impact of receiving SSS payouts on expenditure

\begin{tabular}{llllllllll}
\hline & $(1)$ & $(2)$ & $(3)$ & $(4)$ & $(5)$ & $(6)$ & $(7)$ & $(8)$ & $(9)$ \\
VARIABLES & Total & Durables & $\begin{array}{l}\text { Durables } \\
\text { subset }\end{array}$ & $\begin{array}{l}\text { Non- } \\
\text { durables }\end{array}$ & Food & Tobacco & $\begin{array}{l}\text { Clothes } \\
\text { /Personal care }\end{array}$ & Health & Leisure \\
\hline Received SS × Jan & 10.96 & 25.42 & 17.15 & -13.56 & -10.34 & -1.938 & -0.111 & 3.104 & 1.202 \\
& $(105.7)$ & $(47.89)$ & $(44.50)$ & $(85.97)$ & $(22.58)$ & $(1.984)$ & $(10.43)$ & $(27.82)$ & $(32.62)$ \\
Received SS × Feb & 170.4 & 78.94 & 50.26 & 91.79 & 18.00 & 1.000 & 7.930 & -12.82 & 39.06 \\
& $(117.3)$ & $(49.61)$ & $(41.93)$ & $(100.4)$ & $(21.92)$ & $(2.097)$ & $(8.395)$ & $(26.39)$ & $(54.58)$ \\
Received SS × Mar & 221.6 & 52.35 & 50.50 & 170.5 & -9.365 & -2.991 & 1.495 & -14.51 & 40.79 \\
& $(179.1)$ & $(49.03)$ & $(46.32)$ & $(167.2)$ & $(19.99)$ & $(2.499)$ & $(7.264)$ & $(27.42)$ & $(53.17)$ \\
Received SS $\times$ & 93.58 & $62.38^{*}$ & $57.99^{* *}$ & 34.20 & 24.85 & -1.395 & $11.16^{* *}$ & -34.18 & 7.451 \\
announce-to-pay & $(95.86)$ & $(32.30)$ & $(26.03)$ & $(84.04)$ & $(16.19)$ & $(1.898)$ & $(5.537)$ & $(31.45)$ & $(28.71)$ \\
Received SS $\times$ & $185.7^{*}$ & $79.09^{* *}$ & $63.42^{* *}$ & 106.0 & 2.166 & -1.336 & 8.770 & 16.14 & 29.78 \\
Aug-Sep 2016 & $(98.10)$ & $(35.30)$ & $(28.42)$ & $(82.81)$ & $(18.38)$ & $(2.097)$ & $(6.582)$ & $(29.40)$ & $(39.63)$ \\
& 94.09 & 48.21 & 32.89 & 46.20 & 6.902 & -0.726 & 4.595 & -1.649 & -2.303 \\
Received SS $\times$ & $(95.73)$ & $(39.94)$ & $(34.76)$ & $(78.81)$ & $(18.41)$ & $(2.414)$ & $(6.789)$ & $(26.37)$ & $(28.84)$ \\
Oct-Dec 2016 & 75.33 & 47.37 & 39.31 & 27.60 & -13.18 & -1.812 & 3.015 & 2.897 & 13.82 \\
Received SS $\times$ & $(105.9)$ & $(33.80)$ & $(29.08)$ & $(92.86)$ & $(19.71)$ & $(2.278)$ & $(6.099)$ & $(26.67)$ & $(32.91)$ \\
Jan-Mar 2017 & 125.5 & 62.46 & 49.35 & 63.29 & -11.86 & -1.848 & 9.350 & 10.25 & 9.948 \\
Received SS $\times$ & $(106.2)$ & $(38.58)$ & $(34.65)$ & $(95.81)$ & $(19.91)$ & $(2.799)$ & $(8.237)$ & $(33.34)$ & $(36.45)$ \\
Apr-May 2017 & 15,970 & 16,019 & 16,019 & 15,970 & 16,019 & 15,909 & 15,914 & 16,019 & 16,019 \\
Observations & 0.384 & 0.128 & 0.124 & 0.440 & 0.727 & 0.848 & 0.383 & 0.197 & 0.183 \\
R-squared & & & & & & & & &
\end{tabular}

Notes:

${ }^{1}$ Standard errors clustered at the household level in parentheses. ${ }^{* *},{ }^{* *}$, and * represent statistical significance at the 1, 5 , and $10 \%$ level of significance respectively

${ }^{2}$ Dependent variables are shown at the top of each column. All expenditure values are reported at the couple (respondent and spouse if respondent is married) and monthly level. Total expenditure excludes cash gifts. Durables include furniture/furnishings, household appliances, home and vehicle repair/maintenance. Durables subset includes only furniture/furnishings and household appliances. Non-durables are based on the difference between total expenditure and durables. The sub-categories of non-durables captured in columns (5)-(9) are not exhaustive ${ }^{3}$ Results are estimates of coefficients in Eq. (2). The sample is restricted to respondents who are age-eligible for SSS (i.e. aged 65 and above in 2016), Singapore citizens, live in public housing flats, and with a propensity score of $0.2-0.8$ 
Table 23 Robustness check for expenditure-accounting for misreporting of SSS payout receipt

\begin{tabular}{|c|c|c|c|c|c|c|c|c|c|}
\hline & (1) & (2) & (3) & (4) & (5) & (6) & (7) & (8) & (9) \\
\hline VARIABLES & Total & Durables & $\begin{array}{l}\text { Durables } \\
\text { subset }\end{array}$ & $\begin{array}{l}\text { Non- } \\
\text { durables }\end{array}$ & Food & Tobacco & $\begin{array}{l}\text { Clothes } \\
\text { /Personal care }\end{array}$ & Health & Leisure \\
\hline \multirow[t]{2}{*}{ Received SS × Jan } & 8.175 & 25.60 & 17.35 & -16.55 & -10.15 & -1.906 & -0.153 & 4.486 & 2.436 \\
\hline & (107.4) & $(47.89)$ & $(44.52)$ & $(88.05)$ & $(22.57)$ & $(1.971)$ & $(10.41)$ & $(27.71)$ & $(32.47)$ \\
\hline \multirow[t]{2}{*}{ Received SS × Feb } & 170.1 & 78.94 & 50.31 & 91.50 & 17.96 & 1.008 & 7.868 & -12.55 & 39.37 \\
\hline & $(117.8)$ & $(49.56)$ & $(41.90)$ & (100.9) & (21.93) & $(2.092)$ & $(8.403)$ & (26.39) & $(54.68)$ \\
\hline \multirow[t]{2}{*}{ Received SS × Mar } & 220.3 & 54.60 & 52.25 & 166.8 & -8.503 & -2.932 & 1.698 & -12.63 & 43.40 \\
\hline & (182.7) & (49.23) & $(46.55)$ & (170.9) & (19.96) & $(2.487)$ & $(7.186)$ & $(27.44)$ & $(53.21)$ \\
\hline \multirow{2}{*}{$\begin{array}{l}\text { Received SS } \times \\
\text { announce-to-pay } \times \\
\text { received in } 2016 \\
\text { and } 2017\end{array}$} & 135.0 & $62.74^{*}$ & $60.00^{* *}$ & 76.84 & 15.40 & -1.707 & $11.79^{*}$ & -31.40 & 12.26 \\
\hline & (104.6) & $(37.41)$ & (29.04) & $(90.54)$ & $(17.26)$ & $(2.244)$ & $(6.187)$ & (35.42) & $(36.67)$ \\
\hline \multirow{2}{*}{$\begin{array}{l}\text { Received SS × post-pay } \\
\times \text { received in } 2016 \\
\text { and } 2017\end{array}$} & 114.3 & $60.64^{*}$ & $56.39^{*}$ & 53.70 & -9.874 & -1.444 & 6.330 & -22.83 & 5.856 \\
\hline & $(99.27)$ & $(36.04)$ & $(31.02)$ & (86.54) & $(18.61)$ & $(2.364)$ & $(5.735)$ & $(25.25)$ & (32.08) \\
\hline Observations & 15,970 & 16,019 & 16,019 & 15,970 & 16,019 & 15,909 & 15,914 & 16,019 & 16,019 \\
\hline R-squared & 0.385 & 0.128 & 0.124 & 0.440 & 0.728 & 0.848 & 0.384 & 0.199 & 0.184 \\
\hline
\end{tabular}

Notes:

${ }^{1}$ Standard errors clustered at the household level in parentheses. ${ }^{* *},{ }^{* *}$, and ${ }^{*}$ represent statistical significance at the 1,5 , and $10 \%$ level of significance respectively

${ }^{2}$ Dependent variables are shown at the top of each column. All expenditure values are reported at the couple (respondent and spouse if respondent is married) and monthly level. Total expenditure excludes cash gifts. Durables include furniture/furnishings, household appliances, home and vehicle repair/maintenance. Durables subset includes only furniture/furnishings and household appliances. Non-durables are based on the difference between total expenditure and durables. The sub-categories of non-durables captured in columns (5)-(9) are not exhaustive

${ }^{3}$ Results are estimates of coefficients in Eq. (3). In view of space constraint, we show only the coefficients from interacting the policy variables with the dummy which represents the subset of individuals who reported receiving SSS payout at least once in 2016 and at least once in 2017. The suppressed category of individuals is those who reported not receiving SSS payout in 2016 and 2017. The sample is restricted to respondents who are age-eligible for SSS (i.e. aged 65 and above in 2016), Singapore citizens, live in public housing flats, and with a propensity score of $0.2-0.8$ 
Table 24 Robustness check for expenditure-accounting for spousal receipt of SSS payout

\begin{tabular}{|c|c|c|c|c|c|c|c|c|c|}
\hline & (1) & (2) & (3) & (4) & (5) & (6) & (7) & (8) & (9) \\
\hline VARIABLES & Total & Durables & $\begin{array}{l}\text { Durables } \\
\text { subset }\end{array}$ & $\begin{array}{l}\text { Non- } \\
\text { durables }\end{array}$ & Food & Tobacco & $\begin{array}{l}\text { Clothes } \\
\text { /Personal care }\end{array}$ & Health & Leisure \\
\hline \multirow{2}{*}{$\begin{array}{l}\text { Only respondent } \\
\text { rcv SS } \times \text { announce-to-pay }\end{array}$} & 92.26 & 55.18 & $52.95^{*}$ & 42.10 & 28.21 & -0.179 & $11.97^{* *}$ & -41.57 & 2.280 \\
\hline & (111.4) & $(36.26)$ & $(28.77)$ & (99.58) & $(17.82)$ & $(1.571)$ & $(6.029)$ & (32.98) & (35.27) \\
\hline \multirow{2}{*}{$\begin{array}{l}\text { Only spouse rcv SS } \times \\
\text { announce-to-pay }\end{array}$} & 59.87 & 16.91 & 30.76 & 43.15 & $93.77^{* *}$ & 2.012 & $17.26^{* *}$ & -110.8 & -12.89 \\
\hline & (158.8) & (39.96) & (32.10) & (147.8) & $(36.81)$ & $(1.830)$ & (8.396) & $(74.20)$ & (57.23) \\
\hline \multirow{2}{*}{$\begin{array}{l}\text { Both rcv SS } \times \text { announce- } \\
\text { to-pay }\end{array}$} & 109.7 & $74.87^{*}$ & $69.29^{* *}$ & 35.36 & $50.94^{* *}$ & 0.555 & 11.59 & -50.59 & 5.009 \\
\hline & (120.5) & $(42.66)$ & $(34.81)$ & $(104.1)$ & $(23.56)$ & $(2.411)$ & $(8.342)$ & $(40.32)$ & (41.74) \\
\hline \multirow{2}{*}{$\begin{array}{l}\text { Only respondent rcv SS } \times \\
\text { post-pay }\end{array}$} & 142.8 & 49.53 & 37.80 & 93.15 & 1.027 & -0.0568 & 8.244 & 22.33 & 1.177 \\
\hline & (106.6) & (35.72) & $(29.82)$ & $(90.86)$ & (17.90) & (1.988) & $(6.511)$ & $(23.27)$ & (30.08) \\
\hline \multirow{2}{*}{$\begin{array}{l}\text { Only spouse rcv SS } \times \\
\text { post-pay }\end{array}$} & 186.1 & 17.24 & 14.25 & 168.8 & 42.57 & 2.795 & $15.85^{*}$ & -85.69 & 116.5 \\
\hline & (156.7) & $(46.57)$ & $(40.09)$ & (141.3) & (35.32) & $(2.282)$ & (9.249) & $(52.43)$ & (74.40) \\
\hline \multirow[t]{2}{*}{ Both rcv SS $\times$ post-pay } & 105.5 & 61.79 & 51.00 & 43.39 & 10.08 & 0.288 & 3.690 & -28.27 & 35.09 \\
\hline & $(117.3)$ & $(42.79)$ & (38.08) & $(101.4)$ & $(26.01)$ & $(2.897)$ & $(8.202)$ & $(32.23)$ & (38.70) \\
\hline Observations & 15,569 & 15,617 & 15,617 & 15,569 & 15,617 & 15,507 & 15,513 & 15,617 & 15,617 \\
\hline R-squared & 0.383 & 0.128 & 0.124 & 0.438 & 0.729 & 0.858 & 0.381 & 0.198 & 0.181 \\
\hline
\end{tabular}

Notes:

${ }^{1}$ Standard errors clustered at the household level in parentheses. ${ }^{* * *}, * *$, and * represent statistical significance at the 1,5 , and $10 \%$ level of significance respectively

${ }^{2}$ Dependent variables are shown at the top of each column. All expenditure values are reported at the couple (respondent and spouse if respondent is married) and monthly level. Total expenditure excludes cash gifts.

Durables include furniture/furnishings, household appliances, home and vehicle repair/maintenance. Durables subset includes only furniture/furnishings and household appliances. Non-durables are based on the difference between total expenditure and durables. The sub-categories of non-durables captured in columns (5)-(9) are not exhaustive

${ }^{3}$ Results are estimates of coefficients in Eq. (4). In the interest of space, we do not show the coefficients from the placebo leads. The sample is restricted to respondents who are age-eligible for SSS (i.e. aged 65 and above in 2016), Singapore citizens, live in public housing flats, and with a propensity score of $0.2-0.8$ 
Table 25 Robustness check for expenditure-using non-age-eligible sample as a control group (propensity score 0.2-0.8)

\begin{tabular}{llllllllll}
\hline \multirow{2}{*}{ VARIABLES } & $(1)$ & $(2)$ & $(3)$ & $(4)$ & $(5)$ & $(6)$ & $(7)$ & $(8)$ & $(9)$ \\
& Total & Durables & $\begin{array}{l}\text { Durables } \\
\text { subset }\end{array}$ & $\begin{array}{l}\text { Non- } \\
\text { durables }\end{array}$ & Food & Tobacco & $\begin{array}{l}\text { Clothes } \\
\text { /Personal care }\end{array}$ & Health & Leisure \\
\hline Received SS × Jan & 111.0 & 5.357 & -12.66 & 105.7 & 7.445 & -3.227 & -4.391 & 47.79 & 35.54 \\
& $(153.9)$ & $(38.17)$ & $(34.88)$ & $(145.2)$ & $(22.58)$ & $(2.466)$ & $(12.17)$ & $(40.10)$ & $(48.63)$ \\
Received SS × Feb & 153.5 & 73.85 & 37.24 & 79.19 & 19.53 & -1.315 & 13.62 & 17.77 & 44.15 \\
& $(170.9)$ & $(45.52)$ & $(37.66)$ & $(158.9)$ & $(21.25)$ & $(1.995)$ & $(10.31)$ & $(42.65)$ & $(66.39)$ \\
Received SS × Mar & $470.8^{* *}$ & 58.21 & 40.48 & $413.1^{* *}$ & 3.183 & -3.691 & 7.109 & 58.16 & 86.22 \\
& $(206.6)$ & $(48.21)$ & $(44.08)$ & $(192.1)$ & $(18.80)$ & $(2.598)$ & $(8.428)$ & $(41.05)$ & $(60.52)$ \\
Received SS $\times$ & $228.1^{*}$ & 31.31 & 14.87 & $199.6^{*}$ & $26.94^{*}$ & -1.533 & $20.49^{* * *}$ & 37.98 & 35.32 \\
announce-to-pay & $(125.3)$ & $(25.85)$ & $(19.94)$ & $(114.9)$ & $(15.67)$ & $(2.126)$ & $(6.378)$ & $(37.39)$ & $(35.69)$ \\
Received SS × post- & $262.7^{* *}$ & $63.79^{* * *}$ & $46.10^{* *}$ & $198.2^{*}$ & 6.973 & -0.766 & $13.32^{* *}$ & 40.09 & 32.94 \\
pay & $(124.5)$ & $(23.33)$ & $(18.26)$ & $(114.1)$ & $(16.52)$ & $(2.258)$ & $(6.467)$ & $(34.54)$ & $(31.12)$ \\
Observations & 17,387 & 17,440 & 17,440 & 17,387 & 17,440 & 17,340 & 17,335 & 17,440 & 17,440 \\
R-squared & 0.582 & 0.158 & 0.120 & 0.598 & 0.767 & 0.775 & 0.500 & 0.214 & 0.206 \\
\hline
\end{tabular}

Notes:

${ }^{1}$ Standard errors clustered at the household level in parentheses. ${ }^{* *},{ }^{* *}$, and ${ }^{*}$ represent statistical significance at the 1 , 5 , and $10 \%$ level of significance respectively

${ }^{2}$ Dependent variables are shown at the top of each column. All expenditure values are reported at the couple (respondent and spouse if respondent is married) and monthly level. Total expenditure excludes cash gifts. Durables include furniture/furnishings, household appliances, home and vehicle repair/maintenance. Durables subset includes only furniture/furnishings and household appliances. Non-durables are based on the difference between total expenditure and durables. The sub-categories of non-durables captured in columns (5)-(9) are not exhaustive

${ }^{3}$ Results are estimates of coefficients in Eq. (1). The sample is restricted to respondents who are Singapore citizens, live in public housing flats, and with a propensity score of $0.2-0.8$. The treated group consists of individuals aged 65 and above in 2016 who received SSS payouts, while the control group consists of younger individuals aged 56 to 63 in 2016 who are not age eligible to receive SSS payouts yet 
Table 26 Robustness check for impact of receiving SSS payouts on total expenditure

\begin{tabular}{lllllllll}
\hline \multirow{2}{*}{ VARIABLES } & $(1)$ & $(2)$ & $(3)$ & $(4)$ & $(5)$ & $(6)$ & $(7)$ & $(8)$ \\
& No leads & Balanced & $\begin{array}{l}\text { Ethnic } \\
\text { trends }\end{array}$ & $\begin{array}{l}\text { Flat-type } \\
\text { trends }\end{array}$ & Age FE & WIS/ GST & Abadie & $1-1$ matching \\
\hline Received SS $\times$ Jan & - & 9.866 & 16.57 & 10.13 & 9.867 & 17.50 & 117.0 & - \\
& - & $(106.1)$ & $(102.9)$ & $(109.9)$ & $(104.9)$ & $(103.3)$ & $(130.8)$ & - \\
Received SS $\times$ Feb & - & 164.0 & 170.3 & 176.2 & 169.7 & 143.6 & 135.7 & - \\
& - & $(118.0)$ & $(115.1)$ & $(122.9)$ & $(117.4)$ & $(114.6)$ & $(88.12)$ & - \\
Received SS $\times$ Mar & - & 229.0 & 232.0 & 249.6 & 223.1 & 186.1 & $245.0^{*}$ & - \\
& - & $(181.2)$ & $(179.8)$ & $(192.1)$ & $(179.4)$ & $(118.7)$ & $(136.4)$ & - \\
Received SS $\times$ Jan- & - & - & - & - & - & - & - & $187.36^{* *}$ \\
Mar & - & - & - & - & - & - & - & $P=0.053$ \\
Received SS $\times$ & 36.41 & 91.26 & 97.47 & 93.36 & 91.64 & 91.10 & 109.2 & $158.21^{*}$ \\
announce-to-pay & $(75.78)$ & $(96.35)$ & $(93.59)$ & $(99.24)$ & $(95.07)$ & $(88.30)$ & $(68.02)$ & $P=0.086$ \\
Received SS $\times$ post- & 57.10 & 111.8 & 115.6 & 122.8 & 109.4 & 91.88 & $145.6^{* *}$ & $170.22^{*}$ \\
pay & $(72.68)$ & $(93.40)$ & $(91.45)$ & $(95.32)$ & $(91.94)$ & $(89.12)$ & $(69.20)$ & $P=0.065$ \\
Observations & 15,970 & 15,671 & 15,970 & 15,970 & 15,970 & 11,171 & 1466 & 368 \\
R-squared & 0.384 & 0.384 & 0.386 & 0.391 & 0.385 & 0.501 & - & - \\
\hline
\end{tabular}

Notes:

${ }^{1}$ Standard errors clustered at the household level in parentheses. ${ }^{* *}, *^{*}$, and * represent statistical significance at the 1 , 5 , and $10 \%$ level of significance respectively

${ }^{2}$ All expenditure values are reported at the couple (respondent and spouse if respondent is married) and monthly level. Total expenditure excludes cash gifts

${ }^{3}$ Columns (1)-(8) show results from additional robustness checks carried out. These checks are: (1) removal of the lead terms; (2) restricting the sample to a "balanced" panel, where each individual has at least one observation in the preannouncement, announcement-to-disbursement, and post-disbursement periods; (3) allowing for ethnicity-specific time fixed effects; (4) allowing for flat-type-specific time fixed effects; (5) adding age fixed effects as a control; (6) adding receipt of additional welfare payments (Workfare Income Supplement; GST Vouchers) as a control—sample is smaller because this data is not collected every wave and not everyone responds every wave; (7) reweighting each observation by their propensity of receiving SSS as in Abadie (2005); and (8) DiD matching with a 1-1 nearest neighbour match. Eq. (1) describes the baseline model used in these checks

${ }^{4}$ For columns (1)-(6), the sample is restricted to respondents who are age-eligible for SSS (i.e. aged 65 and above in 2016), Singapore citizens, live in public housing flats, and with a propensity score of $0.2-0.8$. The number of observations in these columns refers to the number of individual-month observations. For columns ( 7 ) and (8), the number of observations refers to number of respondents, and the sample is not restricted by the propensity score. The sample, however, is smaller than the full sample due to data availability issues specific to the estimation of (7) and (8) 
Table 27 Robustness check for impact of receiving SSS payouts on durables

\begin{tabular}{lllllllll}
\hline \multirow{2}{*}{ VARIABLES } & $(1)$ & $(2)$ & $(3)$ & $(4)$ & $(5)$ & $(6)$ & $(7)$ & $(8)$ \\
& No leads & Balanced & $\begin{array}{l}\text { Ethnic } \\
\text { trends }\end{array}$ & $\begin{array}{l}\text { Flat-type } \\
\text { trends }\end{array}$ & Age FE & WIS/ GST & Abadie & $1-1$ matching \\
\hline Received SS $\times$ Jan & - & 25.78 & 22.45 & 25.60 & 24.31 & -2.849 & 13.08 & - \\
& - & $(47.95)$ & $(47.20)$ & $(49.42)$ & $(47.45)$ & $(54.26)$ & $(36.59)$ & - \\
Received SS $\times$ Feb & - & 79.68 & 76.12 & 78.95 & 78.98 & 43.61 & 46.08 & - \\
& - & $(50.01)$ & $(47.81)$ & $(52.19)$ & $(49.52)$ & $(43.16)$ & $(36.89)$ & - \\
Received SS $\times$ Mar & - & 52.89 & 54.48 & 56.41 & 54.03 & 67.94 & $56.85^{*}$ & - \\
& - & $(49.56)$ & $(49.31)$ & $(49.66)$ & $(49.36)$ & $(66.14)$ & $(29.63)$ & - \\
Received SS $\times$ Jan- & - & - & - & - & - & - & - & 49.05 \\
Mar & - & - & - & - & - & - & - & $P=0.14$ \\
Received SS $\times$ & 40.76 & $64.38^{* *}$ & $62.38^{*}$ & $64.66^{*}$ & $63.08^{* *}$ & 49.50 & $53.41^{* *}$ & $69.19^{* *}$ \\
announce-to-pay & $(27.89)$ & $(32.44)$ & $(32.29)$ & $(34.42)$ & $(32.12)$ & $(31.23)$ & $(20.98)$ & $P=0.028$ \\
Received SS $\times$ post- & 35.68 & $56.83^{*}$ & $57.27^{*}$ & $59.87^{*}$ & $56.60^{*}$ & 36.39 & $36.76^{*}$ & 47.61 \\
pay & $(27.77)$ & $(31.79)$ & $(31.65)$ & $(33.25)$ & $(31.38)$ & $(31.79)$ & $(19.91)$ & $P=0.16$ \\
Observations & 16,019 & 15,721 & 16,019 & 16,019 & 16,019 & 11,196 & 1467 & 368 \\
R-squared & 0.127 & 0.128 & 0.129 & 0.134 & 0.129 & 0.100 & - & - \\
\hline
\end{tabular}

Notes:

${ }^{1}$ Standard errors clustered at the household level in parentheses. ${ }^{* *}, *^{*}$, and * represent statistical significance at the 1 , 5 , and $10 \%$ level of significance respectively

${ }^{2}$ All expenditure values are reported at the couple (respondent and spouse if respondent is married) and monthly level. Durables include furniture/furnishings, household appliances, home and vehicle repair/maintenance ${ }^{3}$ Columns (1)-(8) show results from additional robustness checks carried out. These checks are: (1) removal of the lead terms; (2) restricting the sample to a "balanced" panel, where each individual has at least one observation in the preannouncement, announcement-to-disbursement, and post-disbursement periods; (3) allowing for ethnicity-specific time fixed effects; (4) allowing for flat-type-specific time fixed effects; (5) adding age fixed effects as a control; (6) adding receipt of additional welfare payments (Workfare Income Supplement; GST Vouchers) as a control—sample is smaller because this data is not collected every wave and not everyone responds every wave; (7) reweighting each observation by their propensity of receiving SSS as in Abadie (2005); and (8) DiD matching with a 1-1 nearest neighbour match. Eq. (1) describes the baseline model used in these checks

${ }^{4}$ For columns (1)-(6), the sample is restricted to respondents who are age-eligible for SSS (i.e. aged 65 and above in 2016), Singapore citizens, live in public housing flats, and with a propensity score of $0.2-0.8$. The number of observations in these columns refers to the number of individual-month observations. For columns ( 7 ) and (8), the number of observations refers to number of respondents, and the sample is not restricted by the propensity score. The sample, however, is smaller than the full sample due to data availability issues specific to the estimation of (7) and (8) 
Table 28 Robustness check for impact of receiving SSS payouts on durables subset

\begin{tabular}{lllllllll}
\hline \multirow{2}{*}{ VARIABLES } & $(1)$ & $(2)$ & $(3)$ & $(4)$ & $(5)$ & $(6)$ & $(7)$ & $(8)$ \\
& No leads & Balanced & $\begin{array}{l}\text { Ethnic } \\
\text { trends }\end{array}$ & $\begin{array}{l}\text { Flat-type } \\
\text { trends }\end{array}$ & Age FE & WIS/ GST & Abadie & $1-1$ matching \\
\hline Received SS × Jan & - & 17.56 & 14.09 & 19.84 & 16.80 & -11.86 & -8.470 & - \\
& - & $(44.54)$ & $(43.77)$ & $(45.82)$ & $(44.13)$ & $(51.19)$ & $(32.89)$ & - \\
Received SS × Feb & - & 50.81 & 47.02 & 51.95 & 51.27 & 8.538 & 20.86 & - \\
& - & $(42.27)$ & $(39.67)$ & $(44.42)$ & $(41.92)$ & $(27.80)$ & $(31.24)$ & - \\
Received SS $\times$ Mar & - & 51.09 & 51.57 & 56.97 & 53.11 & 63.01 & $46.70^{*}$ & - \\
& - & $(46.85)$ & $(46.73)$ & $(46.78)$ & $(46.50)$ & $(65.24)$ & $(27.26)$ & - \\
Received SS $\times$ Jan- & - & - & - & - & - & - & - & 37.24 \\
Mar & - & - & - & - & - & - & - & $P=0.20$ \\
Received SS $\times$ & $41.58^{*}$ & $59.50^{* *}$ & $57.64^{* *}$ & $61.81^{* *}$ & $59.28^{* *}$ & $48.45^{* *}$ & $48.09^{* * *}$ & $55.12^{* *}$ \\
announce-to-pay & $(21.59)$ & $(26.15)$ & $(26.02)$ & $(28.51)$ & $(25.89)$ & $(22.34)$ & $(16.98)$ & $P=0.04$ \\
Received SS $\times$ post- & 28.05 & 44.26 & 43.96 & $48.94^{*}$ & 43.46 & 27.21 & $29.73^{*}$ & 36.00 \\
pay & $(23.41)$ & $(27.30)$ & $(27.17)$ & $(28.91)$ & $(26.79)$ & $(26.50)$ & $(16.71)$ & $P=0.21$ \\
Observations & 16,019 & 15,721 & 16,019 & 16,019 & 16,019 & 11,196 & 1467 & 368 \\
R-squared & 0.123 & 0.124 & 0.125 & 0.130 & 0.125 & 0.085 & - & - \\
\hline
\end{tabular}

Notes:

${ }^{1}$ Standard errors clustered at the household level in parentheses. ${ }^{* *},{ }^{* *}$, and * represent statistical significance at the 1 , 5 , and $10 \%$ level of significance respectively

${ }^{2}$ All expenditure values are reported at the couple (respondent and spouse if respondent is married) and monthly level. Durables subset includes furniture/furnishings and household appliances

${ }^{3}$ Columns (1)-(8) show results from additional robustness checks carried out. These checks are: (1) removal of the lead terms; (2) restricting the sample to a "balanced" panel, where each individual has at least one observation in the preannouncement, announcement-to-disbursement, and post-disbursement periods; (3) allowing for ethnicity-specific time fixed effects; (4) allowing for flat-type-specific time fixed effects; (5) adding age fixed effects as a control; (6) adding receipt of additional welfare payments (Workfare Income Supplement; GST Vouchers) as a control—sample is smaller because this data is not collected every wave and not everyone responds every wave; (7) reweighting each observation by their propensity of receiving SSS as in Abadie (2005); and (8) DiD matching with a 1-1 nearest neighbour match. Eq. (1) describes the baseline model used in these checks

${ }^{4}$ For columns (1)-(6), the sample is restricted to respondents who are age-eligible for SSS (i.e. aged 65 and above in 2016), Singapore citizens, live in public housing flats, and with a propensity score of $0.2-0.8$. The number of observations in these columns refers to the number of individual-month observations. For columns ( 7 ) and (8), the number of observations refers to number of respondents, and the sample is not restricted by the propensity score. The sample, however, is smaller than the full sample due to data availability issues specific to the estimation of (7) and (8) 
Table 29 Robustness check for impact of receiving SSS payouts on non-durables

\begin{tabular}{|c|c|c|c|c|c|c|c|c|}
\hline & (1) & (2) & (3) & (4) & (5) & (6) & (7) & (8) \\
\hline VARIABLES & No leads & Balanced & $\begin{array}{l}\text { Ethnic } \\
\text { trends }\end{array}$ & $\begin{array}{l}\text { Flat-type } \\
\text { trends }\end{array}$ & Age FE & WIS/ GST & Abadie & 1-1 matching \\
\hline \multirow[t]{2}{*}{ Received SS $\times$ Jan } & - & -15.00 & -5.038 & -14.48 & - & 21.31 & 108.5 & - \\
\hline & - & $(86.33)$ & $(83.11)$ & $(87.69)$ & $(85.73)$ & (85.22) & $(123.7)$ & - \\
\hline \multirow[t]{2}{*}{ Received SS $\times$ Feb } & - & 84.61 & 94.51 & 97.38 & 91.04 & 100.5 & 90.50 & - \\
\hline & - & $(100.9)$ & $(98.60)$ & $(104.0)$ & $(100.8)$ & (105.9) & (76.87) & - \\
\hline \multirow[t]{2}{*}{ Received SS $\times$ Mar } & - & 177.3 & 178.7 & 193.5 & 170.3 & 119.7 & 190.4 & - \\
\hline & - & $(169.3)$ & $(167.9)$ & $(179.7)$ & $(167.3)$ & (106.8) & (128.3) & - \\
\hline \multirow[t]{2}{*}{ Received SS $\times$ Jan-Mar } & - & - & - & - & - & - & - & 137.39 \\
\hline & - & - & - & - & - & - & - & $P=0.12$ \\
\hline \multirow{2}{*}{$\begin{array}{l}\text { Received SS } \times \text { announce- } \\
\text { to-pay }\end{array}$} & -1.687 & 29.89 & 38.11 & 31.31 & 31.65 & 46.04 & 58.58 & 88.76 \\
\hline & $(64.79)$ & $(84.55)$ & $(81.37)$ & $(84.88)$ & $(83.24)$ & (82.23) & $(62.34)$ & $P=0.25$ \\
\hline \multirow[t]{2}{*}{ Received SS $\times$ post-pay } & 21.01 & 54.90 & 58.25 & 62.63 & 52.82 & 55.70 & $108.5^{*}$ & 119.76 \\
\hline & $(59.87)$ & $(80.02)$ & $(77.87)$ & $(79.66)$ & $(78.42)$ & (79.68) & $(62.46)$ & $P=0.10$ \\
\hline Observations & 15,970 & 15,671 & 15,970 & 15,970 & 15,970 & 11,171 & 1466 & 368 \\
\hline R-squared & 0.439 & 0.439 & 0.443 & 0.446 & 0.440 & 0.515 & - & - \\
\hline
\end{tabular}

Notes:

${ }^{1}$ Standard errors clustered at the household level in parentheses. ${ }^{* *},{ }^{* *}$, and ${ }^{*}$ represent statistical significance at the 1 , 5 , and $10 \%$ level of significance respectively

${ }^{2}$ All expenditure values are reported at the couple (respondent and spouse if respondent is married) and monthly level. Non-durables are based on the difference between total expenditure and durables

${ }^{3}$ Columns (1)-(8) show results from additional robustness checks carried out. These checks are: (1) removal of the lead terms; (2) restricting the sample to a "balanced" panel, where each individual has at least one observation in the preannouncement, announcement-to-disbursement, and post-disbursement periods; (3) allowing for ethnicity-specific time fixed effects; (4) allowing for flat-type-specific time fixed effects; (5) adding age fixed effects as a control; (6) adding receipt of additional welfare payments (Workfare Income Supplement; GST Vouchers) as a control-sample is smaller because this data is not collected every wave and not everyone responds every wave; (7) reweighting each observation by their propensity of receiving SSS as in Abadie (2005); and (8) DiD matching with a 1-1 nearest neighbour match. Eq. (1) describes the baseline model used in these checks

${ }^{4}$ For columns (1)-(6), the sample is restricted to respondents who are age-eligible for SSS (i.e. aged 65 and above in 2016), Singapore citizens, live in public housing flats, and with a propensity score of $0.2-0.8$. The number of observations in these columns refers to the number of individual-month observations. For columns (7) and (8), the number of observations refers to number of respondents, and the sample is not restricted by the propensity score. The sample, however, is smaller than the full sample due to data availability issues specific to the estimation of (7) and (8) 


\section{Appendix 4}

\subsection{Additional results for non-age-eligible sample}

Table 30 Summary statistics for baseline demographics considered in propensity score estimation-comparison between those who expected and did not expect SSS payout, among individuals aged 56 to 63 in 2016

\begin{tabular}{|c|c|c|c|c|c|c|c|c|c|c|c|c|}
\hline & \multicolumn{6}{|c|}{ Untrimmed sample } & \multicolumn{6}{|c|}{ Trimmed sample (propensity score $0.2-0.8$ ) } \\
\hline & \multicolumn{2}{|c|}{$\begin{array}{l}\text { Expected SS } \\
\left(N^{1}=1558\right) \\
\end{array}$} & \multicolumn{2}{|c|}{$\begin{array}{l}\text { Did not } \\
\left(N^{1}=1425\right) \\
\end{array}$} & \multirow[t]{2}{*}{$\begin{array}{l}\text { Norm } \\
\text { diff }^{2}\end{array}$} & \multirow[t]{2}{*}{$\begin{array}{l}\text { Diff in } \\
\text { means }^{3}\end{array}$} & \multicolumn{2}{|c|}{$\begin{array}{l}\text { Expected SS } \\
\left(N^{1}=1430\right) \\
\end{array}$} & \multicolumn{2}{|c|}{$\begin{array}{l}\text { Did not } \\
\left(N^{1}=1380\right) \\
\end{array}$} & \multirow[t]{2}{*}{$\begin{array}{l}\text { Norm } \\
\text { diff }^{2}\end{array}$} & \multirow[t]{2}{*}{$\begin{array}{l}\text { Diff in } \\
\text { means }^{3}\end{array}$} \\
\hline & Mean & SD & Mean & SD & & & Mean & SD & Mean & SD & & \\
\hline Age at 2016 & 59.29 & 2.26 & 59.21 & 2.25 & 0.03 & 0.07 & 59.27 & 2.26 & 59.21 & 2.25 & 0.03 & 0.06 \\
\hline Married & 0.78 & 0.41 & 0.80 & 0.40 & -0.05 & -0.02 & 0.79 & 0.41 & 0.81 & 0.39 & -0.04 & -0.02 \\
\hline Male & 0.46 & 0.50 & 0.47 & 0.50 & -0.03 & -0.01 & 0.47 & 0.50 & 0.48 & 0.50 & -0.02 & -0.01 \\
\hline Chinese & 0.80 & 0.40 & 0.89 & 0.31 & -0.27 & $-0.10^{* * *}$ & 0.83 & 0.37 & 0.91 & 0.29 & -0.22 & $-0.07^{* * *}$ \\
\hline Malay & 0.11 & 0.32 & 0.06 & 0.23 & 0.20 & $0.06^{* * *}$ & 0.09 & 0.28 & 0.05 & 0.22 & 0.15 & $0.04^{* * *}$ \\
\hline Indian & 0.07 & 0.26 & 0.04 & 0.19 & 0.14 & $0.03^{* * *}$ & 0.06 & 0.24 & 0.03 & 0.18 & 0.13 & $0.03^{* * *}$ \\
\hline No formal schooling & 0.04 & 0.19 & 0.03 & 0.17 & 0.04 & 0.01 & 0.02 & 0.15 & 0.03 & 0.16 & -0.02 & 0.00 \\
\hline Primary schooling & 0.24 & 0.43 & 0.21 & 0.41 & 0.07 & $0.03^{*}$ & 0.24 & 0.42 & 0.21 & 0.41 & 0.07 & $0.03^{*}$ \\
\hline Secondary schooling & 0.51 & 0.50 & 0.44 & 0.50 & 0.15 & $0.08^{* * *}$ & 0.51 & 0.50 & 0.44 & 0.50 & 0.14 & $0.07^{* * *}$ \\
\hline Lives in 1-room flat & 0.01 & 0.11 & 0.01 & 0.08 & 0.05 & 0.00 & 0.01 & 0.08 & 0.01 & 0.07 & 0.02 & 0.00 \\
\hline Lives in 2-room flat & 0.03 & 0.16 & 0.01 & 0.11 & 0.11 & $0.01^{* * *}$ & 0.01 & 0.10 & 0.01 & 0.10 & -0.01 & 0.00 \\
\hline Lives in 3-room flat & 0.20 & 0.40 & 0.15 & 0.36 & 0.11 & $0.04^{* * *}$ & 0.21 & 0.40 & 0.16 & 0.36 & 0.13 & $0.05^{* * *}$ \\
\hline Lives in 4-room flat & 0.42 & 0.49 & 0.37 & 0.48 & 0.10 & $0.05^{* *}$ & 0.42 & 0.49 & 0.37 & 0.48 & 0.11 & $0.05^{* * *}$ \\
\hline Lives in 5-room flat & 0.27 & 0.44 & 0.33 & 0.47 & -0.14 & $-0.06^{* * *}$ & 0.27 & 0.44 & 0.33 & 0.47 & -0.13 & $-0.06^{* * *}$ \\
\hline Owns home & 0.91 & 0.28 & 0.94 & 0.24 & -0.09 & $-0.02^{* *}$ & 0.94 & 0.24 & 0.94 & 0.23 & -0.03 & -0.01 \\
\hline No. of hh members & 3.59 & 1.57 & 3.66 & 1.43 & -0.04 & -0.07 & 3.57 & 1.50 & 3.64 & 1.40 & -0.05 & -0.07 \\
\hline No. of total children & 2.01 & 1.32 & 1.91 & 1.16 & 0.08 & $0.10^{* *}$ & 1.96 & 1.26 & 1.91 & 1.15 & 0.05 & 0.06 \\
\hline $\begin{array}{l}\text { Retirement } \\
\text { preparedness }{ }^{4}\end{array}$ & 2.24 & 0.85 & 2.36 & 0.93 & -0.13 & $-0.12 * * *$ & 2.25 & 0.85 & 2.35 & 0.92 & -0.11 & $-0.10^{* * *}$ \\
\hline $\begin{array}{l}\text { Notes: } \\
{ }^{1} N \text { refers to number of } r \\
{ }^{2} \text { Normalised differences }\end{array}$ & esponden & nts & & & 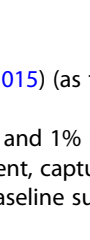 & 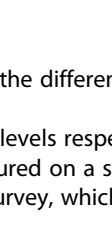 & $y$ & & 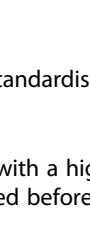 & & 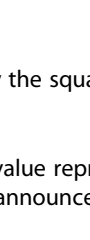 & enting \\
\hline
\end{tabular}


Table 31 Summary statistics for pre-announcement dependent variables (Trimmed sample with 0.2-0.8 propensity score)

\begin{tabular}{|c|c|c|c|c|c|c|}
\hline & \multicolumn{3}{|c|}{ Aged 56 to 63 in 2016} & & & \\
\hline & Expec & & & \multicolumn{3}{|c|}{ Did not } \\
\hline & $\overline{N^{1}}$ & Mean & SD & $\overline{N^{1}}$ & Mean & SD \\
\hline Rcv private cash $\operatorname{trf}^{2}$ & 7875 & 0.33 & 0.47 & 7633 & 0.31 & 0.46 \\
\hline Amount received ${ }^{2,3}$ & 7857 & 231.35 & 461.00 & 7621 & 242.54 & 504.07 \\
\hline Give private cash rrf $^{2}$ & 7814 & 0.29 & 0.45 & 7569 & 0.30 & 0.46 \\
\hline Amount given ${ }^{2,3}$ & 7809 & 122.02 & 354.73 & 7562 & 149.46 & 416.81 \\
\hline Rcv income from work & 8869 & 0.70 & 0.46 & 8625 & 0.71 & 0.45 \\
\hline Amount of income $e^{3}$ & 8839 & 1951 & 2514 & 8594 & 2393 & 3057 \\
\hline Prob of working full-time after age 62 & 1965 & 48.45 & 34.68 & 1928 & 46.78 & 35.22 \\
\hline Prob of working full-time after age 65 & 2174 & 37.68 & 33.48 & 2151 & 34.91 & 33.51 \\
\hline Prob of working full-time after age 70 & 2171 & 22.27 & 29.04 & 2149 & 18.91 & 28.07 \\
\hline Total expenditure ${ }^{2}$ & 8784 & 2835 & 3686 & 8537 & 3198 & 3545 \\
\hline Durables ${ }^{2,3}$ & 8822 & 164 & 618 & 8569 & 183 & 630 \\
\hline Durables subset ${ }^{2,3}$ & 8822 & 100 & 490 & 8569 & 101 & 473 \\
\hline Non-durables ${ }^{2}$ & 8784 & 2671 & 3444 & 8537 & 3015 & 3362 \\
\hline
\end{tabular}


Table 32 Overall impact of expecting to receive SSS payouts on expenditure

\begin{tabular}{|c|c|c|c|c|c|c|c|c|c|}
\hline & (1) & (2) & (3) & (4) & (5) & (6) & (7) & (8) & (9) \\
\hline VARIABLES & Total & Durables & $\begin{array}{l}\text { Durables } \\
\text { subset }\end{array}$ & $\begin{array}{l}\text { Non- } \\
\text { durables }\end{array}$ & Food & Tobacco & $\begin{array}{l}\text { Clothes } \\
\text { /Personal care }\end{array}$ & Health & Leisure \\
\hline \multirow{2}{*}{$\begin{array}{l}\text { Expect SS } \times \\
\text { Jan }\end{array}$} & -68.379 & 18.019 & 19.350 & -86.938 & $-31.640^{* *}$ & -0.555 & -14.250 & -46.806 & 50.585 \\
\hline & (139.636) & $(28.243)$ & (24.608) & (137.294) & $(15.070)$ & (1.590) & $(9.748)$ & (30.136) & (39.239) \\
\hline \multirow{2}{*}{$\begin{array}{l}\text { Expect SS } \times \\
\text { Feb }\end{array}$} & -99.090 & -8.907 & -12.342 & -91.930 & $-42.000^{* * *}$ & $-3.273^{* *}$ & -6.404 & -4.536 & 9.008 \\
\hline & $(121.981)$ & (25.782) & (20.502) & (117.385) & (14.922) & (1.449) & $(9.043)$ & (38.690) & $(42.351)$ \\
\hline \multirow{2}{*}{$\begin{array}{l}\text { Expect SS } \times \\
\text { Mar }\end{array}$} & -57.994 & -10.236 & 0.636 & -49.712 & -4.271 & -0.546 & -10.387 & -26.709 & 36.064 \\
\hline & (120.390) & (29.203) & (20.584) & (110.939) & $(12.340)$ & (1.523) & (7.084) & (32.638) & (46.388) \\
\hline \multirow{2}{*}{$\begin{array}{l}\text { Expect SS } \times \\
\text { announce- } \\
\text { to-pay }\end{array}$} & -84.394 & 10.821 & 6.566 & -95.980 & -11.067 & -0.162 & -3.866 & $-50.422^{*}$ & -9.492 \\
\hline & $(100.114)$ & (21.105) & $(16.892)$ & (93.502) & $(10.247)$ & $(1.212)$ & $(5.514)$ & (27.173) & (31.962) \\
\hline \multirow{2}{*}{$\begin{array}{l}\text { Expect SS } \times \\
\text { post-pay }\end{array}$} & -14.862 & 9.497 & 4.361 & -25.130 & -9.749 & 0.145 & 1.556 & -32.876 & 20.122 \\
\hline & (95.429) & (18.504) & $(14.501)$ & (89.345) & (11.414) & (1.296) & $(5.411)$ & (24.668) & (24.786) \\
\hline Mean & 2835 & 164 & 100 & 2671 & 532 & 20 & 135 & 273 & 260 \\
\hline S.D. & 3686 & 618 & 490 & 3444 & 437 & 71 & 221 & 843 & 886 \\
\hline Observations & 51,240 & 51,402 & 51,402 & 51,240 & 51,402 & 51,054 & 51,039 & 51,402 & 51,402 \\
\hline R-squared & 0.56 & 0.15 & 0.11 & 0.56 & 0.75 & 0.84 & 0.49 & 0.22 & 0.20 \\
\hline
\end{tabular}

Notes:

${ }^{1}$ Standard errors clustered at the household level in parentheses. ${ }^{* * *},{ }^{* *}$, and ${ }^{*}$ represent statistical significance at the 1,5 , and $10 \%$ level of significance respectively

${ }^{2}$ Dependent variables are shown at the top of each column. All expenditure values are reported at the couple (respondent and spouse if respondent is married) and monthly level. Total expenditure excludes cash gifts. Durables include furniture/furnishings, household appliances, home and vehicle repair/maintenance. Durables subset includes only furniture/furnishings and household appliances. Non-durables are based on the difference between total expenditure and durables. The sub-categories of non-durables captured in columns (5)-(9) are not exhaustive

${ }^{3}$ Results are estimates of coefficients in Eq. (1). The sample is restricted to respondents who are not ageeligible for SSS (i.e. aged 56 to 63 in 2016), Singapore citizens, live in public housing flats, and with a propensity score of $0.2-0.8$

${ }^{4}$ Mean and standard deviation statistics are based on pre-announcement levels of the dependent variable for respondents who expected to receive SSS payouts 


\section{Abbreviations}

CPF: Central Provident Fund; CREA: Centre for Research on the Economics of Ageing; DiD: Difference-in-differences; HDB: Housing and Development Board; SLP: Singapore Life Panel; SSS: Silver Support Scheme

\section{Acknowledgements}

We would like to thank Jing Li, for her advice and guidance; Luca Facchinello, Tomoki Fujii, Christine Ho, Seonghoon Kim, Michael Lovenheim, Olivia Mitchell, the editor and an anonymous referee for helpful comments. In addition, we are grateful to the Centre for Research on the Economics of Ageing at the Singapore Management University for financial support, and for providing access to data from the Singapore Life Panel. The Singapore Life Panel is funded by the Singapore Ministry of Education (MOE) Academic Research Fund Tier 3 grant MOE2013-T3-1-009.

Responsible editor: Juan Jimeno.

\section{Funding}

We are grateful to the Centre for Research on the Economics of Ageing at the Singapore Management University for financial support, and for providing access to data from the Singapore Life Panel. The Singapore Life Panel is funded by the Singapore Ministry of Education (MOE) Academic Research Fund Tier 3 grant MOE2013-T3-1-009.

\section{Availability of data and materials}

Data from the Singapore Life Panel is currently not accessible by the public. However, one may apply to the Centre for Research on the Economics of Ageing at the Singapore Management University for data access.

\section{Competing interests}

The IZA Journal of Labor Policy is committed to the IZA Guiding Principles of Research Integrity. The authors declare that they have observed these principles.

\section{Publisher's Note}

Springer Nature remains neutral with regard to jurisdictional claims in published maps and institutional affiliations.

Received: 30 November 2017 Accepted: 8 May 2018

Published online: 30 May 2018

\section{References}

Abadie A (2005) Semiparametric difference-in-differences estimators. Rev Econ Stud 72:1-19

Aguila E, Kapteyn A, Weidmer BA, Robles R (2011) Experimental analysis of the health and well-being effects of a noncontributory social security program working paper

Amuedo-Dorantes C, Juarez L (2015) Old-age government transfers and the crowding out of private gifts: the 70 and above program for the rural elderly in Mexico. South Econ J 81:782-802

Angrist JD, Pischke J-S (2010) The credibility revolution in empirical economics: how better research design is taking the con out of econometrics. J Econ Perspect 24:3-30

Bando R, Galiani S, Gertler P (2016) The effects of non-contributory pensions on material and subjective well being NBER working paper no 22995

Banerjee A et al (2017) From proof of concept to scalable policies: challenges and solutions, with an application. J Econ Perspect 31:73-102

Behrman J, Calderon MC, Mitchell OS, Vasquez J, Bravo D (2011) First-round impacts of the 2008 Chilean pension system reform Michigan Retirement Research Center research paper no WP 245

Blundell R, Francesconi M, van der Klaauw W (2011) Anatomy of welfare reform evaluation: announcement and implementation effects. IZA discussion papers 6050 Institute for the Study of labor (IZA)

Burbidge JB, Magee L, Robb AL (1988) Alternative transformations to handle extreme values of the dependent variable. J Am Stat Assoc 83:123-127

Case A, Deaton A (1998) Large cash transfers to the elderly in South Africa. Econ J 108:1330-1361

Chen Y, Tan YJ (2017) Income and subjective well-being: evidence from Singapore's first national non-contributory pension working paper

Cheng L, Liu H, Zhang Y, Zhao Z (2018) The health implications of social pensions: evidence from China's new rural pension scheme. J Comp Econ 46(1):53-77

Cox D (1987) Motives for private income transfers. J Polit Econ 95:508-546

Cox D, Fafchamps M (2007) Extended family and kinship networks: Economic insights and evolutionary directions. In: Schultz TP, Strauss JA, editors. Handbook of development economics, Volume 4. p. 3711-3784

Cox D, Jakubson G (1995) The connection between public transfers and private interfamily transfers. J Public Econ 57: 129-167

Danzer AM (2013) Benefit generosity and the income effect on labour supply: quasi-experimental evidence. Econ J 123: 1059-1084

Department of Statistics (2017) Latest Data. https:/www.singstat.gov.sg/find-data/search-by-theme/households/ households/latest-data. Accessed 21 July 2017

Euwals R (2001) Female labour supply, flexibility of working hours, and job mobility. The Economic Journal 111:120-134

Fan E (2010) Who benefits from public old age pensions? Evidence from a targeted program Economic Development and Cultural Change 58:297-322

Fetter DK, Lockwood LM (2016) Government old-age support and labor supply: evidence from the old age assistance program NBER working paper no 22132

Galiani S, Gertler P, Bando R (2016) Non-contributory pensions. Labour Econ 38:47-58 
Hernani-Limarino WL, Mena G (2015) Intended and unintended effects of unconditional cash transfers: the case of Bolivia's Renta Dignidad

Houngbedji K (2015) Abadie's semi-parametric difference-in-difference estimator. Stata J 16(2):482-490

Housing and Development Board (2017) About us. http://www.hdb.gov.sg/cs/infoweb/about-us. Accessed 12 Oct 2017

Imbens GW (2015) Matching methods in practice: three examples. J Hum Resour 50:373-419

International Labour Office (2014) Pensions and other social protection benefits for older persons: insights from the ILO world social protection report 2014/15. http://www.social-protection.org/gimi/gess/RessourcePDF.action?ressource. ressourceld $=48037$. Accessed 1 Nov 2017

Jappelli T, Pistaferri L (2010) The consumption response to income changes. Annu Rev Econ 2:479-506

Jensen RT (2004) Do private transfers 'displace' the benefits of public transfers? Evidence from South Africa. J Public Econ 88:89-112

Juárez L, Pfutze T (2015) The effects of a noncontributory pension program on labor force participation: the case of 70 y Más in Mexico. Econ Dev Cult Chang 63:685-713

Kaushal N (2014) How public pension affects elderly labor supply and well-being: evidence from India. World Dev 56: $214-225$

Koh K, Yang H (2017) Does a government public transfer program crowd out intergenerational transfers? Evidence from South Korea. Working paper

MacKinnon JG, Magee L (1990) Transforming the dependent variable in regression models. Int Econ Rev 31(2):315-339 Martinez-Granado M (2005) Testing labour supply and hours constraints. Labour Econ 12:321-343

Ministry of Manpower (2017) Termination with notice. http://www.mom.gov.sg/employment-practices/termination-ofemployment/termination-with-notice. Accessed 14 Nov 2017

Stewart MB, Swaffield JK (1997) Constraints on the desired hours of work of British men. Econ J 107:520-535

Vaithianathan R, Hool B, Hurd M, Rohwedder S (2017) High-frequency internet survey of a probability sample of older Singaporeans: the Singapore life panel CREA working paper

Submit your manuscript to a SpringerOpen ${ }^{\circ}$ journal and benefit from:

- Convenient online submission

- Rigorous peer review

Open access: articles freely available online

- High visibility within the field

Retaining the copyright to your article

Submit your next manuscript at $\gg$ springeropen.com 